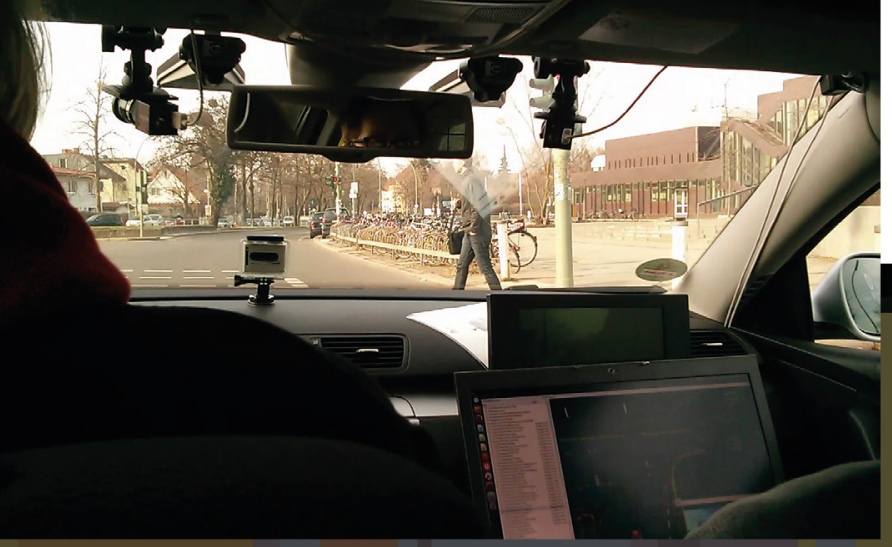

Keeping Autonomous Driving Alive

An Ethnography of Visions, Masculinity and Fragility 


\section{Göde Both}

Keeping Autonomous Driving Alive 

Göde Both

\section{Keeping Autonomous Driving Alive}

An Ethnography of Visions, Masculinity and Fragility

Budrich Academic Press GmbH

Opladen • Berlin • Toronto 2020 
(C) 2020 This work is licensed under the Creative Commons Attribution-ShareAlike 4.0. (CC-BY-SA 4.0)

It permits use, duplication, adaptation, distribution and reproduction in any medium or format, as long as you share under the same license, give appropriate credit to the original author(s) and the source, provide a link to the Creative Commons license and indicate if changes were made.

To view a copy of this license, visit https://creativecommons.org/licenses/by-sa/4.0/

(C) 2020 Dieses Werk ist beim Verlag Barbara Budrich GmbH erschienen und steht unter der Creative Commons Lizenz Attribution-ShareAlike 4.0 International (CC BY-SA 4.0):

https://creativecommons.org/licenses/by-sa/4.0/

Diese Lizenz erlaubt die Verbreitung, Speicherung, Vervielfältigung und Bearbeitung bei Verwendung der gleichen CC-BY-SA 4.0-Lizenz und unter Angabe der UrheberInnen, Rechte, Änderungen und verwendeten Lizenz.

\section{(c) $(1)(0$}

This book is available as a free download from www.barbara-budrich.net (https://doi.org/10.3224/96665009). A paperback version is available at a charge. The page numbers of the open access edition correspond with the paperback edition.

Diese Dissertation wurde von der Humanwissenschaftlichen Fakultät der Universität zu Köln im November 2019 angenommen.

A CIP catalogue record for this book is available from

Die Deutsche Bibliothek (The German Library)

C 2020 by Budrich Academic Press, Opladen, Berlin \& Toronto

www. budrich-academic-press.de

$\begin{array}{ll}\text { ISBN } & 978-3-96665-009-0 \\ \text { eISBN } & 978-3-96665-983-3 \\ \text { DOI } & 10.3224 / 96665009\end{array}$

Die Deutsche Bibliothek - CIP-Einheitsaufnahme

Ein Titeldatensatz für die Publikation ist bei Der Deutschen Bibliothek erhältlich.

Budrich Academic Press

Stauffenbergstr. 7. D-51379 Leverkusen Opladen, Germany

86 Delma Drive. Toronto, ON M8W 4P6 Canada

www. budrich-academic-press.de

Jacket illustration by Bettina Lehfeldt, Kleinmachnow - www.lehfeldtgraphic.de

Photo Credits: Göde Both

Typesetting by Linda Kutzki, Berlin - www.textsalz.de

Printed in Europe on acid-free paper by Books on Demand GmbH, Norderstedt 


\section{Table of contents}

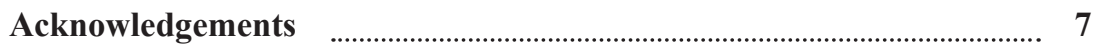

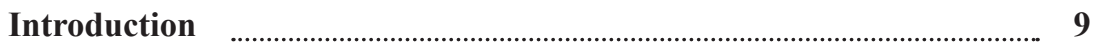

Sustaining autonomous driving _................................................................. 12

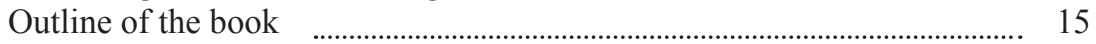

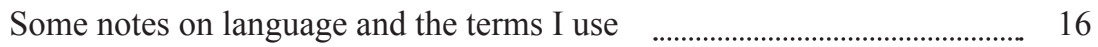

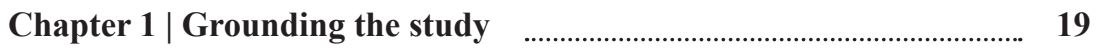

Theoretical approach $\ldots$

Humanist social science ........................................................................ 19

More-than-human social science _.......................................................... 21

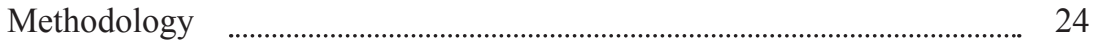

Technology and gender _............................................................................ 25

Narratives and storytelling _........................................................................ 26

Expectations, promises, and visions ……………………………………... 27

Research design _................................................................................................ 28

Selecting a field site and negotiating access ………………………........... 31

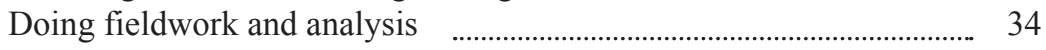

Chapter 2 | The AutoNOMOS project ……………………….................. 39

The project members …………………………………………………………... 39

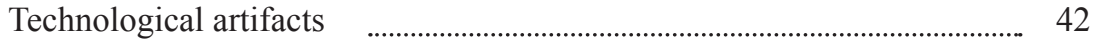

A mosaic of visionary stories $\ldots$

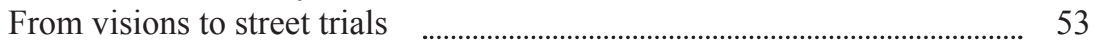

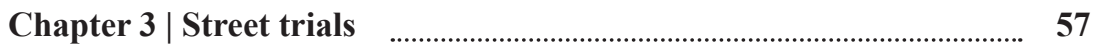

The "real world"

Assembling MiG $\quad$.......................................................................................... 59

On the road $\ldots$

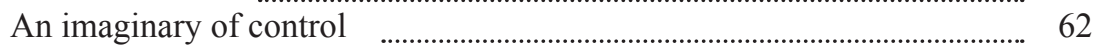

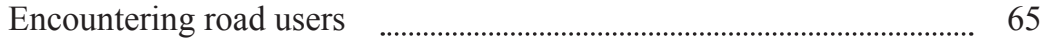

The lonely, disembodied driver $\ldots$

Taking care of "him" _...………………………………………………………. 68

Reconciling tensions 


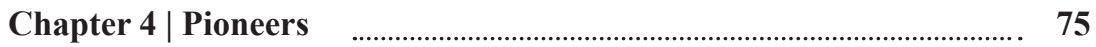

Distancing from automobility _........................................................................ 75

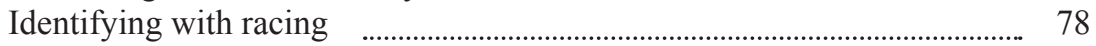

Masculinizing autonomous driving _.......................................................... 80

Chapter 5 | Video demonstrations _...…………………………………...... 93

a) The hero's journey _...………………………………………………………. 94

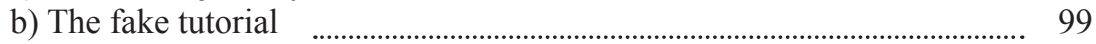

Fragile demonstrator _............................................................................. 102

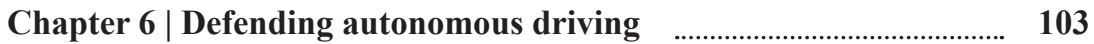

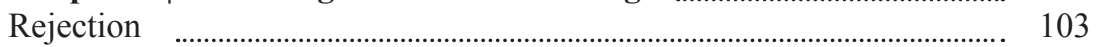

Accommodating rejection ……............................................................. 108

a) Valuing being chauffeured over driving ………………………....... 109

b) Appeasing the audience ………………………………………….... 110

c) Celebrating control and technical mastery ……………………......... 111

"Is your project a real project?" …………………………………………….. 113

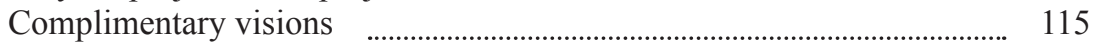

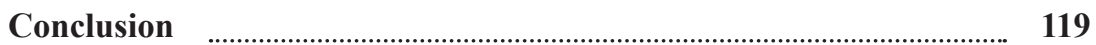

Care

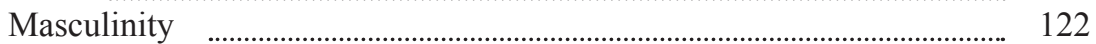

Narrative

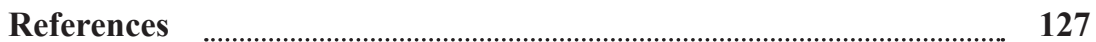

Index 


\section{Acknowledgements}

It is a privilege and joy to thank the many people who have made this book possible. The research in this book would have impossible without the openness of members of the field of research in autonomous driving. I am indebted to Raúl Rojas for granting me access to his robotics project. I thank all the project members for letting me shadow them and for sharing their stories and thoughts.

I am thankful for the many scholars who helped me expand and clarify my research during numerous workshops, conferences, and colloquia, including Stefan Beck (†), Anna-Lena Berscheid, Andreas Bischof, Søsser Brodersen, Ivanche Dimitrievski, Maren Heibges, Shreeharsh Kelkar, Ulf Mellström, John Law, Jörg Niewöhner, Josefine Raasch, Estrid Sørensen, Lucy Suchman, Helen Verran, Judy Wajcman, Nathan Wittstock, and Yutaka Yoshinaka. Rachel Douglas-Jones, Christopher Gad, Brit Ross Whithereik, and other members of the ETHOS Lab offered helpful comments in the Technologies in Practice Salon at ITU Copenhagen.

I finished writing this book at the Center for transdisciplinary Gender Studies at Humboldt-University Berlin and I am grateful for the encouragement of many people there, including Karin Alexander, Smilla Ebeling, Felicitas Günther, Simon Herchenbach, Gabrielle Jähnert, Anna Kraher, Kerstin Rosenbusch, Sigrid Schmitz, and Marie Springborn. I thank Sumi Jessien of Budrich Academic Press for handling the publication process with care.

I owe a substantial debt to my PhD advisors, Diana Lengersdorf and Maja Horst, who always had an open ear for me when I needed it during my fieldwork and beyond. They were a constant source of encouragement and guidance. Diana Lengersdorf and Maja Horst have read the book's draft and offered helpful comments that significantly improved the argument. My analysis and writing were also shaped through the autonomous working group Political Ethnography (http://akpe.org/). The working group gave me a home and a bearing while moving between universities and fields. I am indebted to the extensive support and encouragement of its members, including Sina Birkholz, Annett Bochmann, Johannes Coughlan, Alejandro Esguerra, Christiane Howe, Martina Kolanoski, Dörte Negnal, Yannik Porsché, Christine Preiser, Anna Sauerwein, Jan Schank, Thomas Scheffer, and Tim Seitz.

During the journey of pursuing my fieldwork and writing the book, I benefited from the support and advice from many dispersed but close colleagues, including Corinna Bath, Sandra Buchmüller, Marisa Cohn, Sarah R. Davies, Pedro Ferreira, Kathrin Ganz, Irina Gradinari, Sabine Grenz, Julia Gruhlich, Raffael Himmelsbach, Lydia Jenderek, Katrin M. Kämpf, Nicole 
Kirchhoff, Vanessa Krogmann, Petra Lucht, Ksenia Meshkova, Norma Möllers, Lisa Pfahl, Winnie Poster, Bianca Prietl, Sarah Schauberger, Jana Szeimies, and Lena Weber.

I am grateful for the friends who have cheered me on through the years and never wavered in their support, including Martin Atzler, Hannes Beuter, Jessica Euler, Philipp Marquardt, Anne Weitere, and Sebastian Winkler. The journey of writing this book was also shared with my life partner Ulrike A.C. Müller who saw me through the final four years of finishing my research. For her generous love and unwavering support, I dedicate this book to her. 


\section{Introduction}

Autonomous driving is often depicted as a 'disruptive' technology with a potential for having a prominent 'impact' on society. For example, the Scientific Foresight Unit of the European Parliament lists autonomous vehicles as the first of ten technologies "which could change our lives" (van Woensel et al. 2015). Autonomous driving promises that motorized vehicles can be fully automated. That is, driverless cars are expected to be able to navigate through messy everyday traffic without human supervision.

Germany's Federal Government expects autonomous driving to enhance traffic safety and reduce emissions (The Federal Government 2015, p. 8-11). By optimizing traffic flow, it is assumed to make room for more motorized traffic on the existing roads. As a technological fix, autonomous driving is expected to remedy some of automobility's issues, such as, congestions and accidents. What appears desirable for the Federal Government seems threatening to others. For example, some German automotive and technology journalists draw on dystopian science-fiction narratives to locate autonomous driving within a frame of loss of control and robot uprising (Berscheid 2014, p. 28).

The driverless car is a vision. It exists only in the form of expectations and promises that have shaped their potentials. However, there are other technologies related to autonomous driving which have entered everyday traffic. Today's cars are equipped with a multitude of driver-assistance systems, which range from the anti-blocking system to the latest advanced driver-assistance systems (ADAS), such as Tesla's "Autopilot". The "Autopilot" enables a "car to steer, accelerate and brake automatically within its lane." (Tesla 2019) Nevertheless, "Autopilot features require active driver supervision and do not make the vehicle autonomous." (ibid.) ADAS do not fully substitute for drivers. All ADAS require a driver to be present and conscious behind the wheel (Broggi et al. 2016, p. 1630). Neglecting to monitor ADAS can lead to lethal accidents (see Stilgoe 2018).

Autonomous driving is not a novel phenomenon; it is a long-standing modernist dream of control that has yet to be realized. For instance, roboticist Raúl Rojas refers to a 1918 cover of Scientific American depicting a futuristic automobile. Its caption reads "The motorist's dream: a car that is controlled by a set of push buttons" (Rojas 2013). According to Rojas, this exemplifies the promise that drivers could use their driving-time for activities other than operating their vehicle within traffic.

During the past 100 years, driverless cars and autonomous driving have been imagined under various labels, such as automated highway systems 
(hereafter: AHS). Expectations and promises have remained stable over time (Wetmore 2003). Advocates of automated driving promise driverless cars that are supposed to be safer, more efficient, and more comfortable than manually driven cars. Autonomous driving is expected to be feasible and its realization is promised to be within reach. Enthusiasts of driverless cars continually cite technological improvements as reasons for the feasibility of these cars. With each technological advance, enthusiasts claim that their dream can be turned into reality.

Technological progress and its related technological imperative are the ideologically resources that underpin visions of autonomous driving. Technology demonstrations (Smith 2009; Simakova 2010; Rosental 2013) are crucial practices in sustaining autonomous driving. In technology demonstrations sociotechnical assemblages are presented in action as evidence for their worth. Companies and university projects use technology demonstrations to convince external audiences by providing visual 'proof' of the feasibility and of the usefulness of an envisioned technology. It is through the agencies' of these demonstrations, that visions acquire substance as these presentations enact links between concrete technological artifacts and more encompassing visions.

The vision of AHS has been popularized by General Motors, who sold AHS to the U.S. public through a large-scale marketing effort. The company's "Highways and Horizons" pavilion at 1939's World Trade Fair in New York City featured a vision of the city of 1960, which it called "Futurama" (Norton 2011). Inside the pavilion, visitors sat on armchairs mounted on a conveyor and were moved over a $3000 \mathrm{~m}^{2}$ model landscape. Visitors took on the bird's-eye view of a modernist city planner as they looked down on " 10,000 animated model cars, dashing along a fourteen-lane highway, [which, GB] embodied the automatic traffic of tomorrow, kept in lane by radio waves" (Kröger 2016, p. 48). Futurama was envisioned as a city dominated by cars but without the usual gridlock and messiness. GM's vision was more about reconstructing the city to accommodate 1940s cars than presenting the car of the future (Norton 2011, p. 593).

There was a considerable discrepancy between what was envisioned and demonstrated in the form of models and what was technologically feasible (Wetmore 2003). Wetmore argues that GM benefitted from this dream-despite its not being realized — because "by selling the future GM was also selling the present" (ibid.). General Motors' concern in this technological demonstration was to promote automobility (Urry 2004; Böhm et al. 2006) and to secure its future rather than to implement large-scale efforts of automation. Wetmore points out that, at the time of the exhibition, it was uncertain whether cars would remain a dominant form of transportation. It was only after World War II, with the construction of the U.S. national highway system and the emergence of suburban sprawl, that automobility's hegemony solidified (Seiler 2007). 
AHS contributed to making already existing cars more appealing by providing imaginary solutions to automobility's pressing problems and thereby contributing to the hope that automobiles could be further improved. Wetmore argues that the continued appeal of these visions stems from the seductiveness of the technological demonstrations. AHS was never realized outside of carefully staged presentations, whereas other forms of car automation became working systems and achieved mass production. The grand vision of AHS was reduced and individualized into cruise control in the mid-1950s (Kröger 2016, p. 55).

In the new millennium, autonomous driving has become a hot topic in AI and robotics primarily due to the ever-growing civilian market for ADAS and the demand for uncrewed military ground vehicles (Broggi et al. 2016). In 2000, the U.S. Congress passed a mandate (U.S. Government 2000) that by 2015 one-third of the operational ground combat vehicles of the U.S. military were to be uncrewed ("unmanned"). In response to this, the Defense Advanced Research Projects Agency (DARPA) organized a series of Grand Challenges in 2004, 2005, and 2007. DARPA and its predecessor agencies have been a key driver and supporter of AI and robotics since the 1960s (Edwards 1996, pp. 64-65). Prizes and competitions are a well-known method to support technological research and innovation (Maibaum 2018).

DARPA sees military potential in autonomous driving in so far as it promises to increase the security of U.S.-American soldiers. During the opening of the DARPA Urban Challenge 2007, Tony Tether, the director of DARPA from 2001 to 2009, promised "that this technology will save a lot of lives - on the battlefield." DARPA succeeded in enrolling many influential researchers and thus enlarged a research community that was marginal prior to the Grand Challenges (Broggi et al. 2016, S. 1630). During these events, in which research vehicles were required to solve tasks such as completing an autonomous drive through the desert or through simulated suburban traffic, university projects competed with each other for a cash prize.

Researchers are often motivated by the belief that autonomous driving can be compartmentalized into tasks or subproblems to be solved, such as "path-planning in structured areas" (Wang 2012, pp. 103-124). For roboticists in the field of autonomous driving, driverless cars in everyday city traffic are more than a seductive future; today, university projects and automotive companies conduct street trials (Marres 10/21/2016). In street trials, companies and university projects monitor their research vehicles' performance in in everyday city traffic. Research vehicles are computationally enhanced

1 https://youtu.be/-xibwwNVLgg?t=17 [Checked on 03/04/20] 
automobiles that can serve two purposes at once. First, they serve as research instruments in the process of solving subproblems, which involves testing, evaluating, and improving approaches from artificial intelligence (AI) and robotics. The objective is to determine the feasibility of a specific approach, for example, that of a certain sensor configuration paired with a specific algorithm. Second, since solving specific subproblems often materializes in visible movements of the research vehicle or visualizations of the algorithm's output, the research vehicle can also be used for technology demonstrations. Streets trials can serve the two objectives simultaneously.

\section{Sustaining autonomous driving}

So far social science has mostly been concerned with possible implications of driverless cars (Bissell et al. 2018; Büscher et al. 2012; Laurier and Dant 2012) rather than in analysis of empirical materials. These speculatively oriented studies are complemented by empirical studies on acceptance (e.g. Fraedrich and Lenz 2016), which take for granted the feasibility of driverless cars and the future widespread diffusion of autonomous driving. All of these studies tend to reproduce uncritically the rhetoric of governments, private companies, and research projects that are rallying for autonomous driving. The above studies misconstrue contemporary innovation. The proliferation of hyperbolic expectations and visions can be seen as a necessary part of strategic science and technology innovation (Borup et al. 2006, pp. 286-287). The claims of inevitability of autonomous driving are acts of persuasion (Stilgoe 2020, pp. 8-9). Governments are inclined to stimulate hype in order to justify present spending on irreducibly uncertain 'technologies of the future'. Private companies and publicly funded research project are incentivized to claim that driverless cars are within reach; these actors compete for attention and financial resources (Stilgoe 2020, pp. 40-41). With regard to autonomous driving, "the gap between baby steps and giant leaps, between concept cars and transport systems, is filled with promise and speculation." (Stilgoe 2018, p. 33). Given that we are dealing with a vision, the only certainty is that there is no certainty concerning if, when, under which conditions, and for whose benefit autonomous driving will be realized.

Studies that investigate autonomous driving empirically are still rare (Brown and Laurier 2017), but this seems to be changing. For example, Stilgoe reconstructs the competing definitions of problems, solutions, and concerns within the public debate of autonomous driving (2018). What remains missing, however, is an analysis of the lived relations between technological artifacts, researchers, and visions. This study seeks to contribute to an understanding 
of autonomous driving by engaging with technological artifacts and with the practitioners who actually try to realize visions of autonomous driving.

This book is not about if, when, how, and to whose benefit autonomous driving will emerge. Science and Technology Studies consider technological research and innovation to be contingent and heterogeneous (Bijker and Law 1992). The emergence of a particular technology depends on the stabilization of a sociotechnical network of heterogeneous elements; its elements are human and nonhuman. Thus, technological research and innovation is never only 'technological'. Furthermore, technologies are not 'born' feasible. Technologies only seem inevitable in retrospect. This study investigates a technological project in a situation where very little is certain but expectations are high. It analyzes how relations between technological artefacts, visions, and researchers are sustained both symbolically and materially.

This book is not about 'the future'. Rather, it is about how certain visions of the future are kept alive in the observable present. In particular, this study examines research in autonomous driving by engaging with a pioneering project in computer science. Autonomous driving is investigated through the lenses of narrative, care, and gender-technology relations.

Narrative forms are a primary element of autonomous driving. To endow their artefacts with meanings that are recognized by laypersons, researchers in autonomous driving need to construct frames of meaning (Carlson 1992, p. 177) in which autonomous driving makes sense. As autonomous driving is controversial, researchers need to craft persuasive and compelling narratives. These narratives are enacted through texts and speech, but they also enacted through staged performances, including video demonstrations. Visionary storytelling reduces the complexities of research in autonomous driving by concealing its contingencies and uncertainties. Innovation communication is not what comes 'after' technological research but is rather integral to the very processes of innovation (Horst et al. 2017, pp. 892-893).

In the hands of the computer scientists doing research in autonomous driving, these visions are transformed into a variety of enactments, including street trials and video demonstrations. It is through these translations that visions are sustained and acquire substance. Unlike carefully staged video demonstrations, street trials are risky. During Uber's street trials a pedestrian was killed in 2018 (Stilgoe 2020, p. 1). Sociotechnical assemblages of autonomous driving demand care to be held stable in the messy and contingent world of everyday city traffic.

This study is situated within a recent re-orientation in the social studies of technology (Both and Cohn 2017; Cohn 2013; Denis and Pontille 2015; Jackson 2014; Singleton 2010) towards relations of care in sociotechnical assemblages, which connects to earlier studies of repair and maintenance (Orr 1996; 
Mellström 2003). Jackson argues that the social studies of technology display a "productivist bias" (Jackson 2014, p. 234) in so far as novel technologies are valued over old technologies. In other words, Jackson is observing how the assembling and diffusion of technologies is given prominence over the sustaining of networks and maintaining of technologies over time. A focus on caring for technology directs attention away from the generation and expansion of sociotechnical assemblages and towards the maintenance and support of existing sociotechnical imaginaries and their related artifacts.

Enthusiasm for driving cars is often associated with masculinity (Vobker 2016, pp. 185-186). Driverless cars are anticipated by some scholars with the potential of undermining the masculine coupling of drivers and cars (Balkmar and Mellström 2018; Manderscheid 2018; Redshaw 2018). This tendency can also be observed in popular culture. For example, a sports car company framed its cars as "man's last stand" 2 in a TV ad. The company continued along the lines by framing autonomous driving as a ploy to emasculate men (Both and Weber 2014). The incapacitation narrative makes autonomous driving an interesting case for studies of masculinity and technology. Technology in Germany is created, imagined, researched, and developed in male-centered communities (Solga and Pfahl 2009). How do researchers in the field of autonomous driving negotiate masculinity in the light of being framed as contributing to the incapatication of the driver?

Masculinities and technologies may converge or diverge in terms of subjectivities, identities, practices, and symbols. Relations of masculinity and technology remain a curiously under-researched area. Sociology of technology tends to ignore gendered aspects of its object of study (Cockburn and Ormrod 1993, pp. 9-10; Berg and Lie 1995; Wajcman 2004; Lengersdorf 2011). Technology is analyzed as a 'general' phenomenon, thereby leaving its cultural and social specificities unexamined. To illustrate this point, the latest German Introduction to Sociology of Technology - a textbook with more than 400 pages - covers gender studies and feminist technology studies in a single paragraph (Häußling 2014, pp. 129-130). ${ }^{3}$ The gender-blindness of the bulk of studies in the sociology of technology is open to criticism because it fails to account for the power relations that constitute and are constituted by technology. Performances of masculinity play a role both in the technology-centered communities and in the ways in which technologies are assembled.

2 https://www.youtube.com/watch?v=Ya8QXq7diYw [checked on 12/14/19]

3 A previous German introduction to sociology of technology (Degele 2002) dedicated a whole chapter to technology and gender. 
Feminist technology studies (Bray 2007; Faulkner 2001; Wajcman 2000), or "technofeminism" (Wajcman 2004), conceptualizes gender and technology relationally - that is, as co-productions. My study contributes to this body of work by studying how masculine subjectivities and relations between masculinity and technology are (re-)configured within a research project of computer scientists in Germany.

Studies of men and masculinities, tend to underplay the significance of technology in many - though certainly not all-men's lives (Lohan and Faulkner 2004, p. 319; Mellström 2004, p. 369). This is puzzling because historical research shows that the very definition of modern technology is coterminous with masculinity (Oldenziel 1999); during the professionalization of engineering in Germany, for example, different forms of masculinity competed over what constitutes an engineer (Paulitz 2012). Few studies of men and masculinities investigate how homosocial communities may be centered on a shared passion for and intimacy with machines - a centering that has been observed, for example, in studies of communities of Swedish engineers (Mellström 1995), of British robotics hobbyists and U.S. American software developers (Kleif and Faulkner 2003), of Chinese automobile mechanics in Malaysia (Mellström 2003), and of Swedish car modifiers (Balkmar 2012).

\section{Outline of the book}

Autonomous driving is not independent of the actors involved in the constitution of the phenomenon. This is to observe that autonomous driving cannot be understood in terms of an institution or an object-in-itself. Germany's Federal Government, together with Germany's automotive industry, its journalists, and many others, are helping to enact autonomous driving. Social scienceeven if only to a very small degree-is also participating in its constitution. As a matter of fact, this very text that you are reading at the moment helps to enact autonomous driving as a sociotechnical phenomenon. Social scientists who study autonomous driving cannot claim that they are only 'observing' the phenomenon from a distance. No "god-trick" (Haraway 1988, p. 587) may be used to articulate a detached and innocent perspective. There are only partial perspectives on autonomous driving.

In order to account adequately for the phenomenon, then, it becomes necessary to study autonomous driving relationally. This is accomplished by pairing the relational ontology of actor-network-theory with ethnography. This study has engaged, by means of ethnographic fieldwork, with members of the field of research in autonomous driving. Between June 2012 and November 
2015, I conducted fieldwork within a male-centered computer science university project in Berlin, Germany.

In chapter 1, I explicate my theoretical and methodological framework and elaborate on the design of my study. In chapter 2, I introduce my field site by describing the university project as an assemblage of project members, technological artefacts, and visionary stories. I analyze how its vision is translated into street trials. I continue in chapter 3 by zooming in on street trials. I describe how project members assemble their computationally enhanced vehicle for-what they call - the "real world" of mundane city traffic. I reconstruct the imaginary of control realized in the configuration of the research vehicle. I conclude this chapter by analyzing how the project members take care of the computationally enhanced vehicle during street trials. In chapter 4 , I use my disconcertment during fieldwork as a method to trace the ambivalent relations of computer scientists, cars, and driving. By analyzing project members' narratives, I show how research in autonomous driving is masculinized. Chapter 5 takes a tour through the fantastic genres of video demonstrations. Video demos appear to document the uses and capacities of technologies, but they are actually a medium in which members can live out their fantasies without "real world" restraints. In video demos, visions can be narrated as if they were already realized. I analyze its genres and its performative effects for the project. Chapter 6 resumes the discussion of the performativity of innovation communication. I scrutinize the different strategies of promoting autonomous driving to varying audiences. I show how project members try to settle controversies over autonomous driving and their status as a robotics research project. The final chapter offers a conclusion to the study. I close this introduction by briefly elaborating on the challenges and opportunities related to the languages I use in this study.

\section{Some notes on language and the terms I use}

American English is my second language. I decided to write in English ${ }^{4}$ rather than German because I would like my study to contribute to the international conversations in social science. I did not want my study to be inaccessible for anglophone audiences. However, my fieldwork took place in mostly German-speaking settings. I wrote most of my fieldnotes in German and I conducted my interviews predominately in German. Given that I report upon

4 I am indebted to Daniel Barber, a native speaker and professional editor, who corrected the spelling and grammar in large parts of the book. 
my research in English, this poses both a challenge and an opportunity. I use a number of interview excerpts in this study, and when I translated interview segments from German into English I became aware of many subtleties in utterances that I would not have been able to detect if I had not interpreted them myself. This effort of translation has contributed to my analysis. The downside of this effort was that, while I gradually grew confident in understanding what the members meant when they said something in German, I was often unsure whether my translation made sense in the English language. In particular, the casual and intimate tone of my conversations with project members tended to be lost in translation, as it exceeded my proficiency of English. This is why, during a later stage of my writing, I hired Sally Hoffmeister, a professional interpreter and native speaker of English, to translate the remaining interview excerpts. I edited and corrected these excerpts in order to capture the often hermetic and elliptic phrasing of the members. I sought a compromise between readability and preservation of the natural flow of the conversations.

When reporting on my fieldwork, I tried to use members' terms (Emerson et al. 2011, pp. 142-144) whenever possible. That is how I settled on autonomous driving rather than, e.g., (fully) automated driving, which is a term preferred by other projects and Germany's state agencies (Gasser et al. 2012; The Federal Government 2015, 2017). In other instances, I deliberately chose to use terms from academic literature rather than the terms of the members. One such instance is my decision to use the term "demonstrator" rather than "prototype." A prototype of a driverless car would insinuate a technological artifact that is capable to display all functionalities required to fully substitute for human drivers. However, a demonstrator or "proof of concept" (a term used by members) is in actuality limited to certain capabilities. For example, when the TU Braunschweig presented its demonstrator in October 2010, its functionality was not nearly as significant as advertised. It was capable of driving on Braunschweig's inner-city ring, but only in a clockwise direction because turning left on intersections is more difficult to realize. Nevertheless, the TU Braunschweig send out a press release claiming to be the first in the entire world to have achieved automated driving in "real urban traffic" (im realen Stadtverkehr) (TU Braunschweig 10/7/2010).

Political ethnography (Bochmann et al. 2019), as a specific form of qualitative social research, does not stop at the reconstruction of practitioners' meanings and theories; it seeks to develop an observer's or analyst's theory, which goes beyond theories provided by members within the field (Strübing et al. 2018, p. 91). Unresolvable tensions usually arise between members' theories and the analyst's theory. For example, my reconstruction of masculinitytechnology relations in Chapter 4 will most likely be disputed by practitioners, 
for these findings are in conflict the gender-neutral self-understanding common amongst scientists and engineers (Paulitz et al. 2016).

Some of the words and concepts I use are difficult-if not impossible - to translate without friction. For example, account or to account has a specific meaning in social science conversations and maps onto several different German expressions. Naturally, the same translational friction is at issue with various German words, such as Sinn (meaning, sense, or purpose) and Sinnfrage (question of meaning, search for meaning). Whenever I was unsure about whether my use of the English language captured the meaning I sought to convey, I added the German word in parentheses and in italics. There are also some German terms, such as Informatik (computer science), that I deliberately choose to translate in a specific way so as to make them legible for international audiences. 


\section{Chapter 1 | Grounding the study}

The aim of this chapter is to develop a "minimal methodology" (Sørensen 2009 , p. 28) that serves to ground the empirical study. I start by outlining my theoretical approach and then proceed to present the methodology, the research design, and its methods. I account for my generation and archiving of empirical materials, thereby showing how they have shaped my fieldwork and redirected my research questions.

\section{Theoretical approach}

This is a study of an imaginary that ties (human) members, artifacts, and visions together within the field of research in autonomous driving. My theoretical approach draws on social sciences, with an emphasis on anglophone theorizing in Science \& Technology Studies (hereafter: STS) and Gender Studies. Since this chapter begins by laying down the key concepts of the study, I will initially proceed by referring simply to 'members' of or 'practitioners' in the field without further specifying who I studied. While we will learn more about them in the course of this chapter, for now it matters only that they are members of the field of research in autonomous driving.

\section{Humanist social science}

My theoretical approach can be traced back to the premise that both technology and gender can be studied as socially constructed (Cockburn and Ormrod 1993, pp. 7-12). I will use Berger and Luckmann's sociology of knowledge (1991 [1966]) to understand how practitioners who see autonomous driving as self-evident maintain their promises and visions conceptually when faced with hegemonic definitions of automobility.

Berger and Luckmann write within a humanist social science tradition; they focus on the role of knowledge in a society constituted by relations between people or groups of people. If we take their theory of knowledge as a starting point, then we are able to investigate autonomous driving as socially constructed. This is to say that everything we know about autonomous driving has been and is still being negotiated between varying actors. Knowledge on autonomous driving is still in the making. The knowledges we are dealing with are either expectations, e.g. what autonomous driving would look like if it was eventually realized, or accounts of the state of the art and progress in the domain of autonomous driving. There are competing accounts or diverging 
expectations as to what the characteristics of autonomous driving are or will be (Chapter 6).

The meanings of autonomous driving are also in the making; they are neither self-evident nor pre-determined. Autonomous driving acquires meaning within a symbolic universe. A symbolic universe is a frame of reference in which "all human experience can $[\ldots]$ be conceived of as taking place" (p.114). Symbolic here refers to "processes of signification that refer to realities other than those of everyday experience" (Berger and Luckmann 1991 [1966], p. 113). Symbolic universes "integrate different provinces of meaning and encompass the institutional order in a symbolic totality [...]" (Berger and Luckmann 1991 [1966], p. 123).

Symbolic universes can become problematic if alternative symbolic universes challenge their self-evidence. Let us assume, for example, that for us the dream of autonomous driving is self-evident. In our symbolic universe, autonomous driving therefore makes sense and is desirable. What happens, however, if former Porsche and Volkswagen CEO Matthias Müller comes along and calls autonomous driving "a hype lacking justification" (N.N. 2015)? Müller thereby sets forth an alternative definition of reality. In his definition, autonomous driving has no place and therefore no right to be pursued further.

To immunize itself against challenges, symbolic universes "develop a conceptual machinery to account for such deviations and to maintain the realities thus challenged" (Berger and Luckmann 1991 [1966], pp. 130-131). Berger and Luckmann describe two strategies that serve to protect a symbolic universe when it becomes problematic: therapy and nihilation. Therapy concerns "itself with deviations from the 'official' definitions of reality" (Berger and Luckmann 1991 [1966], pp. 130-131). Nihilation seeks to neutralize threats by conceptually liquidating deviant definitions of reality that are outside of the challenged symbolic universes. Berger/Luckman (Berger and Luckmann 1991 [1966], pp. 132-133) describe nihilation as a form of negative legitimation. Definitions of realities or the reality of phenomena are denied because they do not fit into the universe. There two forms: either the deviant phenomenon is assigned an inferior status, such that it cannot really be taken seriously, or the deviant definitions of reality are accounted for in terms of concepts from one's own universe. The aim here is to incorporate the deviant conceptions by translating them into one's own universe. A threat to one's universe is translated into an affirmation.

The concept of symbolic universe is useful for understanding how visions of autonomous driving are maintained conceptually as they are challenged by alternative definitions of reality. However, it is important to note that the symbolic universe is an anthropocentric concept. The origins and dynamics of symbolic universes are independent of materiality. As we will see in the course 
of this study, the symbolic universe of researchers in the field of autonomous driving is entangled with the affordances of information and communication technology (hereafter: ICT). Berger/Luckman's concept of symbolic universes cannot grasp the transmission between the symbolic and the material.

To understand how members imagine and perform autonomous driving in both its symbolic and material dimensions, we need concepts and theoretical toolkits that neither privilege human relations (e.g., humanist social science) nor marginalize human relations (e.g., mainstream computer science). This is to say that we cannot narrowly focus on material or 'technical' relations and ignore how these relations are shaped in cultural and social contexts. Yet to adopt a humanist approach - i.e, one that privileges human relations - is also inadequate, for this would fail to account for the ways in which autonomous driving is heavily inflected by the availability and affordances of highprecision GPS and sensors (such as laser scanners or RADAR). To understand autonomous driving in both its symbolic and material dimensions, we need a posthumanist social science, or what has been called a "more-than-human social science" (Whatmore 2003, pp. 90-92).

\section{More-than-human social science}

\section{Imaginaries}

Imaginaries is a concept suitable for grasping the entanglement of the symbolic and the material. Imaginary is a term of art that may be used as a hybrid concept. This is because it can be used to describe relations of humans and nonhumans. Although it has acquired popularity within STS, it is rarely defined and often used in different ways (McNeil et al. 2017). My use of imaginary refers not to Jasanoff's socio-technical imaginaries (Jasanoff 2015), which have been used to study nations, institutions, and policies, but rather to the members' shared imaginary, "a collective fantasy landscape of at least partly shared ideals, practices and images" (Balkmar 2012, p. 35). Technoscientific imaginaries tie together promissory practices and material practices. This type of imaginary "looks to the future and future possibility through technoscientific innovation but is equally constrained by the very present conditions of scientific work" (Marcus 1995, p. 4 cited in McNeil et al. 2017, p. 445). Expectations and visions shape laboratory practices and vice versa. According to Lucy Suchman,

[imaginary] shares with the more colloquial term imagination an evocation of both vision and fantasy. In addition, however, it references the ways in which how we see and what we imagine the world to be is shaped not only by our individual experiences 
but also by the specific cultural and historical resources that the world makes available to us, based on our particular location within it. And perhaps most importantly for my purposes here, cultural imaginaries are realized in material ways. (Suchman 2007, p. 1 footnote 1)

Balkmar, Marcus and Suchman put emphasis on the collective nature of imaginaries. They draw attention to the ways in which the beliefs, fantasies, and ideals at issue in imaginaries are shared and situated rather than held by individuals alone.

Imaginaries are necessarily involved in knowing and knowledge-making. They are "constitutive of, and constituted by, ontic and epistemic commitments" (Verran 1998, p. 238). For example, how members demonstrate their version of autonomous driving and how they perceive and understand driving in everyday city traffic are constituted by an imaginary.

Robotics \& AI is a field where the boundary between fact and fiction is continuously breached (Richardson 2015, p. 113). Robots "materialize the cultural imaginaries that inspire them and which they work in turn to enact" (Suchman 2007, p. 226). In this field, imagination and materiality are not separable ontological domains but rather intertwined.

\section{Relationality and heterogeneity}

Actor-network-theory (hereafter: ANT) offers anti-essentialist sensitivities for doing more-than-human social science. It presumes that "things are what they are in relation to other things, not because of essential qualities" (Gad and Bruun Jensen 2010, p. 58). ANT is fundamentally relational: it treats everything "as a continuously generated effect of the webs of relations within which they are located" (Law 2009, p. 141). Established categories, such as society and technology or men and women, as well as widely used distinctions, such as social/technical and masculine/feminine, are themselves effects of relations. Consequently, society and technology cannot serve as explanatory categories, nor do the categories of women or men "hold inherent explanatory power" (Faulkner 2009a, p. 15).

Since the 'social' and the "technical' are outcomes of "purifications" (Latour 1993, pp. 10-12), all "relations should be seen as both social and technical" (Law and Bijker 1992, p. 290). This is the principle of heterogeneity, which seeks to eschew both social and technological determinism. This means that technology is neither fully determined by society nor something that can be reduced to purely technological relations. Instead, technology is constituted by relations between heterogeneous elements (Callon and Law 1997, pp. 167-170). 
I draw on the concept (sociotechnical) assemblage-which I use interchangeably with network - as a means of referring to the intertwining of heterogeneous elements, such as humans, ICTs, materials, narratives, and meanings. The concept of sociotechnical assemblage entails a figure-ground reversal in studying technology: what is foregrounded is no longer the tangible artifact with its implied fixed boundaries, but rather the relations that constitute a sociotechnical assemblage. However, the concept of sociotechnical assemblages is not limited to the study of technology.

ANT's principle of performativity states that "nothing has reality or form outside of the enactment these relations" (Law 2009, p. 141). Relations do not hold by themselves; they must be performed or enacted. Everything is a matter of doing. Technology is performed. Gender is enacted. Everything is practice. Nothing exists outside of practice. To say that gender and technology are performed does not mean that they are matters of individual achievement. Robinson Crusoe is of no interest here. Rather, gender and technology are conceptualized as the outcomes of collective accomplishments. This theoretical premise entails that gender is a process rather than a given essence or structure. Gender is an analytical category. Women/men or femininity/ masculinity are outcomes of the analysis and not its starting point.

If technologies can be conceptualized as sociotechnical assemblages, then gender, too, can be conceptualized as a sociotechnical assemblage. Vivian Lagesen argues,

Leaning on ANT, we may claim that doing gender is an on-going movement where associations with bodies, norms, knowledge, interpretations, identities, technologies, and so on, are made and unmade in complex ways. Thus, gender is fluid and flexible because new associations are established, while old ones are dissolved. (Lagesen 2012, p. 445)

But what about the seemingly 'natural' connection between masculinity and technology? If this gendered association appears to be stabilized, it is because it is made stable through the making and re-making of narratives, identities, and representations that "uphold stable gender practices" (Sørensen et al. 2011, pp. 52-54).

Within ANT translation is a concept for understanding and describing processes of innovation. Translation carries many meanings: to interpret, to betray, and to move. For example, Latour (1987) analyzes how goals, interests, and actors are translated in processes of innovation. Latour studied the biography of a rapid personal transportation system called Aramis (Latour 1996), which has a vision that is strikingly similar to that of autonomous taxis (see chapters 2 and 4), except that it takes place on tracks. Aramis ultimately failed 
to become a working system. Latour describes how a technological project is translated between different media (e.g. plans, trials, chips) and achieves different degrees of realization over the course of its history. For example, the vision of Aramis on paper in 1970 has less substance than Aramis' simplified test site at Orly in 1973. Latour argues that the only way for a project to become more realizable is through compromise.

ANT shares with the Social Construction of Technology the premise that technologies are shaped through conflict (Bijker and Law 1992, pp. 8-11). For instance, the shape of the TSR2 fighter plane was negotiated between competing government agencies, the manufacturers and Soviets Union's RADAR capabilities.

ANT argues that researchers in technology are "heterogeneous engineers" (Law 1987). Heterogeneous engineers seek to associate entities of various kinds, such as skills, artifacts and even weather conditions. In Law's analysis of the colonial expansion of the Portuguese, he demonstrates how a new type of ship has to embody different relations in order to withstand trials of strength, such as forces of nature. For an artifact to stabilize it needs to maintain its shape in the face of other entities that seek to dissociate it. The fate of the networks that heterogeneous engineers assemble is decided by these trials of strength.

Over the years, ANT has received a great deal of criticism within social science. For instance, German sociologists typically criticize Latour for his lack of rigor and coherence, as well as for the incompatibility of his theory with those of mainstream social theory (Kneer et al. 2008). Another point of controversy is ANT's proposition that intentions can be inscribed into artifacts or infrastructure. For example, organizational researcher Paula Jarzabkowski and STS practitioner Trevor Pinch argue that ANT analyses tend to "black box' the social interactions within which activities are accomplished to focus on the materials themselves" (Jarzabkowski and Pinch 2013, p. 585).

\section{Methodology}

ANT is particularly suitable for analyzing processes of stabilization (Hyysalo 2010, pp. 37-40). The label ANT invites misreadings. ${ }^{5}$ ANT is not a theory in the sense that it seeks to explain anything. In fact, it dismisses large-scale sociological theories and is instead descriptive (Law 2009, pp. 141-142). ANT is interested in practice, materiality and the accounts of actors ('how'

5 However, alternative labels, such as sociology of translation (Callon 1986), actant-rhizome ontology (Latour 1999), or material semiotics (Law 2009) have not gained wider usage. 
questions) (Sismondo 2004, p. 65). It does not seek generalizable causal explanation ('why' questions) but rather offers a "set of sensitivities" (Mol 2010, p. 265) which are useful in developing "throwaway explanations" (Latour 1988 cited in Gad and Bruun Jensen 2010, p. 76) for specific assemblages. Hence, ANT analysis can only explain in retrospect why a network did or did not succeed in stabilizing.

\section{Technology and gender}

If the 'social' and the 'technical' are the outcome of "purifications" (Latour 1993, pp. 10-12) - this applies as well to other binaries, such as men/women or masculine/feminine - then I can neither take them for granted as a starting point of analysis nor use them as a means of explanation. Where do we start then? A popular method of ANT is to follow the actors and their associations (Latour 1987) in order to describe how these actors assemble their world (Latour 2005). In an ANT analysis, what is central are the accounts and practices of actors. Rather that starting with the categories of the analyst, "actors ought to be given voice in their own categories" (Gad and Bruun Jensen 2010, p. 76). At the beginning, we need to assume that actors "know their own practices best" (Gad and Bruun Jensen 2010, p. 76).

Feminist STS scholars have challenged the "Machiavellism" (Hyysalo 2010, pp. 39-40) of many ANT analyses for their overemphasis on central actors or emergent artifacts. Haraway charges Latour for intensifying the "structure of heroic action" (Haraway 1997, p. 34), contrary to his own intent. Famously, Latour did not address gender issues in his textbook Science in Action (1987). Marginal actors and "implicated actors" (Clarke 2005, pp. 46-48) may easily be left out of ANT analyses, even though they can be affected-sometimes with grave consequences - by "network externalities" (Star 1991, p. 43). The fields of technological research and design are often male-centered. As such, women and minorities tend to be absent from ANT analyses unless, for example, these analyses are focused on the domestication of technology. Another common critique of ANT analyses is the reluctance of many authors to consider gender, class, race, and other markers of social inequality as analytical categories (Wajcman 2004, p. 103).

Other feminist scholars view ANT as helpful in overcoming analytical shortcomings in constructivist studies of gender and technology (Omrod 1995; Lagesen 2012). Whereas technology is analyzed as fluid and malleable, gender often remains a static and binary category. Studying gender-technology relations with ANT's sensitivities can be way to minimize reification and to keep gender flexible and dynamic. This involves investigating how uncertainties are overcome and how controversies are settled (Lagesen 2012, p. 444). 
Gendered meanings are only considered if they are actively used as resources to stabilize networks (Omrod 1995, pp. 44-45).

\section{Narratives and storytelling}

Communication cannot be separated from other aspects in the making of technology (Horst et al. 2017, pp. 892-893). There is no innovation without communication. ANT studies demonstrate that innovation cannot be understood independently of the communication around it. "Instead, it is an integral part of the way in which a technology is developed, appropriated, and used" (Davies and Horst 2016, pp. 138-139).

Plesner and Horst argue that "visionary communication" (Plesner and Horst 2012, 2013) can be a means to gain support, build networks and thus contribute to the stabilization of a new technology. Narratives are crucial not only the legitimation of technology but also in the allocation of resources. Stories and sense-making are the very stuff of which technological projects are made. The production of narratives is a crucial part of innovation.

Narrative is the main device for making sense of social action (Czarniawska 2004, pp. 6-10). Without narrative, action would be reduced to behavior, or to merely arbitrary events with no significance. Without interpretation there can be no understanding. The capacities of envisioned technologies are narrated through different genres and forms of communication. Expectations and promises of innovations are embedded in narratives.

I assume narratives to be crucial in the development, sharing, and circulation of meanings. Narrative is a mode of knowing and communicating (Czarniawska 2004, pp. 6-12). As such, narratives define tacitly the frames of reference according to which we imagine technologies and perceive actual steps taken towards their realization. Narratives order (Law 1994): they associate elements with one another or dissociate elements from one another.

Technologies can be aligned with multiple narratives and there are no technologies without some kind of narrative attached to them. Prominent examples are narratives of technological progress, which associate technological innovation with societal progress. Narratives integrate events or elements in a meaningful whole. Like images, they emphasize some aspects while hiding others - as is the case, for example, with narratives of autonomous driving.

Narratives in innovation are central to the reduction of complexity and uncertainty (Deuten and Rip 2000). According to Deuten and Rip, the work that is performed by stories is often neglected in analyses. Narrative can constrain or act forcefully. Stories are not free-floating, for they are often produced in relation to other narratives and they depend to a certain degree on material enactments. 
Czarniawska defines narrative as "a spoken or written text giving an account of an event/action or series of events/actions chronologically connected" (2004, p. 17). Czarniawska distinguishes between narratives and stories: the naked narrative is a purely chronological account, whereas stories are emplotted narratives (2004, p. 17). Emplotment constructs characters, attributes functions to events and provides an interpretative theme. In doing so, it turns random events $(2004$, p. 32) and purposeful action into something meaningful.

Narratives deal with existing plots and interpretative themes; they may also involve acts of positioning. They are produced in relation to other narratives. They are a collective and contingent achievement. While they are not the product of individual minds, they provide crucial elements in the making of individual and institutional identities. Identity can be created by a self-narrative (Czarniawska 1997). I understand identity not as a set of unchanging and essential characteristics of an individual, group or artifact, but rather as a creative process (Tonso 2007). For example, Horst (2013) argues that when scientists talk about their work, they enact particular understandings of what science, projects, and scientists are or should be. Members perform identities by drawing on different cultural resources, such as narratives, images, or discourses. Identities are enacted through positioning (Davies and Harré 1990) and narration within available cultural frames. Positioning can take many forms, such as taking up, identifying with, or rejecting subject positions.

\section{Expectations, promises, and visions}

How do I understand expectations, promises and visions, and how do I distinguish them from one another? Technological expectations are "real-time representations of future technological situations and capabilities" (Borup et al. 2006, p. 286). Promises are expectations with wishful and subjective elements. Technological visions are "strategic framework[s] for realizing expectations" (Davies and Horst 2016, pp. 141-142).

Expectations, promises, and visions are not free-floating. They depend on materiality and embodiment to take on substance. Borup et al. ask,

to what extent are expectations the enunciated views and ideas of people (utterances), and in what way do they become 'inscribed' in texts, actions, bodies, materials, objects and machines (embedded)? (2006, p. 292)

Expectations, promises, and visions are not limited to the imagination. Leaning on Borup et al., I conceptualize them as co-produced by imagination and materiality. 
Expectations, promises, and visions are never neutral (Davies and Horst 2016, pp. 144-146). They are normative and interested accounts. Technological visions often include a script which organizes relations between imagined users and envisioned technologies. Visions include assumptions regarding societal and ecological problems and how they ought to be solved. In this sense, visions can be connected to problematizations (Callon 1986, p. 203; Plesner and Horst 2013, p. 1120).

Expectations are not just statements about the future, for they also enable - that is, perform-certain things in the present. Expectations, promises, and visions are not only interesting for their intrinsic qualities but also because of what they can do. Expectations, promises, and visions can be performative (Davies and Horst 2016, pp. 141-142) in the sense that they do not simply represent the envisioned technology in a context; they fabricate a context for the technology to be realized. They can give meaning and purpose to a technological project and perform an identity. Expectations and promises are not facts but means of generating desired attention. Expectations can be generative by providing structure and legitimation, attracting interest and fostering investment.

\section{Research design}

Autonomous driving is an emerging technology and as such it is messy, ambiguous and uncertain. How can we understand something that is still in the making and has not stabilized? STS researcher John Law asks, "How might method deal with mess?" (Law 2004, p. 2)? His answer is that standard social sciences methods will produce a single reality and thereby distort whatever you are seeking to describe. We necessarily order, even as we try to describe mess. Order and mess are mutually constitutive (Suchman 2011a, pp. 28-29). If we order too much, we make a mess out of it. When investigating an emerging technology, such as autonomous driving, we cannot expect single answers.

To be open towards the ambivalences, dynamics, and uncertainties, we have to start with a negative argument. This is where ANT's sensitivities become particularly valuable. The advantage of ANT over many humanist social theories is that it does not define in advance who/what does and does not play a role in processes of innovation. ANT is sensitive to messiness and materiality (Law 2009, pp. 141-142). It simultaneously helps one move beyond the study of technology as a self-evident and bounded artifact (Hyysalo 2010, p. 39).

We need a research design that comes with a minimal set of assumptions. What is necessary is not 'High Theory' but "sets of sensitivities" (Mol 2010, 
p. 265) which are open to the unexpected and adaptable to researchers' imaginary of autonomous driving. If we do not want to fixate the phenomenon before investigating it, then we need to refrain from defining the shape and ontological status of an emergent technology prior to its analysis. In this manner, the object of study - researchers' imaginary of autonomous driving - is simultaneously turned into an empirical and methodological question. If we want to be open towards imaginaries of autonomous driving, we will have to devise an adaptable research design.

This section describes the research design of my study. It begins by arguing that ANT should be coupled with ethnography in order to explore the imaginary of autonomous driving. Following this, I will describe how I operationalized my research questions by conducting an ethnographic "window study" (Czarniawska 1997, pp. 64-65). Finally, I will outline the materials I generated and describe how I analyzed them.

My research design is an ethnographic window study. In a window study, the researcher "opens an arbitrary time window and describes all that can be seen through it" (Czarniawska 1997, pp. 64-65). What is relevant, routine or exceptional is not decided by the ethnographer alone. It is negotiated with the members. I did not decide prior to the analysis what kind of case it is because for ANT analyses, this should be treated as an empirical question (Latour 2005, pp. 143-144). My study did not start off as a case study of an emerging technology; it developed into one through time.

If one claims that imaginaries are inflected by and realized in the design of a sociotechnical assemblage, then one cannot study the imaginary of an emerging technology from a distance. We know very little about roboticists' imaginary of autonomous driving in social science. As a research strategy, ethnography can open up 'new' objects (Breidenstein et al. 2013, p. 175) for social science. By describing what researchers actually do and how they account for their practices, ethnography can be instrumental in accounting for technoscientific practices without contributing to the generation of myths (Braun-Thürmann 2002, p. 29). If one only relies on interview material or published accounts, it will be hard to reconstruct what is actually relevant to the members and how they really go out about doing their research. This is why it is important to become a quasi-member of the field oneself. Interviewing alone does not do the trick. By triangulating data generated through participant observation, ethnographic interviewing, videography and document analysis, one can learn what members find relevant and how they imagine autonomous driving. By analyzing what practitioners actually do, in relation to what they hope and claim to do, and what they mean when they describe their goals and accomplishments, we can understand and appreciate the problems members are dealing with from their own perspectives. The latter is very important, as 
social scientists and computer scientists often do not speak the same language. In addition, our systems of relevance can be very different. For example, roboticists tend to think from the position of the artifact or system (Vertesi 2012, p. 406) rather from the position of the user or bystander. A distanced analysis of a social scientist might misrepresent practitioners' meanings.

Ethnography is both research process and its outcome, e.g. this book. One of the key challenges of doing ethnography is to iteratively develop a research design that integrates theoretical approach, research questions, methods, and data materials into a sound whole. Sociologists call this objective "adequacy" (Gegenstandsangemessenheit) (Strübing et al. 2018, p. 86). Questions and hypotheses are constantly modified in the course of the study (Lengersdorf 2015).

In order to achieve adequacy in ethnographic fieldwork, full immersion and empirical saturation (Strübing et al. 2018, p. 88) within the field is a must. Immersion makes it possible to identify problems of double relevance (Breidenstein et al. 2013, pp. 167-170) — in other words, problems that are relevant to roboticists and to social science audiences. Immersion is necessary to understand what is going on and to understand the world from members' points of view. As a trained computer scientist, ${ }^{6}$ I tend to be less misled by practitioners' tech lingo "purposefully saturated with anthropomorphism" (Wajcman 2017, p. 121) or by far-fetched promises inspired by science fiction stories. Both my training ${ }^{7}$ and the empirical saturation that results from my fieldwork enable me to claim some authority in writing about autonomous driving, even though I was not involved in the design aspect of the project. I am thus able to judge for myself whether some utterance or demonstration has substance or takes advantage of a gullible audience. This is an extremely important resource with respect to autonomous driving, as many visionary stories circulate that tend to conceal any uncertainty, ambivalence and complexity of autonomous driving in urban traffic. Researchers in AI and robotics are "profoundly optimistic about their practices; they describe any obstacle in

6 Technically, I studied „Informatik“. German ,informatic” is the translation for computer science. It has little to do with what is internationally called informatics (e.g. a study program at University of California, Irvine) or information science (e.g. a program at University of Aarhus). The German misnomer "Informatik" hides the fact that German computer science is fundamentally machine-centric.

7 During my academic studies in computer science, I took courses in areas relevant to robotics, such as basic and advanced signal processing, image processing, pattern recognition, and machine learning. Thus, before I started my fieldwork I was mostly familiar with the theoretical foundations of the field; my practical engagement with robotics was limited to a course in areal robotics. 
robotics as a matter of the flaws in current science and technology—without questioning if their robotic projects are feasible" (Richardson 2015, p. 113). As a trained computer scientist, I can understand roboticists' perspectives and, at least to a certain degree, possess an expert opinion on my own.

My training in computer science provided me with a set of sensibilities that was relevant during my fieldwork. It equipped me with a roboticist's sensibility of seeing the world. It has helped me become aware of the limitations and inherent logic of ICTs and given me an appreciation for the hard work that is required in order for ICT artifacts to function. My background in computer science and robotics is an advantage that I have over ethnographers without backgrounds in computer science and robotics; yet there is also a downside to this. During the longer part of my $\mathrm{PhD}$ journey, my training in computer science felt more like a barrier that prevented me from reaching "estrangement" (Czarniawska 2008, pp. 133-137) and analyzing what is taken for granted in computer science's imaginaries and practices. As a trained computer scientist, it is not simply that I risked 'going native'; I was already a quasi-native. Belonging to the same gender category as the majority project members can also be seen as a similar issue.

\section{Selecting a field site and negotiating access}

When I first developed the idea for the study, in the summer of 2011, I had just received my university diploma in computer science. I wanted to pursue a $\mathrm{PhD}$ in Social Science in order to learn more about ICTs in relation to masculinity. Autonomous driving appeared to be a new and emerging field. It drew my attention due to its promises to make drivers expendable and to overthrow the hegemony of private car ownership in urban areas. My intuition was that the emergence of new transportation technologies could destabilize the links between masculinity, cars, and driving. I expected the field to be controversial with respect to the doing of masculinity.

It was through a friend that my attention was drawn to my future field site. While I was searching for a field site, a friend of mine wrote his computer science Master's thesis on pedestrian detection in a project in autonomous driving at Freie Universität Berlin (hereafter FU). In addition to my friend's stories about the project, I was attracted by the video demonstrations featured on the landing page of the project's website. Throughout the years, the group has assembled three experimental vehicles, ${ }^{8}$ and the project was proud to

8 Regular automobiles enhanced with sensors, GPS, and actuators to allow control through computers. 
demonstrate their work through these videos. The website's landing page narrated the project's history as a continuous success story:

The AutoNOMOS team is part of the Artificial Intelligence Group of the Freie Universität Berlin. We, researchers and students, have the vision to develop the technology for driverless cars of the future. The team was founded in 2006 around Prof. Dr. Raúl Rojas. In 2007 the group managed to reach the semi-finals of the DARPA Urban Challenge 2007. The AutoNOMOS group managed to become one of the chosen projects in 2009 for a market-oriented program $\left(\right.$ ForMaT $^{9}$ ) created by the Federal Ministry of Education and Research as initiative within the German High-Tech Strategy. ${ }^{10}$

The project's website was filled with press releases and video demos about their latest achievements. The video demonstrations covered numerous areas. These videos demonstrate various ways of controlling a car through computers. I downloaded all the videos, press releases, and articles on the project, and I took screenshots of the website. I started to archive everything on my hard drive.

To negotiate access to the field site, I went to my friend's thesis defense to approach Prof. Rojas in person. I signaled my interest in spending time with the group in order to learn more about how the project team engages with autonomous driving. Rojas granted me access and said that he sees my project as benefiting them as a form of "project documentation" (Fieldnote 02/14/13).

Rojas is the only real name in my presentation of the empirical material. While I do refer to actual publications written by projects members, I have otherwise taken this drastic measure in order to make it difficult to decipher which first name maps to which actual member. I anonymized all the project members (apart from Rojas) by using popular male 'German' first names, such as Thomas and Michael. I did this for two reasons, but it comes with a cost. First, the project was male-dominated during my fieldwork. With students coming in to write their qualification theses and leaving afterwards, it was hard to specify, at any given point in time, exactly how many people belonged to project. I mostly followed what I recognized as an all-male informal 'core' team, which consisted of 8 members at the beginning of my field work and 5 at the end.

9 ForMaT is an acronym for "Forschung für den Markt im Team" (research team for the market). The funding line (Hiepe 2007) was limited to teams from Eastern Germany, officially called 'new federal states' (Neue Länder). All of Berlin counts as a 'new federal state.' As a result, West Berlin's FU was able to benefit from the funding line.

10 https://web.archive.org/web/20110719204731/http://autonomos-labs.com/ [Checked on 03/04/20] 
During my fieldwork there was one female project member. She is only mentioned here because I do not want to expose her. Second, some of the members had backgrounds in migrant families or were migrants themselves. For example, Prof. Rojas was born in Mexico City and came to West Berlin in the 1980s to write his $\mathrm{PhD}$ on the production process of Das Kapital (Rojas 1989) before being appointed as Professor for Artificial Intelligence (Thio 2012). My use of male 'German' names makes any diversity within the project team invisible. This is open to criticism, as I homogenize the project team through my description.

Almost all the practitioners during my fieldwork were men. I am using the heteronormative categories of men and women as if these were unproblematic. The field I am describing is heteronormative. During my field work non-binary genders were not present and non-heterosexual sexualities were never a topic of conversation. However, at no point in time did I ask members how they self-identify in terms of gender and sexual identity. This binary classification of project members relies on my interpretation alone. The field of autonomous driving research is an extreme case of gendered divisions of labor. In this study I intentionally use the heteronormative categories of men and women to highlight that this is a man's world.

To study men and masculinities with an almost exclusively male group of computer scientists runs the risk of reifying masculinity as a feature of men. In addition, it may contribute to reproducing the equation of technology and masculinity. However, as laid down in my theoretical approach, I assume gender to be a sociotechnical assemblage. It is an effect of sociotechnical processes. Gender is something that results from the making and unmaking of links within an assemblage. If technology and masculinity appear to be a fixed, 'natural' connection, it is not because of a given 'male essence' or because technology is inherently patriarchal; it is an effect of the constant iterations that maintain the stability of the connection. Nevertheless, relations between masculinity and technology are historically, culturally and mutually constituted and thus potentially open for transformation.

Finally, I also homogenized the project team in terms of their academic training. My typification of all members as computer scientists in the area of robotics and artificial intelligence neglects the fact that one of core team members was an electrical engineer and that some of the students who became temporary members of the project (as part of their qualification theses) were from technical universities rather than non-technical universities, such as FU. 


\section{Doing fieldwork and analysis}

In June 2012 I started visiting the project whenever my university positions in western Germany would allow it - that is, predominantly during non-teaching seasons. I used participant observation to generate fieldnotes. I started by "memoing" (Emerson et al. 2011, pp. 171-199) my analytical insights and questions and by keeping a research diary.

Ethnographers are embodied research instruments which are calibrated by moving between field and desk (Knorr-Cetina 2002, pp. 36-37). During the first phase, in 2012, I became acquainted with the field and my field site. On my first day out with the project members and one of their automobiles, I decided to take pictures and to film the interactions inside the car; in total I recorded videos of five different test-drives. Since project members were used to having journalists around, they did not seem uncomfortable being filmed. Braun-Thürmann (2002) has also observed that roboticists are skilled in presenting themselves while going about their work. At the end of the first phase, I expanded my repertoire to include ethnographic interviewing (9 in total). In February 2013 I returned for a more intense stay. I continued to visit the project for special occasions until November 9, 2015, when a point of empirical saturation had been reached.

During my fieldwork in the project, I usually introduced myself as a computer scientist. This was intended to position myself as somebody who can appreciate their engagement with ICTs. As we know from other studies of scientists and engineers, researchers tend to draw from multiple discourses when describing a technology (Wynne 1988, pp. 160-161), e.g. public and private discourses. When I am recognized as a fellow computer scientist who is interested in the details of their work, practitioners tend not to sugarcoat the limitations of their approach to autonomous driving. In fact, some members were very open about the difficulties in automating driving. It is noteworthy that the level of rapport was different with each individual member. Some addressed me as if I were a journalist, or some other outsider to the project, by trying to 'sell' me autonomous driving.

For some practitioners, the fact that I was a computer scientist who was interested in hanging out with other computer scientists - and not in doing 'proper' work in computer science-seemed troubling. Doing ethnography does not belong to the canon of computer science practice in Germany. This led to some interesting reactions, ranging from one member suspecting me of plagiarizing his $\mathrm{PhD}$ thesis to another ignoring me completely once he found out that I was not a proper project member. After I had shadowed Michael for a while, he eventually introduced me to temporary project members as a 
recurring guest for whom "everything is interesting" (Fieldnote 08/22/13). This was a typification with which I could identify.

I tell these things not out of vanity, but because I find the nature of the rapport and the manner in which I was positioned to be crucial to what kind of stories were told to me and how they were told. I view the stories that emerged during participant observation and in the ethnographic interviews as co-fabricated (Whatmore 2003, pp. 90-92). This becomes salient with respect to heroic storytelling. For example, in chapter 4 one will find a "side-story" which Stefan tells me. Stefan succeeds in turning an account of a malfunctioning research vehicle into an exciting story that concerns the life and death of the project. I support this storytelling by constantly giving reassurance and responding emotionally at important moments in the narrative. I assume that with a different audience the story would have been told differently. The stories they shared, and the way in which I showed interest in the technical details, not only made me an audience to their storytelling but also possibly contributed to male bonding. If I did not belong to the same gender category as the project members and had not studied computer science, then I might not have become a competent quasi-member. For example, a female who is not a computer scientist might have had difficulties escaping tokenism (Götsch 2014, pp. 81-82). As a male computer scientist among male computer scientists, I had little difficulties of blending in.

During the period of my fieldwork, the 'core' group in the project was a homosocial association. As an ethnographer and a computer scientist, I was able to participate in male homosocial bonding over technology. It should be noted that it is not the physical co-presence of men that constitutes male homosocial associations. As opposed to men-only clubs, for instance, members of male homosocial associations often do not see themselves as a group constituted by gender (Meuser 2007, p. 41). Male homosocial associations are groups of men with a shared imaginary for orientation (Meuser 2010, p. 301).

The course of my fieldwork was marked by disappointment when it occurred to me that I might be at the right place but at the wrong time. This may have been a case of "ethnographer's anxiety" (Law 1994, pp. 43-47) - that is, an anxiety that can overcome ethnographers when they come to believe that the interesting stuff always happens when they are not around. What was it that made me anxious and disappointed? I arrived at my field site during the aftermath of a $€ 2,2$ million project that had funded 12 researchers and 8 student assistants. The project team became smaller and smaller because members' contracts could not be extended due to lack of funding. The party was over. After the first year it dawned upon me: this is not a project that is continuously heading towards the future (as insinuated in the success story of project's landing page); it is a precarious project struggling to continue (see Kröger 2012). The observable work 
in the project primarily took the form not of development or research - as I had hoped - but rather of maintenance and science communication. This redirected my research questions from the making of autonomous driving to the imagining of autonomous driving. I will return, in the following chapter, to the precarious state of the project during my fieldwork.

In this final section, I elaborate on the types of materials that I selected for analysis. I developed my perspective as an ethnographer in the social sciences through group interpretation sessions (Forschungswerkstatt) (Reichertz 2013). Ethnography is craftwork; you cannot learn only by reading text books. I have benefited from learning from experienced ethnographers with backgrounds in STS, Sociology, Gender Studies, and European Ethnology. In interpretation group sessions, I not only presented my own materials but also learned from joint interpretations of materials from other research projects.

My archive includes different forms of data materials that emerge from four sources:

(1) Naturally occurring materials or found materials i.e. materials produced by project members: video demonstrations, promotional texts (mostly from the website), scientific articles, reports, magazine articles for interested audiences, and qualification theses.

(2) Materials co-fabricated with project members: ethnographic fieldnotes, ethnographic interviews (audio and transcriptions), and videos of rehearsal drives and technology demonstrations.

(3) Materials produced with project members by journalists: radio debates/ features, television programs, and articles concerning on the project.

(4) My analytic notes: memos and research diary, notes from group interpretation sessions and from feedback sessions with my $\mathrm{PhD}$ advisors.

The differences between these types of materials pose a challenge. At first, I consulted literature on each specific form - that is, video analysis for demonstration videos (Reichertz and Englert 2011), videography for my own videos of street trials (Tuma et al. 2013), and interview analysis (Helfferich 2011) for my ethnographic interviews. However, this seemed unsatisfactory since these approaches are constructed for studies with only one type of material.

The literature that I consulted on ethnography (Hammersley and Atkinson 2007; van Maanen 2011; Gay y Blasco and Wardle 2007; Breidenstein et al. 2013; Emerson et al. 2011; Gobo 2008; Dellwing and Prus 2012; Fetterman 2010) and narrative analysis (Czarniawska 1997, 2004, 2008, 2014) deals explicitly with the problem of how to integrate different types of data material into an analysis. This does not mean that I use all the different materials in each chapter; the empirical chapters (2-6) have different analytic foci and rely on different materials. 
I identified the project's video demonstrations as found materials. I view them as naturally occurring materials constructed under certain circumstances and with specific intentions. These video demonstrations were already around when I entered the field. I was not able to observe their process of production. However, what makes them relevant to my study is that they were consequential for the members during the time of my fieldwork. As documents, video demonstrations are an additional layer of meaning (Sinnschicht). I analyzed them with respect to their content and form. In other words, I treated them as stories in their own right by giving attention to: the characters they mobilize; their themes and figurations; the type of narrative they deploy; and the manner in which specific visions are articulated. In addition, I took into consideration how members interpret the genre of video demonstrations, both in general and according to specific instances. This relates to the performative aspects of the videos. What do these videos do for the project? What are their consequences? How are they both beneficial and harmful elements of the project?

My fieldnotes were supported by my own video recordings. It was overwhelming to observe safety drivers monitoring and operating their research vehicles. So many things were happening simultaneously inside and outside the car! My videos of street trials enabled me to slow down and repeat the action that had taken place inside the research vehicle. This helped me to see reoccurring patterns and to give attention to finer details. Watching excerpts from my videos with other social scientists proved to useful in challenging my own interpretations and bringing me to an understanding of what was happening during the recorded events.

From the nine interviews that I conducted with project members (including two who were former members at the time) and an expert from Stanford University, I eventually selected six for transcription and open coding. I identified passages that puzzled me for more detailed analysis. In contrast to the stories that I was told informally during participant observation, the interviews were opportunities for eliciting stories and capturing them on tape. Many of the stories that I elicited seemed well-rehearsed. I understand the narration in these interviews to be the result of an available repertoire of stories and interpretative themes (Czarniawska 2014). In my study, most practitioners have experience being interviewed by journalists. On many occasions, the stories and narratives I elicited through interviews and informal chats are seen as collectively produced and rehearsed. Other stories were constructed specifically for me; the stories from the safety drivers that I analyze in chapter 3 provided an opportunity for the safety drivers to reflect on their experiences, tactics, and strategies in monitoring and operating a research vehicle. Identities are enacted through positioning and narrating within a shared imaginary. 



\section{Chapter $2 \mid$ The AutoNOMOS project}

The AutoNOMOS project is a research project in autonomous driving. In this chapter, I introduce the AutoNOMOS project by conceptualizing it as local network that is made up of roboticists, computationally enhanced automobiles, and visionary stories. I begin by describing my field site and the project members' perception of the state of the project. I continue by describing the computationally enhanced automobile "MiG", the main demonstrator and research instrument of the project, and the manner in which MiG relates to a mosaic of visionary stories. The chapter concludes by tracing the assembly of a global network that shapes the conditions of street trials.

\section{The project members}

The AutoNOMOS project is part of FU (Freie Universität Berlin). A ride on the subway takes me to the posh neighborhood of Dahlem, which is outside the S-Bahn-ring that encloses Berlin's inner-city districts. This comes with a change of scenery. The subway emerges above ground until it reaches Dahlem Dorf (literal translation "Dahlem village"). The subway station exit is a half-timbered structure. An air of privilege surrounds Dahlem; it is less busy than the inner-city districts of Berlin. There is little motorized traffic apart from the main avenues. On a weekday, one can see more people walking on the side streets than driving on them. The streets are quiet, with little motorized traffic, but there are parked cars on every side street. There are lots of trees and individual mansions with gardens, some of which host departments of FU. Among these mansions you can find other buildings that make up FU: there are larger concrete buildings from the 1950s on, as well as the main buildings from the 1970s, which-with their metal (rather than concrete or brick) facade-remind me of a space station.

You might be surprised to find a project on autonomous driving at FU. After all, it is not a technical university! FU was founded, following World War II, as an alternative to the Humboldt University, which is located in what was then East Berlin. FU was one of the hotspots of the student rebellion that took place in the second half of the 1960s. Today, it is one of Germany's largest and most prestigious universities, with more than 30,000 students. It hosts many departments, ranging from medicine to a variety of humanities, social sciences, and natural sciences. However, there is no engineering department.

The AutoNOMOS project is part of Intelligent Systems and Robotics Group (formerly Artificial Intelligence Group) at the Institute of Computer Science, 
which belongs to the Department of Mathematics and Computer Science. The project members are hosted inside an office building on a calm, tree-lined side street. The space of the project is dispersed, as it includes several offices, a seminar room which is used for project meetings, and a shared kitchen, as well as the shared workshop of the RoboCupSoccer ${ }^{11}$ team and the autonomous driving scale model team. The project members share the building with other working groups from the computer science department. In the office building, the team works on the software and holds their weekly Monday morning project meetings. These meetings take place at the institute's seminar room, which consists of rows of tables and a black board in the front. The seminar room is also used for oral exams (e.g. defenses of master thesis). At the Monday morning meeting a project member will typically present his/ her ongoing work or material from attended conferences. Less often plans are discussed. During the window of my study the project meetings were often canceled due to a lack of presenters. The Monday morning meeting is supposed to be attended by all members of the project. Apart from lunch, it is the only regular event I oversaw where most of the project members come together.

Most project members were computer scientists from non-technical universities. Many studied at FU. They often became project members while pursuing their program of study in computer science. Courses on subjects from the areas of robotics and AI are electives that often take the form of educational projects, such as RoboCupSoccer. The majority of team members worked on robots before entering the AutoNOMOS project. However, the study program of computer science does not offer courses in automotive engineering or electrical engineering.

The Intelligent Systems and Robotics Group is led by Prof. Raúl Rojas. The management of the AutoNOMOS project is undertaken by $\mathrm{PhD}$ students or post-doctoral researchers. The project is also the topic of many qualification theses (B.Sc. to PhD). The AutoNOMOS project belongs to FU, but it relies heavily on third-party funding. Industrial $\mathrm{PhDs}$ are externally funded. Graduate students either work for free as part of their qualification theses or are hired as student assistants (studentische Hilfskräfte). The FoRmaT project (2009-11) made the AutoNOMOS project grow into a team of 25 members, ranging from student researchers to post-docs. When the funding from the FoRmaT project ran out, many project members finished their studies and left university; they received lucrative offers from the automotive industry

11 RoboCupSoccer is organized around domestic and international events where University teams compete by having their robots play soccer against each other. 
(Interview Stefan 08/23/13). Project members applied for research grants but many were rejected. Rojas claims that funding institutions for basic research, such as the German Research Foundation (Deutsche Forschungsgemeinschaft), no longer support autonomous driving because they think, "this is now up to the [automotive, GB] industry" (Interview Rojas 07/13/15). With few paid positions left in the project, it has decreased in size. This might sound surprising when one considers the hype surrounding autonomous driving at the time my field work

The AutoNOMOS project is an elite group. Becoming a member is time-consuming and generally demanding. Potential members are expected to be skilled in programming in $\mathrm{C}++$. According to a temporary member of the project, it took him three months to become acquainted with the code while working two days a week in the project (Fieldnote 08/26/13). The project, then, is open only to students who are able and willing to make a huge commitment. Rojas views the educational projects of RoboCupSoccer and the autonomous driving scale model project as less demanding: "Students [male gender, GB] who do not have so much time at their disposal and who only want to learn some aspects of robotics join these projects" (Interview Rojas 07/13/15).

Metaphors of stasis occur frequently when the remaining project members describe the current state of the project. During ethnographic interviews and informal chats, project members often contrast their perception of stasis in the present with their memory of a heroic and lively past of the project. The stories they tell about the past highlight passion and dedication, often involving collectively spent nights of coding and testing (Chapter 4). During a group meeting I joined in December 2012, a plan is announced in which the subproject focused on the third research vehicle will "hibernate" (Fieldnote 12/03/12) until spring. This means that all the remaining resources will be concentrated on their second research vehicle (the first research vehicle had already been decommissioned and scavenged for parts). During an interview nine months later, Stefan expresses his dissatisfaction with what he perceives as stasis:

In principle, we have only been showing the $\mathrm{car}^{12}$ to the press for two years, but nothing has progressed. The development is standing still. ("Wir zeigen seit zwei Jahren eigentlich immer nur noch das Auto in der Presse, aber bewegt hat sich da überhaupt gar nichts mehr. Also die Entwicklung steht.“) (Interview Stefan 08/23/13).

$12 \mathrm{He}$ refers to the second research vehicle, $\mathrm{MiG}$, which will be properly introduced shortly. 
Stefan's assessment of the development as "standing still" does not imply that the project has been discontinued. The project has research vehicles at its disposal but lacks the necessary members for exploiting the potential of these vehicles. Stefan points out that the project members are continuously demonstrating "the car" for TV and print journalists. In the following vignette, I asked Thomas how much time he spends with working with the press.

Thomas tells me that they take journalists for a ride in the car five times a year. He would prefer an interview once a month, including a photo session, because this does not require a second project member. Journalists call him "every other day," but he is not available at the moment. All the paper work, such as contracts, makes it even more time-consuming. (Fieldnote 07/23/15)

Journalists are eager to film the research vehicle in action. For the project members, however, this means dedicating a significant portion of their time towards preparing, rehearsing and conducting a demonstration. Interviews and photo sessions require considerably less effort from of the project members.

The project is simultaneously active in relation to the outside - as it is frequently reported on in the media - and perceived as being stagnant on the inside. Christian describes their current work to a journalist by saying "debugging is most of the work we do" (Fieldnote 03/10/14). Debugging means troubleshooting software. For Christian, this takes the form of "feeding" algorithms with data and "observing how they behave" (Fieldnote 03/10/14). Developing something new, e.g. trying out new approaches, was a smaller portion of the whole project during the period of my fieldwork. The larger part of the work in the project was dedicated to its stabilization, its demonstrator (i.e., the research vehicle), and its imaginary of autonomous driving as an emerging technology.

The main research vehicle needs to be kept up and running; it demands technical care work in order to preserve its capabilities (Chapter 3). A bias is manifest in the contrast that is invoked between moving forward through development and sustaining the project through maintenance and science communication. Developmental activities are generally valued over communicative activities and maintenance.

\section{Technological artifacts}

Project members spend most of the day working on their computers in offices (Image 1). Apart from e-mail communication, the predominant use of the computers is the extension and maintenance of the project's code base and 


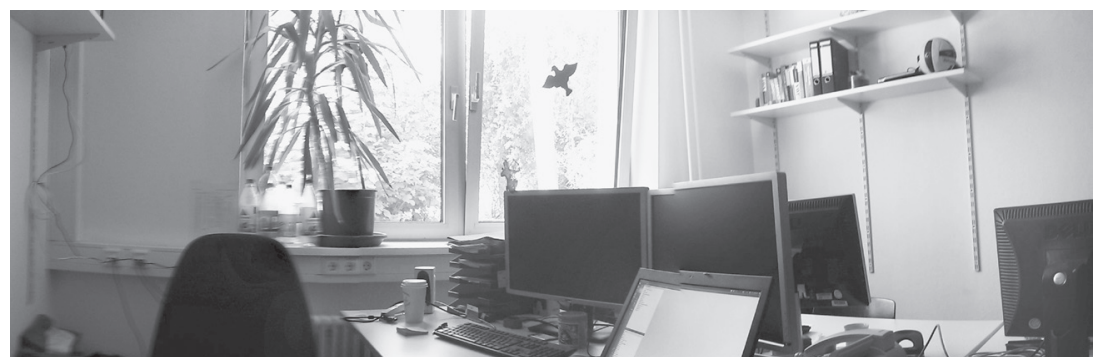

Image 1: One of the office rooms in the building

using the recorded data from street trials for simulations. Computers are the major tools by which members do their jobs.

Yet what makes this project an unusual computer science project is an element of the sociotechnical assemblage that cannot be found in the office building. The computationally enhanced Volkswagen Passat, called "MadeInGermany"13 (hereafter: $\mathrm{MiG}$ ), distinguishes this working group from many other areas and projects in computer science and robotics. The research of the group differs from the majority of the research done in computer science (e.g. databases, formal logics etc.) since it develops software that materializes in visible actions of a tangible artifact, which one can literally inhabit by sitting inside of it.

The technological project is distributed. While its human members, together with their offices and computers, are located in the computer science building, MiG is sheltered in its indoor parking space ("Garage"). The human members and their computers are separated from MiG. In order to go about their daily work, the majority of human project members do not depend on the physical co-presence of the car. Most of their work can be done with the desktop computers in their offices. The office building where the working

13 According to Rojas, the names of their experimental vehicles are part of a strategy to make their efforts visible by literally putting themselves on the map (Interview Rojas 07/13/15). They named their first car "Spirit of Berlin" and their second research vehicle "MadeInGermany." The use of these geographical markers does not come without associations. While Spirit of Berlin was supposed to be a reference to the land speed record-setting race cars (all named "Spirit of America"), "MadeInGermany" refers to the well-known trademark which was initially introduced as a British warning label against inferior German products in the 19th century. Today, "Made in Germany" signals high-quality industrial products rather than cutting edge ICTs (Trischler 2007, p. 45). Associating their car with the brand "Made in Germany" is a powerful move. By appropriating a global trademark, this computer science project claims membership in German engineering and manufacturing. 


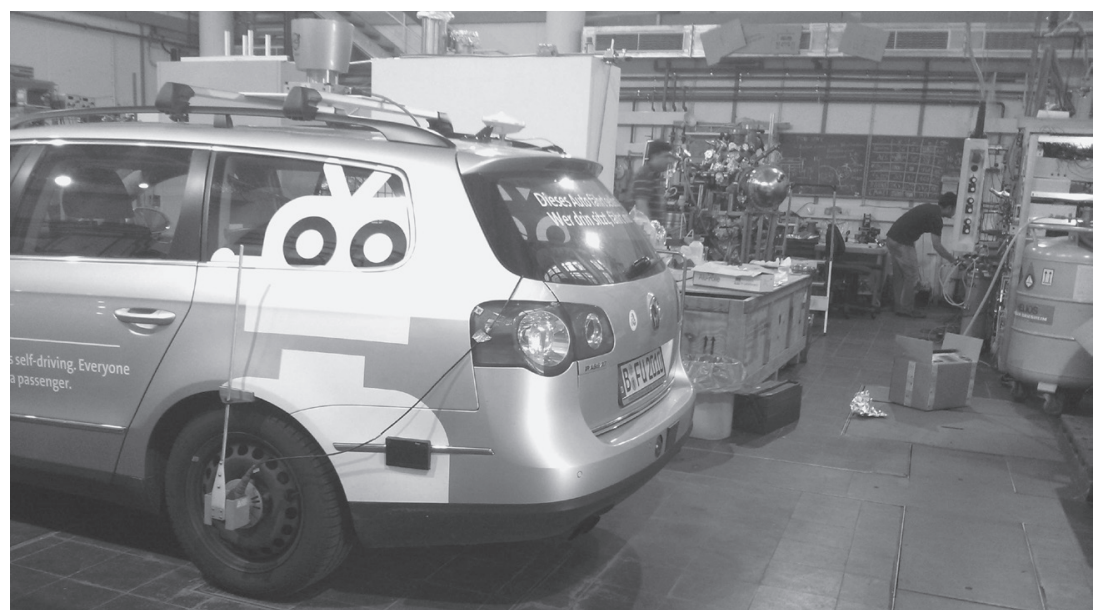

Image 2: MiG (front) in its "garage" with physicists (background) and their equipment

group is based does not have an indoor parking space. From the office building it is a brief walk to its "garage." You walk through a quiet street lined with old trees and enter the physics department, a large concrete building from the 1970s. The indoor parking space is inside a large physics laboratory.

Michael enjoys entering the physics laboratory from the top entrance where a metal staircase leads to the ground. He loves this view of the laboratory. The ceiling of the laboratory is two stories high. From the top of the staircase you can see over a vast collection of experimental apparatuses from the physics department. Some of them seem actively used; others seem to just be stored here. Michael often jokes that the project members started to call these apparatuses "doomsday devices" because the members do not know what they are for but they look as if they belonged to mad scientists. Physically separated from the physicists' experimental apparatuses by office cabinets and in the corner near the big door, MiG is parked inside the laboratory. Some of MiG's modifications are visible from the outside, such as the rotating LIDAR on top of the roof (Image 2).

The laboratory space is shared, yet team members rarely engage with their hosts. They joke about their colleagues from the Physics Department by projecting the science fiction trope of "doomsday devices" onto their equipment. Among these "doomsday devices" is a Volkswagen Passat station wagon modified by Volkswagen Research with additional sensors, actors, and an interface that the project members use to access some aspects of the MiG's IT infrastructure (Wang 2012, pp. 64-67). 
Members have an abundance of terms indexing MiG. When they are among themselves they usually use terms like "the car" ("das Auto"), "MiG" or "Passat." Yet when communicating to lay or expert audiences, e.g. in articles and presentations or during public engagement events, other terms are more likely to be used: "autonomous vehicle," "autonomous car," "driverless car," "self-driving car," "experimental vehicle," "research vehicle," "test vehicle," "research platform," "test-rig," "robot," and "prototype".

Each label presupposes a typification. These terms are not 'just' descriptive. They position the project and MiG in a specific way. The typifications come with certain claims about its present purpose or its imagined potentials. Some of these terms, such as "test-rig," "research platform," and "research vehicle," suggest that MiG is an instrument for conducting basic research in robotics and artificial intelligence (see Reuschenbach et al. 2011, p. 435). Terms such as "autonomous car" or "autonomous vehicle" suggest that MiG is a result of their research. In other words, these terms perform the project as a project in applied research. Such terms might even insinuate that the project is developing the autonomous vehicle as a certified consumer product. Clearly, however, this is out of reach for a university project.

The semantic space opened up by these labels indicates that MiG oscillates between two poles: research instrument and demonstrator. For the project members, it is at once a means to conduct research and a means to communicate results of the research to different audiences. These two poles are irreducible to one another.

\section{A mosaic of visionary stories}

The landing page of the project's website proclaims, "We, researchers and students, have a common vision for developing the technology of the driverless cars of the future." 14 An introduction for a conference paper written by project members says, "It is the ultimate aim to have a completely autonomous car that can drive in daily traffic by [on, GB] its own without human intervention" (Czerwionka et al. 2011, p. 78). These are elements of visionary stories that constitute the last piece of the triangle. The roboticists and their technological artifacts are tied together by a vision. Yet the vision is not a singular promissory narrative. As I will argue in this section, the vision emerges from a mosaic of related visionary stories. From an analyst's perspective, some

14 https://web.archive.org/web/20140619185441/http://autonomos.inf.fu-berlin.de:80/ [Checked on 03/27/19] 
elements of the vision can be seen as unable to fit together. It is for this reason that I adopt the metaphor of a mosaic. With a mosaic, one's visual impression depends on one's distance from it. Up close it may seem messy, yet from a distance a beautiful pattern may become visible.

In the following vignette, I engage in a discussion with two project members about MiG's new 'outfit,' which leads to the articulation of a particular problem.

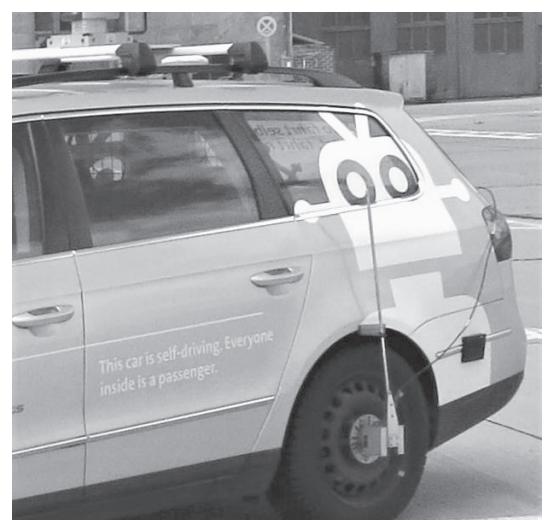

Image 3: The inscription on MiG in 2015

I am meeting Thomas at the car's garage to join him and other team members for a public engagement event. I notice that the stickers on the MiG's chassis have been altered since my last visit in the garage. At the height of the trunk, you can now see (Image 3) a schematic drawing of the upper body of an old-fashioned science fiction robot with antennas on its head. Next to it, there is an explanation (in German and English, depending on the side of the car). It says, "This car is self-driving. Everyone inside is a passenger." I share my surprise about the new logo with Thomas. He says "it's cool" and explains that it was put on by their partner in Switzerland, who had recently invited the project as an attraction for the opening of a new business campus.

When we arrive at the public engagement event, I ask another team member, Martin, for his take on the new sticker. He likes the new logo, too. He reports that during test-drives in Kleinmachnow (a suburb of Berlin) it has drawn more attention towards the car. He argues that it has never been clear what the old logo- three interlinked tori-actually means (Fieldnote 06/13/15).

The stickers on MiG's chassis change from time to time. Project members are pleased with this sticker. Thomas and Martin identify with the new inscription. Despite the fact that it was applied by their Swiss hosts, they see it as reflecting MiG's essence. For them it solves a problem. They have experienced that, during street trials, MiG can be easily mistaken by project outsiders for the Google Street View car (Kröger 2012). ${ }^{15}$ The demonstrator's meaning

15 In Germany in 2008, Google's initiative to send out cars to take panoramic pictures for its "Street View" service had sparked a controversy that was widely reported in the news. 
is not self-evident; it relies on an inscription to become legible. The sticker makes visible what is otherwise visible only to specialists. It makes visible that this is not a normal car, that it is more than a car-it is a robot! By drawing on retro science fiction symbolism, MiG is positioned as the embodiment of the "driverless car of the future." 16 The sticker figures MiG as if the vision had already been realized. Retro science fiction serves as an interpretive template. To become a meaningful, an image of the past is inscribed onto MiG. The "self-driving" automobile relies on a vision of the past to become meaningful.

Visionary storytelling can serve many functions. In the above vignette, it addresses the problem of being ignored or misunderstood by project outsiders. The next interview transcript illustrates how visionary storytelling can also serve as a tool to manage a project. Start-out stories are particularly important for future-oriented projects, since at the beginning of a project little is certain (Deuten and Rip 2000, p. 78). In order to orient members' actions, a technological project needs a story in which the envisioned technology plays a role. In the following interview transcript, Rojas accounts retrospectively for the circumstances that led to the production of a particular start-out story.

My question is motivated by my curiosity about why it is that a team with success in robotics in laboratory environments moves outside into the messiness of everyday traffic. Robotics usually takes place in highly constrained and controlled environments, as is the case with industrial robots or RoboCupSoccer. Rojas justifies his decision to move to autonomous driving as stemming from a need for new challenges. Providing new opportunities for challenges is narrated as his leadership strategy to keep up morale. Visionary storytelling serves as a management tool to build a shared sense of purpose for the project members.

GB: What was your motivation for taking the step "out of the laboratory"?

R: Oh well, yeah, ..... (thinks) I think it was a kind of saturation. (laughs) We were already world champion 2004, 2005. You could say we had done everything in RoboCupSoccer. And then I thought, now we need a new challenge. And then the competitions with autonomous vehicles started, and I was mostly interested in the real deployment and the societal effects. When we started up in Stanford 2006, we were together with the Stanford group that later went to Google. The journalists asked, "Why are you doing this?" The people from Stanford always said because of safety.

16 https://web.archive.org/web/20140619185441/http://autonomos.inf.fu-berlin.de:80/ [Checked on 03/27/19] 
(GB expresses attentiveness)

R: (Indirectly citing Stanford knowledge) because autonomous vehicles will be safer, no one will die, no one will be run over any more. I said something different. I always said I do it,

(GB expresses attentiveness)

because then you can really make car-sharing a reality in the cities. And that would relieve the strain on the cities. Instead of 1 million vehicles in a city you could make do with 100 or 200000 .

That would really make traffic safer, but even more it would make it so much more efficient - there would be less environmental pollution, traffic would even be faster, there wouldn't be a sea of cars at every corner of the city. That was the difference in perspective. Both things are complementary, but I always underlined the social aspect in the sense of a new kind of city (Interview Rojas 07/13/15).

My question prompts Rojas to tell the origin story of the vision of the project. It is a story about a story. Rojas begins with the story of how he and his $\mathrm{PhD}$ students became interested in autonomous vehicles and ends with the kind of potential that they see in autonomous driving. The story Rojas tells me adopts the narrative form of a hero's journey. In the genre of product creation stories, project teams are the heroes in the beginning (Deuten and Rip 2000, p. 69). The story creates characters with typifications and a setting. The initial state of the story is that its heroes (Rojas and his group of junior researchers) have succeeded in past adventures (RoboCupSoccer) and are in need of a new challenge. The DARPA Grand Challenges open up new opportunities for adventure. In turn, Rojas and his team travel to the heartland of ICT innovations, Silicon Valley, ${ }^{17}$ and seek the wisdom of their mentors, i.e. Sebastian Thrun and his team at Stanford University. ${ }^{18}$ A second group of supporting characters, the journalists, make an appearance and confront the researchers from Berlin and Stanford. They ask about the researchers' motives and expectations. Their answers differ. The Stanford group promises to make driving safer. Rojas' motivation for developing technologies for autonomous

17 During my fieldwork, Silicon Valley was the world-wide center for research and innovation in autonomous driving. German car makers had also opened up subsidiaries for research and innovation in autonomous driving in Silicon Valley.

18 The Stanford team had created the first computationally enhanced car to finish a DARPA Grand Challenge (Broggi et al. 2016). 
driving goes beyond of that of their mentors. He imagines the possibility of significantly reducing individual motorized city traffic by making car-sharing schemes more convenient. Autonomous vehicles are the means to make cities more sustainable and livable. The role of the hero has shifted from project team to the imagined end-products of the research projects (Deuten and Rip 2000, p. 88).

Different narratives articulate elements of the project's vision on different occasions, for varying audiences (see chapter 6), and through multiple genres and media. Occasions for visionary storytelling are manifold, and may include: public engagement events (e.g. "Long Night of the Sciences", "Science Slam", "TEDx"19); technology demonstrations (e.g. Freie Universität Berlin 9/13/2011; Bundesministerium für Bildung und Forschung 8/15/2012); public lecture series; ${ }^{20}$ interviews (e.g. Schönball 2009; Tychsen 2014; Boytchev 2014; Eva-Maria Götz, Michael Roehl 5/27/2015); discussions with spokespersons of the automotive industry; ${ }^{21}$ articles for non-specialist audiences (e.g. Rojas 2012, 2013, 2014); and academic texts for specialist audiences (Wang 2012; Rojas and Ulbrich 2013; Reuschenbach et al. 2011; Czerwionka et al. 2011). ${ }^{22}$

Another outlet for visionary stories is the project's website, which features video demonstrations ${ }^{23}$ and self-descriptions of the project. The website features a section covering frequently asked questions (FAQ) by journalists and other outsiders. FAQs are a common format in technological cultures. They were popularized in USENET newsgroups to deal with recurring questions of newcomers that had already been addressed by its members (Hersch 1997). The following excerpt from the project's FAQ is a response to the question: "You describe your car as 'green'. Why?" The question is skeptical and demands an explanation. The following answer justifies driverless car research by envisioning a specific use for autonomous vehicles.

In our vision of the future, autonomous vehicles will be deployed as "taxis" in urban areas. Many people today neglect the advantages of car sharing, due to the dominating inconvenience: it's a pain not to have a car available on demand at any time of the day. One solution would be cars that independently picks [sic] passengers up. With a signal to the coordination system, the next available vehicle collects the passenger

19 https://www.youtube.com/watch?v=zmffUHFM6Kk [Checked on 03/27/19]

20 E.g. "Berliner Gespräche” (Berlin) "Telepolis Gespräch" (Munich)

21 According to Rojas (2012), automotive industry representatives rejected the vision as "blasphemy" because it does not take the 'joy of driving' seriously.

22 My presence in the field in the also opened up opportunities for visionary storytelling (Chapter 3 \& 4).

23 The genre and format of video demonstrations is explored in chapter 4. 
meterprecise from their current GPS position, and proceeds directly to the desired destination or connection to other mode of transport. This would allow an optimal mix of cars, buses and other transport modes to be achieved. Through the transport of multiple passengers per vehicle, road traffic density could be reduced. Cars, currently spending $80 \%$ of their time unused, would no longer pose a burden. Remaining cars could flow faster and more efficiently through traffic. Time and energy would be saved. This is a vision of the future which is only viable in the long term, and requires social acceptance. It is however an attractive alternative to the current situations in metropolises like Tokyo and Mexico City. In the states [In countries, GB] with high populations only beginning to increase personal mobility — China and India — this offers an opportunity to pursue a more environmentally sustainable course. This is why we describe autonomous driving as "green." 24

The answer tells a visionary story in which autonomous driving could play a role in making motorized transportation more efficient and, as a result, cities more livable and sustainable. At the beginning, the vision is told from the frog's-eye view of a car user and promises that autonomous taxis will be more comfortable than conventional car-sharing schemes. The vision associates autonomous driving with taxi and ride-sharing services. It uses taxi services and ride-sharing services as familiar frames of meaning to project them onto the future (see Czarniawska 2008, p. 33-38).

The perspective then shifts from the individual user of mobility services to the bird's-eye view of policy makers and city planners. It promises that if autonomous vehicles are integrated as components of an intelligent public transportation infrastructure, then trips with other modes of public transportation can be made seamless. This would then diminish the advantage of individual cars for personal transportation.

This vision translates traffic and personal transportation into an engineering problem that can be optimized for efficiency by automation and digitalization. It argues that limited resources, such as time, energy and space, could be used more efficiently — thereby making cities more sustainable and livable - if the urban landscape were dominated by shared autonomous vehicles and other means of public transport, rather than by privately owned, manually driven cars. It tells a story of hope for those dreaming of cities that are less dominated by cars. Rojas uses an old-timey picture of Berlin in his presentation slides and in one of his articles (Rojas 2012) to illustrate for technology-savvy audiences how the streets of Berlin appeared before they were taken over by cars and

24 https://web.archive.org/web/20140323085746/http://autonomos-labs.com:80/ [Click on "FAQ", checked on 03/27/19] 
trucks. A photograph from the past here serves as the basis for projection onto the future.

The project's vision of autonomous driving emerges from the mosaic of promissory stories that I have described above. The vision enacts a "problematization" (Callon 1986) - that is, it identifies a set of problems which it promises to solve through technological innovation. Problematization is a double move. From the position of the network builder (Rojas and his team), it defines actors in a such a way that their project appears indispensable to those who care about sustainable and livable cities. In this case, problematization takes place through the definition of a series of problems associated with privately owned and manual driven cars - for instance, they take up precious city space while both being used and not being used. Problematization also defines today's automobile users. Car users are imagined as rational agents that choose between different modes of transportation. They are imagined as being open towards car-sharing schemes, as long as they are convenient. Convenience is characterized by the reduction of walking distances, e.g. walking to a parked shared car or a metro station. Convenience does not involve the habit of driving a car oneself or the emotional attachment to one's own car.

The project's problematization draws on a graphic and widely shared image - "a sea of cars at every corner" (Blechlawine an jeder Kreuzung) - as well as on the "antagonisms of automobility" (Böhm et al. 2006): if too many people pursue the 'freedom of the road' at the same time and place, it will lead to congestion and immobility. The image of a sea of cars defines individual car use as an issue to be resolved. However, the proposed solution does not address the issue directly; it does not, for example, demand a reduction of parking spaces or a ban of cars from densely inhabited areas. Rather, the problematization defines autonomous taxis as a "detour" (Latour 1987, pp. 111-113) for actors interested in greener cities. The vision appeals to its recipients: 'If you want to make the city more livable and personal transportation more efficient by radically reducing the number of cars without loss of the convenience, then you will have to take a detour!' The solution is to reconfigure driver-car relations. The vision suggests a radical break with today's "regime of automobility." (Böhm et al. 2006) Instead of being privately owned by individuals, cars are imagined as publicly shared. Instead of being driven by humans, they are supposed to be controlled by ICTs. Instead of having cars independent of existing regimes of public transportation, the autonomous taxi integrates cars as an element within an all-encompassing public transportation system.

What does the vision do for the project? As an emergent, prospective story, it ascribes potentials to an imagined end product that is narrated as a direct consequence of the project's present research. Visions are performative in the sense that they do not simply represent the envisioned technology in a context; 
they fabricate a context for MiG. Crafting a vision around MiG creates a rhetorical space for it in the future. It envisions a network in which autonomous vehicles could contribute to a transition towards more sustainable cities.

The vision is transgressive. It has literally led Rojas' group of junior researchers out of their basement in the Institute of Computer Science and onto the streets. By crafting a future, the project's research becomes meaningful beyond the advancement of robotics and AI as an academic field. By associating their project with discourses of sustainable urban transport, the project transgresses the boundaries of computer science expertise. In this vision, the project's competence extends to issues of city and traffic planning (Verkehrsplanung). The computer scientists' expertise in topics of robotics, such as computer vision and trajectory planning, is extended to serve the population of a global mega city like Tokyo or Mexico City. In this manner, the group is constructed as a collective of visionaries skilled in predicting the relevance of the envisioned technology for urban transportation. Like other AI scientists, they claim to have the "ability to speak on behalf of an as yet unknown population of future machines" (Woolgar 1985, p. 566).

Emerging technologies are uncertain (Rotolo et al. 2015). Visionary stories reduce uncertainty by, e.g., performing driverless cars as a stable endpoint of a projected innovation trajectory. The following excerpt from the project's FAQ draws on present and expected innovations to proclaim its inevitability.

Are we standing before a transport revolution?

Autonomous driving will rather be evolutionary, and introduced alongside a gradual adjustment of traffic law. The driver assistance systems of today already offer aspects of autonomous driving, e.g. automatic parking and automatic speed control. Further assistance systems are continually being introduced at the luxury end of the market. Some vehicles offer pre-crash systems to prepare for emergency braking, or even collision avoidance systems which initiate emergency stops. Many component suppliers work on further systems which will continually find entrance to the consumer market. In this way, the required technology will one day sit in every vehicle. The time to allow full autonomous driving will be a question for government. ${ }^{25}$

This piece of the vision narrates autonomous driving as the result of incremental rather than radical innovation. It positions autonomous driving in line with developments in Advanced Driving Assistance Systems (ADAS). It

25 https://web.archive.org/web/20140323085746/http://autonomos-labs.com:80/ [Click on "FAQ", checked on 03/27/19] 
narrates the emergence of autonomous vehicles as the outcome of an evolutionary process of incremental advances. The rising quantity of sensors and ICTs built into each new generation of cars will eventually lead to a qualitative change, turning plain old cars into "driverless cars of the future." The difference between present ADAS and autonomous vehicles is to be found in the responsibilities of the driver. Even the most advanced ADAS does not make the driver expendable. S/he still has the responsibility to monitor his or her car while driving and to intervene if necessary.

The story's protagonist is not embodied by a specific hero. It narrates sociotechnical change as an unstoppable force leading to more and more ADAS. This narrative draws on technological determinism (MacKenzie and Wajcman 1999, p. 5). It constructs technological change as an independent force, outside of society. Policy makers do have a say in it, but only in terms whether autonomous driving should be allowed or not. By imagining driverless cars as the end point of a continuous diffusion of ADAS, the mere possibility of autonomous driving is elevated to a certainty ("the required technology will one day sit in every vehicle").

Analytically, the vision emerging from the mosaic of visionary stories can be understood as a nesting of two distinct visions: the (1) autonomous taxi, a vision of a seamless public transportation system enabled by autonomous vehicles; and the "driverless car of future," a vision of all-purpose autonomous vehicles. (2) Driverless cars are envisioned to be capable of taking over all the functions of human drivers. The nesting of the two visions diverts attention away from the uncertainties inherent in all emerging technologies. It performs the feasibility of driverless cars as a certainty. Such feasibility depends on the expectation that all the functions of human drivers can be safely and efficiently executed by automation and without supervision. Uncertainty is delegated to the domains of policy makers and consumers ("social acceptance"26).

\section{From visions to street trials}

So far, I have described the AutoNOMOS project as a sociotechnical assemblage constituted by relations between its members, its artifacts, and its vision. Yet to give more substance to a vision of the "driverless car of the future," it is not enough to assemble a local network consisting of researchers, narratives, sensors, and ICTs, together with a computationally enhanced

26 https://web.archive.org/web/20140323085746/http://autonomos-labs.com:80/ [Click on "FAQ", checked on 03/27/19] 
automobile embedded in the infrastructure of a University. The project must assemble a global network where additional resources can be allocated (Law and Callon 1992, p. 46). To make the vision more realizable, allies need to be enrolled and a global network needs to be shaped in favor of the realization of the vision.

All projects in autonomous driving have a common adversary: the traffic code and the authorities enforcing them. Project members usually refer to the U.N. Vienna Convention on Road Traffic, which has been ratified by almost all European countries (e.g. Wang 2012, p. 26). Article 8 states, "Every moving vehicle or combination of vehicles shall have a driver" (Inland Transport Committee 1968, p. 11). The Vienna Convention clearly demands that a human driver must always be conscious and present behind the wheel. The latest amendment to Article 8, which is a response to the diffusion of ADAS, is quite clear about the driver's responsibilities: it is "the driver's obligation to monitor and control any kind of action taken by a vehicle system" (Inland Transport Committee 2014, p. 11). If we understand autonomous driving to be unsupervised, then autonomous driving on public roads is illegal. For supervised automated driving, traffic authorities have issued approvals for research and development purposes.

In order to get MiG on the road, the project has to relate to the traffic authorities. The only option was to apply for a special permit for street trials (Erprobungsfahrten). The project had to fulfill two requirements. First, MiG's modifications had to be approved by a licensed workshop. Second, it was necessary to develop a safety concept which demonstrates that MiG is no more dangerous than manually driven cars.

All motorized vehicles on public roads require approval by safety authorities. Researchers cannot simply tinker with a car, reconfigure it a significant way, and then drive on public roads with the presumption that it is alright. Motorized vehicles, in Germany and many other countries, must be approved before they can legally operate on the road. Otherwise, they are considered hazardous and banned from public roads. Finding a licensed car workshop that was willing to vouch for MiG's modifications was difficult. Stefan tells me in an interview how "nobody agreed to give us the signature" (Interview Stefan 08/23/13). For example, the project approached their colleagues in automotive engineering at Technical University Berlin and at FU's own workshop at the Botanical Garden. They all denied the project their signature because they did not want to become liable for modifications that they did not make themselves. Finally, and by coincidence, project members managed to recruit the person from whom they purchased their tires, who gladly vouched for the modifications because he was very fond of the project. Stefan concludes, "without him we could not have made it" (Interview Stefan 08/23/13). 
The project's safety concept (Sicherheitskonzept) is a protocol for testdrives ${ }^{27}$ which spells out rigorous tests that must be passed in computer simulations and on enclosed grounds before a car is able to operate on public roads. The concept demands the presence of a safety driver behind MiG's wheel and of a system observer behind a laptop that monitors MiG's software. The safety concept also prescribes different ways of disconnecting the automobile from its modifications. MiG is fitted with emergency switches which-when applied-disconnect the systems (Wang 2012, pp. 65-66). In addition, the connection between the modifications and MiG is cut temporarily whenever the brake paddle or accelerator is pressed. Rather than using the Passat's built-in actuators, the MiG is fitted with additional motors for steering; this allows a full separation of the systems.

The safety concept was put to test (Prüfung) in a fenced-off area of the former Tempelhof Airport in Berlin. Thomas was the first safety driver of the project. He explained to me in an interview:

The TÜV (Technical Inspection Agency) wanted to know if the whole vehicle could still be controlled if anything happened at 30 or $50 \mathrm{~km} / \mathrm{h}$. And because we had certain requirements in the safety concept and said this and that will work. We can even intervene in that time, we can make sure-even if the components go crazy-that in the end the safety driver can always make sure nothing happens. That was the test. So we drove and the TÜV said, now you turn the wheel right around. And then they wanted to see that it was no problem to control it so that it never gets dangerous. That was more or less the test. That was the test of our safety concept. (Interview Thomas 03/16/15)

In order to pass the test, the project had to demonstrate to the safety authorities that MiG "could be still controlled" by the safety driver. Thomas was able to demonstrate that he could resume control of MiG fast enough when the TÜV forced MiG to exhibit a totally random behavior.

The project's vision promises something which cannot be realized within the regulations of most countries at the time of this writing. ${ }^{28}$ To conduct trials on public roads, the project had to relate to the traffic authorities and turn them from adversaries into allies. In the course of the network-building, MiG was reconfigured to satisfy the demands of their newly won allies. The project managed to negotiate a compromise with the traffic authorities. The

27 Members tend to translate Erprobungsfahrt as "test-drive". "Street trial" is a term taken from STS literature (Marres 2016). I am using the terms "test-drive" and "street trial" interchangeably.

28 The exceptions are autonomous driving on private grounds or forms of guided transportation, such as the driverless Métro de Lille and the driverless Københavns Metro. 
requirement of two drivers - the safety driver ${ }^{29}$ and the system observer-has rendered the full realization of the vision impossible. This can be seen as ironic. For more than 80 years, autonomous driving has been promised to be safer than cars operated by human drivers (Kröger 2016, pp. 45-46), yet today's traffic authorities consider MiG as potentially more dangerous. To be able to demonstrate that automobiles can be made driverless, two new driver figures - the safety driver and the system observer — had to be introduced. To demonstrate the feasibility of autonomous cars, the project had to prove that $\mathrm{MiG}$ is as controllable as any other car operated by a human driver. Ultimately, by being allowed to conduct street trials with MiG, the degree of reality of the project has increased through this very compromise (Latour 1996, p. 99).

To get MiG on the road, the local network had to withstand a series of tests. The project had to demonstrate that MiG is still as controllable as a regular automobile despite its modifications. Simultaneously, MiG is shaped by the global network through its implementation of a safety concept that satisfies the demands of the traffic authorities and the technical inspection agency. The configuration of street trials in urban areas is a compromise between the vision of unsupervised autonomous driving and the goal of reasonably safe motorized transportation.

29 As we will learn in following chapter, the fact that the safety driver sits behind the wheel changes what is put to test in a trial on public roads. 


\section{Chapter 3 | Street trials ${ }^{30}$}

\section{The "real world"}

Traditionally, experiments in robotics are conducted in the controlled environments of enclosed laboratory spaces. Contrary to this, the AutoNOMOS project conducts its street trials in everyday city traffic. This move introduces additional sources of uncertainty and complexity to the sociotechnical assemblage. In the following excerpt from an interview, Thomas compares RoboCupSoccer in the laboratory with autonomous driving "in the real world."

I believe that what is interesting about autonomous driving is the "outside of the laboratory" ("raus aus dem Labor"). The kind of robotics I knew before was RoboCup. That was also very exciting. [...] The disadvantage of the laboratory situation is that the colors had to be exactly the colors and the lights had to be exactly right. Let me put it this way, everything was a little bit fake ("Retorte") in RoboCup. I understand why it is like it is. This is not criticism. And with the vehicle it is like that, you program the robot, but the robotic car ("Fahrzeugroboter") drives in the real world. You cannot say that we only drive when it is sunny sky. It always has to work somehow. (Interview Thomas 03/16/15)

Thomas explains what attracts him to autonomous driving. For computer scientists, autonomous driving is a complex and challenging endeavor. Thomas refers to the expectation that autonomous vehicles should be able to deal with all kinds of weather conditions. The "real world" is a proving ground for roboticists (Richardson 2015, pp. 124-127).

Knowledge about situations in the "real world" is shared through storytelling among project members. This form of storytelling is more than entertainment-although it can certainly serve this goal. Telling stories about "real world" situations is an essential part of the work practices of project members (Orr 1996). In the following vignette, Michael includes me in the project's community of discourse by telling me a particularly popular story.

Michael and I are smoking in front of the building where the human project members have their offices. We talk about the surprisingly nice weather. I ask him whether different weather conditions influence the reliability of the lane detection. Michael

30 This chapter builds on and extends arguments I originally developed for an article (Both 2017). 
tells me that, in a case of wet roads, the contrast is stronger than on dry roads - making the lane detection more robust. He continues by telling me the story of their first autonomous drive on the city Autobahn during heavy snow fall. Michael praises the other drivers for their cautious driving during that event. However, the other drivers did not stick to their lanes. Instead of driving in the original three marked lanes, the other drivers formed two queues because the lane markings were obscured by the snow. The car, however, drove stubbornly in between the two queues in the original middle lane (Fieldnote 02-04-13: 13).

Michael's point is that weather conditions have an impact on MiG's performance. In the story, the car neglects joining the other drivers in their newly formed queues. MiG's performance is interpreted within a frame of adaptation to local traffic conditions. The sociotechnical assemblage is anthropomorphized and attributed to a personality ("stubborn"). The story's point is that $\mathrm{MiG}$ fails to adapt to the other road users. In a situation where lane markings are concealed by snow and all the other drivers ignore them, why does the car still drive within the invisible lanes? I will keep this a mystery to be resolved in the course of this chapter.

Stories about situations figure MiG's relationship with its environment, and especially with other traffic participants and the road infrastructure. These are institutionalized stories of events in which MiG serves as the protagonist. The stories may be very brief and elliptic. Project members recount them externally - in written and oral form, e.g. in popular science articles (Rojas 2013, p. 93), and in public engagement settings - as well as internally to highlight or discuss specific characteristics of the sociotechnical assemblage.

Stories about situations usually recount events in which MiG's capacities to deal adequately with the "real world" are exceeded. Because MiG's behavior becomes problematic in these stories, they are of high significance for the project members. Through listening to the stories about situations, I learned how members make sense of and configure MiG's relationship with its environment, as well as how MiG's affordances inflect the ways that members imagine driving in traffic.

This chapter analyzes the practice of street trials. I begin by following project members from their offices to the indoor parking space and from there onto the road. I describe how MiG is assembled for each test-drive. What members call driving in "autonomous mode" is an effect of the temporary stabilization of the assemblage. I continue by zooming into MiG's configuration of sensors, laptop, and software. I outline the imaginary of control which is realized in the assemblage. Finally, I analyze how members take care of the assemblage during street trials. Fitting MiG into everyday traffic is a challenging task in which irreconcilable goals need to be managed. 


\section{Assembling MiG}

A street trial does not begin in the garage or on the road. They already start in the office. This is where MiG prepared for the "real world." In the following vignette, Michael checks and corrects MiG's map for an upcoming test-drive. In robotics and artificial intelligence, it is customary to refer to representations of the environment as maps (Murphy, pp. 42-44). It is a network graph, a collection of nodes (GPS coordinates) and edges (lanes connecting the nodes). The map is an a priori representation of the road infrastructure on which MiG drives. It also includes other elements, such as the position of traffic lights and the priority of streets at intersections (Czerwionka et al. 2011). The mission file is a representation of the test-track ("Teststrecke") encoded as a specific path through the map. The mission file also encodes information about speed limits. A test-track is a stretch of road that has been carefully mapped and modeled in detail beforehand. A test-track can extend from a few hundred meters up to several kilometers.

I am sitting in the office next to Michael. Michael is preparing the car's laptop for the upcoming test-drive. The car's laptop sits on Michael's desk, hooked up to a large screen. Michael starts the "control center"- -software that is used for both simulating and operating the vehicle. He is working on the car while sitting in the office. He loads an old log file from a previous test-drive into the control center. On screen I see the map of the road infrastructure and the actual tracks travelled by the car during a particular test-drive. The recorded tracks depart from the roads of the map at certain points. Michael activates a second layer visualizing data from a specific laser scanner. He begins to correct the map. I ask him how he can tell the actual road from all the different measurements. He explains that he can see where, for example, the bike lane is simply by looking at the visualizations of the sensor data. After a while he says "we definitely have to test-drive this" and continues with a second log file.

Michael loads a second log file from another drive into the control center. He comments, "a nice drive (...) it definitely matches the map." The second log file seems to be more aligned with the map. Puzzled by all the deviations, I ask him what causes those deviations. He suspects that the first one was logged without correcting the GPS positions. I observe how he follows the map and the tracks on screen and I ask him what he is doing. He says that he wants to know whether the tracks are overlaying. (Fieldnote 02/18/13)

Autonomous drives do not start from scratch. MiG does not venture in unknown territory. Before $\mathrm{MiG}$ can autonomously drive anywhere, it must already have been there. It requires a very precise map; the error must not be 
greater than a few centimeters. As we have seen in this vignette, maps can be imprecise: the map and the tracks travelled by MiG do not overlap all the time; the map and the recorded positions are not sufficiently aligned. Michael works on getting the a priori representation of the road infrastructure aligned with the measurements that were made during previous street trials.

After Michael has finished preparing the laptop, we pick up a second project member, Timo, from his office and walk to the indoor parking space. Once we are inside, we unplug MiG from its battery charger and push the car out of the garage to avoid polluting the air inside. On the forecourt the engine is started and the members pop the trunk, booting up the different systems in a pre-determined order. Timo connects the laptop to the ICT systems of the car and launches the "control center." The laptop responds with a feminine voice that says, "System's ready".

I take a seat in the back of the car. This is where I usually sit and film, or simply observe, the action and ask questions. (Fieldnote 02/18/13)

Project members use a laptop to control the car. ${ }^{31} \mathrm{MiG}$ cannot drive autonomously without the laptop. A car-to-computer interface grants the laptop access to the car's steering, accelerator, brake, and signals (Wang 2012, pp. 64-67). The laptop controls MiG's movements with its software. In addition, the laptop serves as MiG's user interface. The human members use the laptop to monitor and control MiG (Image 4). Operation, monitoring and manipulation are all integrated in one piece of hardware; the laptop thus plays a key role in re-assembling the car and-as we will soon see-in diagnosis.

\section{On the road}

Project members distinguish between manual driving and autonomous driving. Manual driving is whenever MiG is operated by the safety driver. In autonomous mode the car is operated by the laptop, which in turn is monitored and controlled by MiG's crew.

During my fieldwork, the most experienced member usually assumed the role of the safety driver (left in Image 4). The safety driver sits behind the steering wheel and monitors the car and the surrounding traffic. $\mathrm{He}^{32}$ takes

31 Detailed technical descriptions can be found in the qualification theses written in the context of the project, e.g. Wang 2012.

32 I use the pronoun 'he' to highlight that the research group is overtly male dominated (Chapter 1). During all test-drives in which I participated, there was an all-male crew. This is not a coincidence; it is an instance of gender division of labor in Germany. 


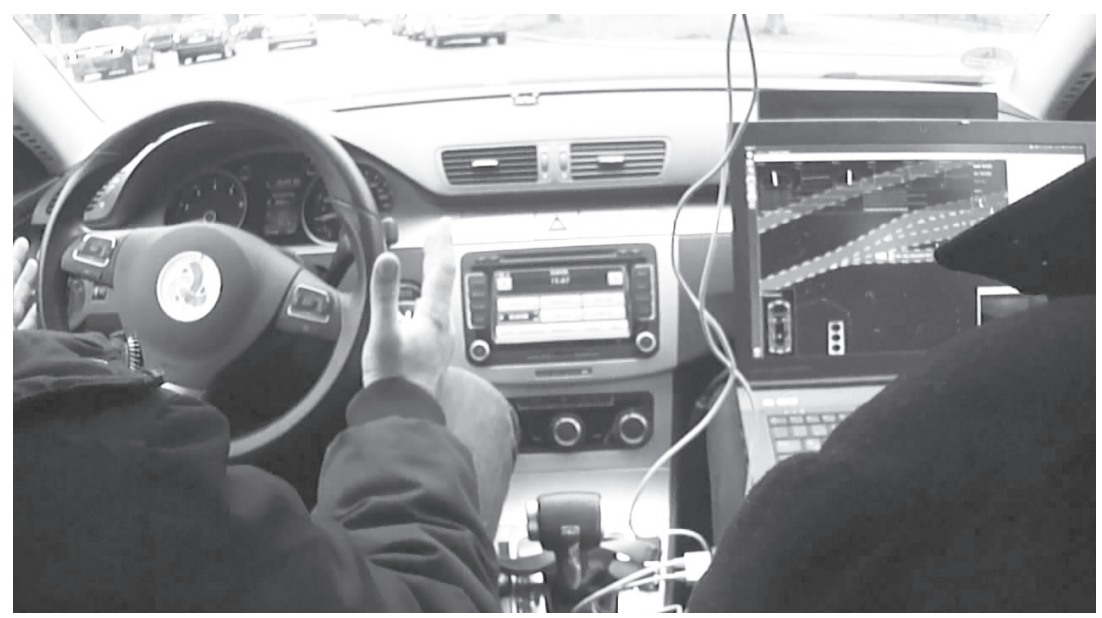

Image 4: The laptop (right) is MiG's user interface (still taken from a video 2/18/13)

control over MiG whenever it cannot handle a situation adequately. A second member, who sits in the passenger seat (right in Image 4) and is informally called "co-pilot," assumes the role of the system observer. He monitors and controls the laptop. The following vignette of a technology demonstration with a journalist takes place in the quiet neighborhood of Berlin-Dahlem, where many of the Freie Universität's buildings are based.

We manually drive to the test-track in order to drive autonomously. A test-track often used during my field work is close to the garage just in front of the university's main building. This test-track is a section of a public two-lane street. The test-track goes up and down the road separated by a grass strip with trees. In each direction it has a driving lane, a lane for parking, and - in between them - a bike lane. On each end of the track the car makes a U-turn to resume driving in the opposite direction.

When we arrive at the test-track, Michael says that a sensor does not work. He then exists the car, opens the trunk and reboots a particular sensor system before returning into the car and resuming driving. Michael counts down: "3-2-1." He flicks a switch at the steering wheel and the laptop responds with a feminine voice: "Engaged". Michael takes his hands off the steering wheel and rests them on his lap. Shortly after, he again takes hold of the steering wheel and resumes control of the car, because it does not drive in the lane as it is supposed to do. He explains to the journalist by pointing towards the laptop screen: "You can see the arrow." He continues by stating that, due to a problem with the correction data, the deviation of the GPS receiver is too big. For this reason, the car assumed it was driving on the other side of the grass strip. The laptop 
is not aligned with the world. Michael stops the car once again. He and Timo fix the problem quickly and we continue to drive autonomously (Fieldnote 03/10/14).

Technology demonstrations oscillate between manual and autonomous driving - that is, between the car being operated by the laptop and by the driver. Safety drivers often switch into autonomous mode in mid-drive or, alternatively, resume control in mid-drive. One moment you are in autonomous drive, and in the next moment MiG is back in manual drive. During trials autonomous driving is a volatile technology. Autonomous driving is enacted as part of a mundane practice - manual driving — that incorporates a stable technology - the automobile. MiG can only drive in autonomous mode when its network, which is constituted by its crew, its ICTs, and the Global Positioning System (GPS) are temporarily stabilized.

The vignette is also indicative of an asymmetry. MiG cannot evaluate whether its actions are adequate in a given traffic situation. The crew is not only responsible for safety, but also to get the car to work and assess MiG's performance. While I will shortly return to the monitoring work performed by the crew, we first need to understand which imaginary is realized in the assemblage. We can only grasp the technical care work done by the crew if we understand what they are monitoring.

\section{An imaginary of control}

Imaginaries are constitutive of and constituted by ways of knowing (Verran 1998). The manner in which members model driving and configure MiG is constituted by imaginary. An imaginary highlights certain aspects while hiding others. It makes some things present while making others absent. In this section, I use imaginary as a lens for investigating how an autonomous vehicle orders urban traffic and, in turn, how it responds to the order that it generates. How does MiG 'know' and 'understand' traffic? And how does its 'knowledge' influence the way it performs driving? These questions will help us to understand why the 'real world' is a challenge for roboticists and to solve the mystery of the snowy drive.

When I ask how the car is able to 'know' and 'understand' traffic, I do not wish to imply that a machine-no matter how advanced it is supposed to be-knows and understands in the manner that humans do. As it is the computer scientists who configure MiG, knowing and understanding should be understood as results of the roboticists' efforts to make the car participate in traffic. In this section, then, I view knowing and understanding as distributed between humans and nonhumans. 
How do the project members make MiG 'aware' of what is going on around the car? The laptop draws together all the sensor data ${ }^{33}$ in order to produce a singular representation of MiG's environment. In other words, the laptop generates a "world model." (Murphy, p. 43) In robotics and artificial intelligence, a world model is a representation of the environment of a robot or software agent. In order to generate a world model, the project members have the laptop make use of different types of resources.

We have already addressed the first type of resource, which includes the a priori representations of the road infrastructure and the test-track-a map and a mission. A priori refers here to the fact that this data must be stored and selected on the laptop before autonomous driving and will not change over the course of the test-drive.

The second type of resource is new to us it refers to the measurements of sensing information that come from the sensors and the GPS (global positioning system) unit during the drive. To enable MiG to locate itself on the map, project members installed a military-precision GPS unit in the car's trunk. The MiG's laser scanners (LIDAR) and RADAR systems constantly monitor the environment of the car. If there are traffic participants, buildings, or vegetation in the vicinity, they will reflect the electro-magnetic waves of the LIDAR or RADAR back to the car. The laptop transforms data from its LIDAR and RADAR systems into computational objects labeled as "obstacles." In the language of robotics and AI, these processes are called object detection and classification.

Translating traffic participants and anything else detected by the sensors into obstacles is a means of bringing the "real world" into the laptop. The world model is supposed to mimic the car in its environment. Each obstacle is rendered meaningful by producing a set of figures: velocity, direction and position (Göhring et al. 2011, p. 408). Based on these figures, obstacles are mapped into the world model. The world model does not only represent, it also simulates. It estimates the future positions of obstacles by taking the orientation and position on the road into account. It simulates a version of how traffic situations could evolve.

Up to this point, we have reached a basic understanding of how the laptop processes sensor data, constructs a world model, and locates itself within this world. Now, we can proceed to how MiG navigates through traffic. The representation of the test-track specifies only a limited number of GPS waypoints - not all of them. The waypoints are connected by the laptop through

33 Project members call this process "sensor fusion" because data from different sensors are brought into alignment. 
a process called trajectory generation (Wang 2012, pp. 103-124). The laptop generates different potential paths and selects them with respect to certain requirements, such as "comfort." The result of this process is a "plan". By executing the plan, the laptop's computations are translated into movements of the research vehicle. As long as everything goes as planned (pun intended), the laptop will command the car along the test-track - much like a tram, though on invisible tracks.

$\mathrm{MiG}$ is seldom alone on the road; there are almost always other traffic participants. How do encounters register themselves from the laptop's point of view and how are they managed? This question leads us to the third type of resource: rules. I will illustrate this with an example.

Rules are linked to what project members call a scenario or-more colloquially_a "situation". A scenario is the context in which a rule is applied, such as yielding to road users on a street with higher priority. When MiG approaches a junction or intersection, it checks the world model for obstacles in certain areas. The following images visualizes the procedure (Image 5).

In the case of (b), for example, if the world model features obstacles in the zone marked in green, then the car will put its plan on hold until the zone is cleared. In other words, MiG will yield until traffic participants with higher priority have passed.

Project members succeed in making a laptop drive a car by ordering the surrounding environment in a specific way. Driving, a multifaceted practice, is transformed into a series of distinct "do-able problems" (Fujimura 1987), such as mapping, localization, path-planning and controlling the vehicle (Wang 2012). The imaginary materialized in the assemblage is physicalist.

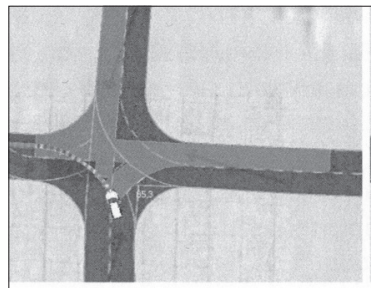

(a) Left Turn

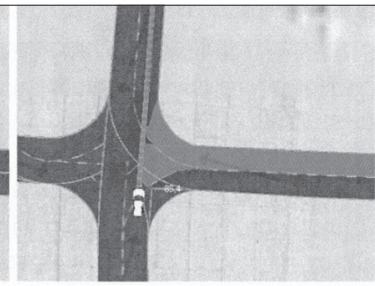

(b) Straight Ahead

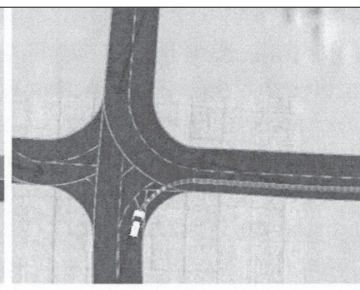

(c) Right Turn

Figure 5.9: Areas where the RightOfWay module searches for obstacles with priority to be right during (a) a left turn, (b) driving straight ahead, or (c) a right turn. Higher priority areas are marked in green while lower priority areas are shown in yellow.

Image 5: The intersection scenario is compartmentalized into three distinct cases. (visualization taken from Wang 2012, p. 118) 
Traffic participants are understood as isolated Newtonian objects moving on a map. In the right-of-way at intersections scenario, for example, we have just learned how the car responds to situations in which this rule is applied. To sum up, MiG uses three types of resources to understand traffic: a priori representations, measurements, and scenario-based rules.

Going back to the mystery of the snowy autonomous drive, we now understand that the other drivers, who drove so cautiously, were represented not as cars but as obstacles moving along the car's trajectory. Since they did not block MiG's projected trajectory, MiG continued to drive as prescribed by its map and mission.

\section{Encountering road users}

Traffic encounters occur because traffic participants share the road with other users. Coordination is necessary to avoid accidents or disturbances in the traffic flow. In the following vignette reporting on a technology demonstration with an international journalist the safety driver resumes control of the MiG because it yields to another car.

Michael, Christian, a journalist, and I are riding in autonomous mode. MiG detects another car in a side street and slows down to yield. However, the driver of the other car makes a friendly gesture at the safety driver, Michael, and waives his right-ofway. Michael takes over control of the vehicle and comments: "interesting situation." Michael explains the situation to the journalist: "He [The other driver, GB] had the right-of-way but he made it clear that he preferred to yield. This is why I had to intervene. Otherwise the car would have waited forever." (Fieldnote 2014-03-10)

For Michael this is an "interesting situation" because MiG's capacities are exceeded. The vignette ends with Michael making an excuse for taking control from the car. He does not intervene due to a particularly dangerous situation or a reckless driver but because of a calm situation and a considerate driver. Micheal resumes control not to prevent an accident but to avoid becoming an obstacle to other road users.

How can we understand the event reported in the vignette? We have to distinguish between the ways that $\mathrm{MiG}$, on one hand, and the two drivers, on the other, achieve an 'understanding' of the situation. How do the nonhuman elements of the assemblage 'interpret' the traffic situation and respond to it? MiG detects an obstacle moving towards its planned path. According to the map, the obstacle is on a street with a higher priority. MiG responds to the obstacle by putting its plan on hold and thus slowing down and coming to a stop. MiG 'assumes' that this particular interpretation of a traffic situation is 
shared by all interaction partners. MiG now keeps its plan on hold as long as it can detect obstacles in the street with the higher priority. The response of $\mathrm{MiG}$ can be reconstructed as an application of a formal rule from the code of traffic.

How do the drivers interpret the situation? Two "driver-car assemblages" (Dant 2004, p. 62) encounter each other. Both drivers try to make sense of what the other driver is up to. As everybody is driving slowly, they establish eye-contact. The other driver sees a driver-car already moving and decides to waive his right-of-way rather than force the other driver-car to stop. Michael recognizes the driver's offer to proceed. He interprets the other driver's gesture and reluctance to proceed as an offer based on the informal rule of giving priority to flowing traffic. A mutual understanding of the situation is achieved between the human drivers by coordinating their actions (Juhlin 2010, pp. 54-57). Instead of relying on the global rules of the traffic code, right-of-way is negotiated locally taking local variations and contingencies into account.

In the above vignette, Michael takes the perspective of MiG. He intervenes because he knows how MiG functions. Due to his intimate relationship with MiG, Michael can predict how it will respond. He knows with certainty that it will not move until the other driver-car has cleared the street. The ability to anticipate all possible responses in particular traffic situation is part of what Brown and Laurier call "co-driving" (2017, p. 419).

The coordination problem is skillfully resolved by Michael. He accepts the offer from the other driver and thus "repairs" (Collins 1990, pp. 62-70) MiG's inadequate behavior. Michael competently manages the relation between the order prescribed by MiG and the unfolding of a local, contingent traffic situation. MiG is programmed on the premise that traffic scenarios evolve along a deterministic path. It 'assumes' that only one rule can be applied to a particular situation, whereas in practice various rule sets can often be applied to a particular situation.

\section{The lonely, disembodied driver}

$\mathrm{MiG}$, as a sociotechnical assemblage, embodies ontic and epistemic commitments concerning driving in urban traffic: Traffic can be known through sensors and maps alone. Everything the car needs to know about its environment can be derived from sensor measurements and maps. There is a correspondence between the maps and what they seek to represent. There is also a correspondence between what is measured by the sensors and what is 'out there.'

Other road users are figured as individual obstacles and driving is figured as evading obstacles. It is presumed that the development of the traffic situation can be estimated by locating the obstacles on the map, treating them like 
Newtonian objects and applying the rules provided by the traffic code. These rules a define a "framework of action together with the actors and the space in which they are supposed to act" (Akrich 1992, p. 208). Based on the rules inscribed into the software, MiG expects the 'obstacle' to behave in a certain way-for example, to exercise its right-of-way or to observe a red light. The imaginary materialized by the assemblage renders urban traffic meaningful as a collection of isolated, law-abiding, moving obstacles.

MiG's rules prescribe other traffic participants to act in an anticipated way. The considerate driver rejects MiG's script by establishing eye-contact with Michael and consequently waiving his right-of-way. With the friendly driver's rejection of the script, the order according to which MiG operates breaks down. ${ }^{34}$

Encounters between the car and other traffic participants are based on the assumption of a universally given interpretation of the interaction background. The understanding is given through the rigorous application of traffic code. The imaginary realized in the car assumes that an interpretation of the interaction background is given by the position of vehicles in relation to a map and the autonomous car. Actions of traffic participants are interpreted as documents of rule-following in accordance with the code of traffic. It assumes that the interpretation of the traffic situation is shared by all.

The imaginary outlines the androcentric subject position of the lonely, disembodied driver. Embodied communication between traffic participants is othered by the assemblage. Other road users are figured as law-abiding obstacles that can interfere with the lonely driver's plan. Therefore, autonomous driving is not only a reconfiguration of cars and their drivers but also a reconfiguration of the relations between driver-car assemblages and other traffic participants.

The imaginary assumes that a shared understanding of traffic situations and their development is given by traffic participants' position and bearing in relation to the road infrastructure. The imaginary combines a physicalist understanding of traffic with a mechanistic application of the legal traffic code. In this way, it others embodied communication between traffic participants. As my vignette has illustrated, this may give rise to a coordination problem. The irony is that MiG, which 'sees' road users as obstacles, would have become an obstacle to other road users if Michael had not anticipated this event.

34 In a way, the considerate driver can be seen as a "spect-actor" during a performance of Augusto Boal's "invisible theater." The 'considerate driver' becomes a spect-actor of a scripted performance without realizing it. 


\section{Taking care of "him"}

We have seen that the safety driver manages tensions between the order prescribed by the car and the contingent unfolding of traffic situations. Based on the lived experiences of the crew members, I will describe how they developed of way dealing with the complexity of the car and its behavior on the road. We have seen that $\mathrm{MiG}$ is a character in stories about situations. In diagnosis, a similar means of reducing complexity can be observed. By personifying the car as a male character and locating themselves within it, they reduce its complexity and blur the distinction between the car and its crew.

The following vignette and still are based on a video I recorded during a drive with Michael (safety driver) and Christian (system observer). This drive served as a rehearsal for an upcoming demonstration with a journalist that was scheduled for the following day. Michael usually referred to the rehearsals as "seeing if everything still works" ("gucken, ob alles noch geht"). This mundane episode illustrates the fluidity, obscurity and speed of situations in street trials, as well as the ways in which these situations pose a challenge to the crew. The vignette has illustrated how uncertainty may arise from letting MiG drive in traffic. Perspective-taking is used a strategy to make sense of the car's actions.

Michael, Christian and I are driving in autonomous mode on a test track that passes the main building of the university. It is a two-lane street separated by a grass strip with trees in the middle. The turning signal makes a sound. MiG slows down and turns left as it begins to make a U-turn. Christian, the co-pilot, observes the plan on the laptop screen. He tells the safety driver Michael, "yes, he sees him," to confirm the detection of an incoming car on the street onto which MiG is turning (Image 6).

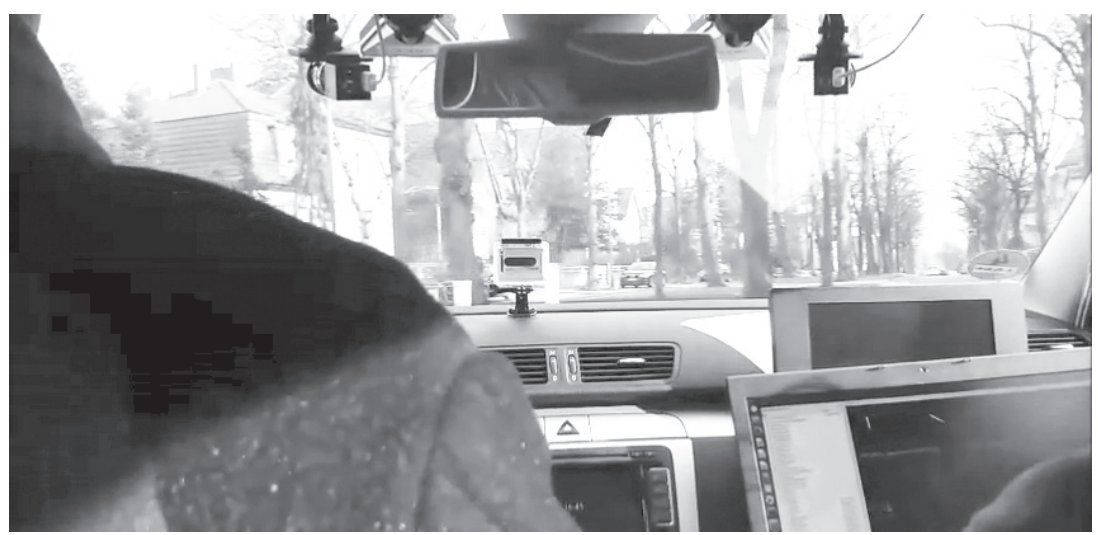

Image 6: Still taken from a video 03/07/2014 
During the second half of the U-turn we hear brief noises from MiG's brakes. Making an assertive gesture with his fingers towards the laptop, Michael comments on MiG's behavior: "Every time, he sees something here." (Image 7)

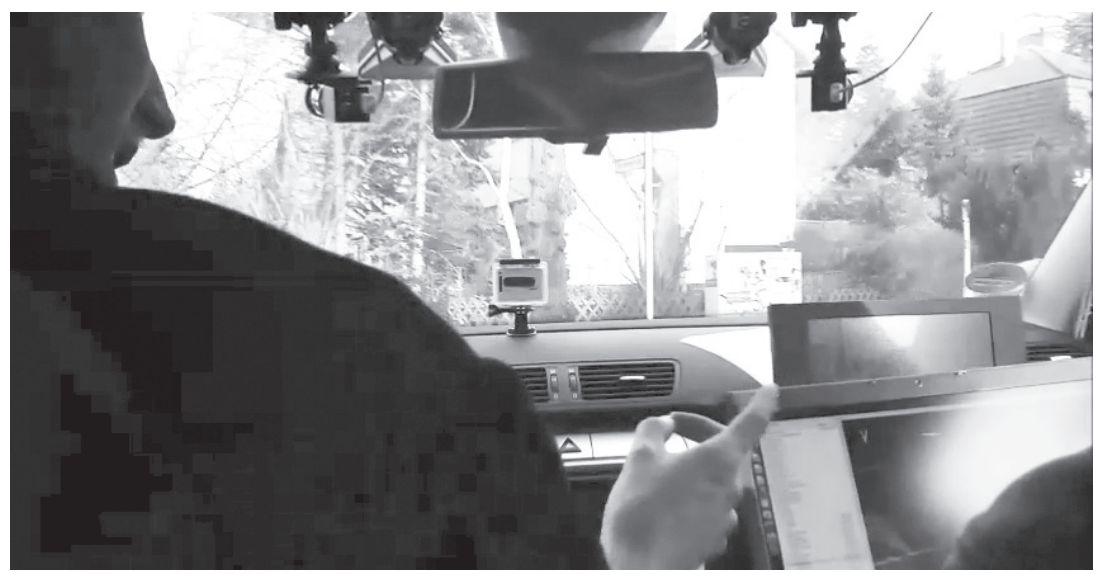

Image 7: Still taken from a video 03/07/2014

Christian speculates that MiG interprets the curb as an obstacle. Michael disagrees: "more likely a bush or a tree or something like that." (Image 8)

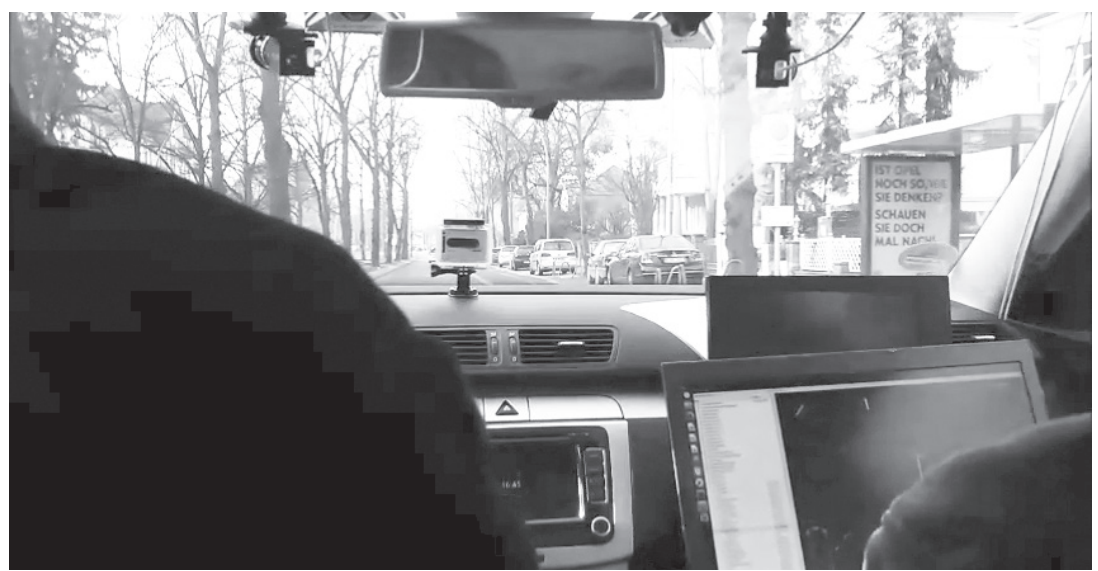

Image 8: Still taken from a video 03/07/2014

Pointing to the laptop screen, Michael explains, "It must be on the street that we grant the right-of-way . He sees something on the street." (Image 9) 


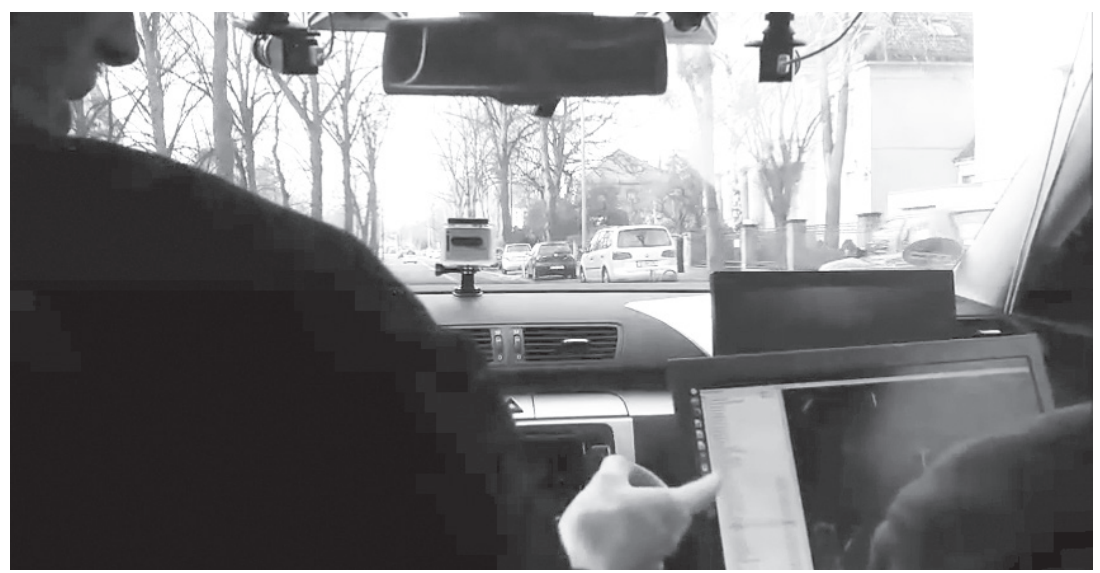

Image 9: Still taken from a video 03/07/2014

Simultaneously, MiG finishes the U-turn, accelerates, and passes a cyclist riding in the bike lane. Christian tells Michael about the anomalies on the laptop screen. They discuss potential causes and explanations while looking at the screen. In this moment, MiG stops at the traffic light. Ignored by the crew, the feminine synthetic voice proclaims the result of the traffic light detection "Red! Yellow! Red! Yellow! Red!" Michael and Christian agree that the anomaly does not deserve any further consideration, since the underlying problem will soon be resolved. (based on a video 03/07/2014)

Michael and Christian are monitoring MiG driving in autonomous mode. An unaccounted braking maneuver stimulates a brief discussion about potential explanations. The crew engages in joint sense-making. The car's response is related to obstacle detection.

Michael and Christian anthropomorphize MiG and attribute to it a personality and identity. This is a common practice in the field of robotics \& AI (Sharkey and Suchman 2013). Michael and Christian figure the car as if it were a male person ("he") who "sees" something "every time." The car becomes a character with a history of previous test drives on the same track. By attributing agency to 'him,' "he" is held accountable for braking. The pattern of using a masculine pronoun is habitualized. The sociotechnical assemblage that member monitor is made sense of as a bounded masculinized subject responding to an external stimulus. Michael and Christian refer to it like they might refer to an old pal.

MiG is so complex that it is treated like a human to a certain degree. "He" works as a short-hand for the complex sociotechnical assemblage-minus themselves. It allows Michael and Christian to talk about it without specifying 
the component or the software module. The "personification" (Interview Robin 06/20/14) of MiG thereby serves to reduce its complexity. The members personify the car, but they still explain its behavior in terms of logic; they could, for instance, make sense of the car's behavior in more human-like terms by saying that is an expression of its 'will' or something done because 'he feels like it.' Although the car's response is indeed unaccounted - there is no traffic participant on the street - the crew assumes that the car's responses are dictated by rule-following.

Anthropomorphism is often a two-lane street, with technomorphism going in the opposite direction (Vertesi 2012, p. 401). Michael and Christian locate themselves within the software of the laptop ("[...] that we grant the way"). Troubleshooting MiG's behavior involves facing the results of their own actions. They or their colleagues programmed the software and produced the maps. In the crew's joint sense-making, the distinction between MiG and themselves becomes blurry.

\section{Reconciling tensions}

MiG is vulnerable, but - like any motorized vehicle - it can potentially do considerable harm. Safety is therefore a crucial concern of the crew during street trials. Handing over control to the car does not rule out the possibility of accidents. In the following interview transcript, Thomas explains how he ensures the safety of the drive and how he makes sense of his experience as a safety driver:

When I'm driving myself, I know what I'm going to do. Almost exactly. So then I just need to see what the others are doing. In an autonomous vehicle, you have to watch what the others are doing and what your own vehicle could do. What would the vehicle do, what would be the worst case? And could the worst case be critical? That means acting sort of like a driving instructor. For a driver, it might be a bit better because a person might be a bit more predictable, so you wouldn't assume that a person would pull the wheel down hard in one direction or something. The vehicle doesn't either (emphasis), but theoretically it might be possible that that happens. A bit like a driving instructor (.) if we drive past a bus now, for example, that could be that kind of situation, $\mathrm{OK}$, so I have to be a bit more careful. (Interview Thomas 03/16/15)

In manual drive Thomas experiences the car as an extension of himself. He imagines manual driving as a state of certainty. He feels in full control of the car and his attention can then focus on what other traffic participants are doing. In autonomous drive Thomas perceives the car as external to him. He presents autonomous driving as a state of uncertainty. 
Callon et al. distinguish between uncertainty and risk (Callon et al. 2009, p. 19). By risk they refer to a potentially dangerous event that could happen and that can be described by statistical methods (for example, the probability of core meltdown in a nuclear power station). Uncertainty, on the other hand, relates to events that we do not know about. "We know that we do not know, but that is almost all that we know: there is no better definition of uncertainty" (p. 21). In the case of the safety drivers, the result is suspicion and presumption. Safety drivers do know that the car can potentially harm somebody, but they will only know the precise cause after it has happened. There is known danger, yet the casual chain is unknown. A responsible safety driver works on being suspicious.

Thomas compares his experience of monitoring autonomous driving to that of a driving instructor supervising a learner. He sees a crucial difference, however, between monitoring human drivers and monitoring an autonomous car: the autonomous car could respond in ways that he would not expect from human drivers. The car could respond in unforeseeable and potentially dangerous ways. In his imagination, a human driver would not act in such an erratic manner. Thomas concludes that human drivers can be more easily supervised because their actions can, at least in principle, be anticipated.

Thomas explains how he uses perspective taking as a means of minimizing the uncertainties involved and thereby of ensuring safety. The relationship is more akin to relations of care than to relations of control. Thomas also draws on a classic technique for fear management: continuously imagining the worst cases while simultaneously monitoring the surrounding traffic situation. In other words, he takes into account all possible responses of the car, such as braking, accelerating, turning, and relates them to what other road users are doing.

Safety drivers view resuming control of the car as the ultimate measure to ensure safety during autonomous drives. Michael reports how his reaction time and the car's distance to other road users are crucial variables.

But if he $[\mathrm{MiG}, \mathrm{GB}]$ slams on the brakes, (...) then I won't be able to react quickly enough if someone comes up super close in the same moment. And then (as a safety driver, G.B.) you have to avoid that kind of situation. You have to watch out - is someone behind me who could crash into the back or something? So that you can judge what is the worst thing that could happen right now. And then when this kind of situation comes up, when it could happen, you'd have to take over and drive yourself and not risk it (.) where in other situations you know that if no one is behind me on the motorway, then nothing can happen anyway. (Interview Michael 2/22/13)

Michel explains how paying attention to both the front and the rear of the car is crucial to monitoring the car in autonomous drive. The possibility of rear-end 
collisions was cited by all safety drivers as a worst-case example. Michael mentions a second strategy to ensure safety. By prospectively resuming control he seeks to avoid traffic situations that could develop in potentially dangerous ways.

Distance is a joint object of concern for MiG and the safety driver. Thomas describes his heightened sense of alertness when other cars come too close to the car.

And what would happen if that guy cuts in and the one behind is too close? Sometimes I say stop, that's too dangerous, and then either I'm being too cautious or sometimes I might say, OK, we're gonna stop this now. That's just too extreme, in the sense that the safety margin is really too small now. (Interview Thomas 03/16/15)

Thomas reports how he manages the fear of losing control. For instance, his fear of not being able to respond fast enough to prevent an accident can be addressed by prospectively resuming control or by accepting the tension. In Thomas' imagined situation, if another car cuts in front of MiG, then MiG will engage in a braking maneuver. The car is programmed to keep distance from other road users along its path relative to its velocity. Contrary to human drivers, the car does not tolerate cutting. ${ }^{35}$ If the following driver is too close, the safety driver will not have time to intervene. Hence, a braking maneuver could lead to a rear-end collision. The safety driver therefore has to make sure that there is sufficient space in front and in back of the car. He makes autonomous driving happen by making space for it.

Thomas also points to a dilemma inherent in the function of the safety driver. A conflict can emerge between ensuring safety and letting MiG proceed. If the safety driver is too cautious, $\mathrm{s} /$ he will prematurely resume control of MiG. However, only if one lets the car drive by itself can one observe whether MiG is able to safely handle traffic situations. Safety drivers need to balance safety concerns with letting the car proceed.

Fear can be a problem, but so can lack of fear. Michael reports how sticking to the routine can lead to a dangerous lack of focus.

(...) and you definitely have to watch out that it doesn't become like a routine. You still have to concentrate and just keep in the back of your mind that it is a trial and that things can always go wrong. And that something can go wrong that you haven't

35 As Brown and Laurier (2017) have noted, this problem occurs in other prototypes and cars with ADAS. The project members also had the experience that their approach works only if other drivers keep distance. It prescribes considerate drivers who do not take advantage of gaps. 
foreseen, but relatively quickly — at least for me - you develop great trust, that I definitely - that I know (emphasis) that it doesn't always do everything right, but I know (emphasis) how it reacts in what situations. (Interview Michael 2/22/13)

Michael makes sense of his experience by figuring his relationship as an intimate bond of trust. Trust is an interesting choice of words, given that he talks about a machine. Trust means that the car behaves in a foreseeable way. Trust is the antidote to fear of the unforeseen. If you trust the car, then you are not afraid of losing control. But if you rely too much on your intimacy with the car, then you may be oblivious to the uncertainties involved. As this is a trial, Michael calls for a critical self-assessment of the apparent sense of control. $\mathrm{MiG}$ is too complex to be reduced to simple rule-following. Having a lot of experience with the car does not mean that the car cannot still surprise you. A careful safety driver is always prepared for the unexpected.

Balancing trust with fear is a strategy he developed to remind himself of the uncertainties involved. For Michael, it is not a problem that the car does not work reliably all the time. Its shortcomings are accepted. On his account, an over-confident safety driver can become an issue; safety drivers need to stay alert and remain suspicious.

In addition to managing the car in relation to other traffic participants, safety drivers have to manage themselves; they have to manage their own emotions. As we have seen, the safety drivers take into account that the car can respond in potentially unforeseeable, erratic ways. They navigate the tension between being overly suspicious and overly confident. If they are too cautious, they will preemptively disconnect the systems, ruling out the capacity of MiG to prove that it could safely deal with a traffic situation. On the other hand, safety drivers must constantly stay alert, because if anything that requires intervention happens, then they need to act immediately-traffic often leaves little time for careful considerations.

I argue that the crew's technical care work serves to temporarily reconcile several different tensions that arise from contradictory goals (Law et al. 2014, pp. 189-190). The goal of driving autonomously can come into contradiction with the goal of ensuring safety. The safety driver must reconcile the tension between letting MiG proceed and re-taking full control of MiG. Given the openness and brevity of traffic situations, safety drivers need to manage their emotions: they must reconcile suspicion with confidence.

The bold promises of the envisioned potentials of autonomous driving over manual driving do not materialize in street trials. In the 'care-ful' stories of the safety drivers the hierarchy of manual and autonomous driving is reversed; manual driving serves as a safe haven for the responsible and careful safety driver. 


\section{Chapter 4 | Pioneers}

A global race over the future of mobility is in full swing: autonomous vehicles are conquering the streets in the U.S. and Germany. And Berlin is right in there (Innovationslabor AutoNOMOS 10/13/10, p. 1). ${ }^{36}$

When I started my fieldwork, I expected members of the AutoNOMOS project to be enthusiastic about cars and driving. I was surprised when I learned that my expectations diverged from members' self-images. The relationship of the members to the dominant culture of automobility (Miller 2001; Sachs 1992; Urry 2004) is complicated. In this chapter, I will use my disconcertments (Raasch and Sørensen 2014, p. 264) as entry points to an investigation of how members assemble gender (e.g. Lagesen 2012) by associating and dissociating between artefacts, meanings, identities, and practices.

The analysis presented in this chapter is based on ethnographic interviews with project members and complemented by fieldnotes. Apart from one instance, I decided against eliciting perceptions of gender directly (Meuser 2010, pp. 193-194). Rather, I analyzed the spontaneous narration that occurs during ethnographic interviews and informal chats to trace the associations and dissociations through which autonomous driving are masculinized according to the members' own codes. For example, I analyze the values, ideals, and narrative forms through which practitioners describe their attraction to the field of research in autonomous driving. I selected episodes for fine-analysis in which links between autonomous driving and masculinity are taken for granted and in which they become problematic.

The chapter starts with describing the ambivalent relationship between members and cars and continues with an exploration of what it means to be a member of a car-centered robotics project and how an idealized member should be.

\section{Distancing from automobility}

I will begin by presenting three brief examples of moments in which my expectations were called into question. Robin, a former project member at that time, had worked in the automotive industry before joining the project. During the ethnographic interview he made his stance on automobility quite

36 "Ein globales Wettrennen um die Zukunft der Mobilität ist in vollem Gange: autonome Fahrzeuge erobern die Straßen in den USA und Deutschland. Und Berlin macht mit." 
clear by saying, "I am proud that I have never owned a car" (Interview Robin 06/20/14), while pointing at his electric bike parked inside his office. When I asked him if he was the only car sceptic in the project, he replied, "It was actually rarely discussed as a topic, since many members were students before and pursued a student's lifestyle" (Interview Robin 06/20/14). Robin imagines car ownership and enthusiasm for cars as being incompatible with student life in a major city like Berlin. Hardly any project member owned a car, and not all of them had a driver's license.

In the second example, journalists' expectations diverge from members' self-image. Journalists are an important audience for the project; they contact the project frequently to do stories on autonomous driving. The following vignette took place at the end of an autonomous test-drive with a journalist. $\mathrm{MiG}$ has just been parked inside the garage again.

The journalist would like to take another photo of them with the car. We push the car out again. First, he gets Christian and Michael to pose in front of the car. Then they have to get inside MiG. Finally, Michael has to point to the big emergency stop button in the foot well. Later, when asked about it, Michael laughs and says he has never done anything like this before. But Stefan had told him that one time the journalists had made them pose in front of the hood with a screwdriver in their hands. He thinks this is ridiculous. (Fieldnote 03/10/14)

The vignette describes how members are asked by journalists to pose for photos with MiG. The emergency buttons are moved into focus. They seem to have a symbolic value for the journalist. These switches can disconnect the additional ICT systems (including the laptop) from the rest of the car. During my fieldwork I have only once observed them in use. When asked about this unusual staging, Michael responds by telling an anecdote about an even more ridiculous and amusing request to pose with a screwdriver. His response clarifies that he sees this as an unnatural connection. The screwdriver is viewed as a misunderstanding of the nature of their research practices.

The screwdriver symbolizes mechanical tinkering with MiG. It positions the project close to car modification and car repair (see Wajcman 1991, pp. 143-146; Balkmar 2012). However, this is not how members like to see themselves. Rather, members tend to reject any comparisons with car mechanics or car modifiers. I interpret this as a distinction along class divisions. Car modification and car repair are usually associated with working-class masculinity rather than middle-class masculinity (Wajcman 1991, pp. 144-145). Distinguishing oneself from car mechanics documents Michael's alignment with computers and robots as part of his professional middle-class identity as a computer scientist. 
The third and final example deals with how members imagine themselves in relation to male car enthusiasts. The following vignette describes a scene where Martin, Thomas and I return from a public engagement event. We presented MiG at the exhibit. I was interested in hearing how they felt about the lack of diversity among the audience:

On the drive to the garage I play the idiot and express my surprise that it's mostly men who are interested in the car. Martin and Thomas are not surprised: "it's about a car." They add that women are only interested in whether it works. Thomas tells an anecdote from his former computer science professor (female). The question was whether a cleaning robot should be able to carry on a conversation. A woman said a robot should just clean. Thomas says his girlfriend found his colleagues in New England off-putting, although she is a computer scientist herself. These colleagues only talked about cars. And even Martin does not share his automobile industry colleagues' fascination with playing around with the electronics in their cars during their free time. Martin makes fun of their hobby. (Fieldnote 06/13/15)

In this vignette, I pose a naïve question in order to elicit a post hoc account of how members perceive the gendered interest in their car during the event. For Martin and Thomas, it is self-evident that MiG appeals predominately to men because it is seen as a car. Thomas argues that men and women have different expectations towards technology. Thomas draws on a binary discourse which constructs men as passionate about technology and women as pragmatic about technology (Landström 2006; Holth 2014). He uses his former female computer science professor as evidence. According to Thomas, she simply expects technology to do its job; she does not wish to be drawn into imagining what else could be technologically feasible.

In the second half of the vignette, Thomas and Martin problematize the link between masculinity and cars. Martin, an industrial $\mathrm{PhD}$ student, distances himself from his male colleagues in the automotive industry, who tinker with their cars passionately in their spare time. Thomas argues that certain men exclude women through their collective obsession with cars. Thomas refers to his girlfriend, who is also a computer scientist, in order to support his claim. In opposition to masculine hands-on tinkering with automobiles and obsession with cars, the field of computer science is constructed as open to all genders. This can be seen as indicative of how computer scientists tend of think of their field as being gender neutral: it is considered to "brainwork" (Faulkner 2009b, p. 185) as opposed to work with physical technological artifacts.

The three examples make manifest members' ambivalent relationship to automobility. During my fieldwork I was disconcerted. If most of the project members are not really interested in cars or driving, I wondered, then why and 
how are they drawn into research in autonomous driving? Before addressing this question, however, it is important to revisit the ambivalent relationship with automobility, for it is more ambivalent than these three examples suggest.

\section{Identifying with racing}

Project Members' ambivalent relationship with automobility was not the only thing that called into question my expectations about the field of research in autonomous driving. As we have learned in chapter 2, the project's imaginary is driven by a desire for full automation. Human drivers are positioned as the source of many problems related to automobility in urban landscapes; manual driving is imagined as undesirable. The imaginary draws on discourses of sustainable mobility. Yet during my fieldwork I came across references to a second imaginary, one which celebrates manual driving through racing. I will present three examples of this imaginary.

During an ethnographic interview with Thomas, I wanted to know how the requirements for MiG's controller were devised. The controller is a part of MiG's software that runs on its laptop and that, among other things, sends instructions to the accelerator, brake and steering. Thomas' reply made me laugh because of the surprisingly graphic and stereotypical imagery.

Thomas: That was Rojas' requirement; he said my grandmother has to be able to drink coffee in the back.

(GB laughs)

Th: I use that as a quote in lectures, too, that those were the requirements. The point is not (emphasis) to show as sporty as possible ("Es geht nicht darum möglichst sportlich zu zeigen") how safe the car goes round the curve at 50, but that the whole thing always (emphasis) works. That it works safely and comfortably. No big jerks, and when it brakes, it brakes gently. (Interview Thomas 03/16/15)

Thomas likes this illustrative requirement, as he uses it during his own talks. In Thomas' story, Rojas mobilizes his grandmother as a potential passenger. In this case, by relating his grandmother to a stereotypical activity (drinking coffee) he serves to signify the demand for a smooth ride. This positions riding in cars as something closer to trains or airplanes, where it is indeed possible to drink your coffee without spilling. The prospective user of autonomous driving is imagined as the exact opposite of Thomas: female, aged and interested in being driven comfortably rather than driving "sporty" (sportlich). In 
this example autonomous driving is constructed in opposition to racing. The imagined user of autonomous driving is feminized.

Another instance when I was puzzled by references to racing was at a neighboring institute in Berlin-Dahlem, where Rojas presented the project to colleagues. During his talk, Rojas used videos to illustrate the project. There was one video I had not seen before as it was not publicly available on the internet. However, I had already heard stories about the events documented in the video. The video was taken during a trade fair for electric cars.

Rojas shows a video in which MiG drives through an obstacle course with squealing tires. Rojas explains that for this a "racing controller" had been developed by a post-graduate "just for fun." The human racing driver was only 2 seconds faster, but that day they used up a whole set of tires (Fieldnote 04/18/13).

The story of this particular moment in the project's history circulates among project members and it has also been shared by the funding initiative. ${ }^{37} \mathrm{As}$ part of the entertainment for the trade fair's audience, a professional race car driver was driving an electric vehicle on an obstacle course. The project members asked the race car driver whether he could race with MiG. He agreed and the project members recorded his tracks while he was driving MiG. They manipulated MiG's controller to allow for greater acceleration and sharper turns. Finally, the members replayed the recorded tracks in a race against the clock.

Each time I heard the story about the race it was noted that they used up a full set of tires during this event. The tires serve as material evidence for their seriousness to race while simultaneously acknowledging the material costs that come with it. By emphasizing that the PhD student did this for enjoyment, Rojas implicitly distinguishes this technology demonstration from the proper conduct of technological research. Despite this rhetorical demarcation, it begs the question of how celebrating racing relates the project's imaginary. Before I take up this question, I would like to present my final example.

During my first field day with MiG, I accompanied Stefan, Michael, and Tim to an enclosed driving ground that was designated for safety training (Verkehrsübungsplatz). On this field day, the members rehearsed a technology demonstration for the Federal Minister of Education and Research, who funded their project at that time. We spent hours driving in circles until all the details of the test-track were manually "fine-tuned" to be smooth and thus able

37 https://web.archive.org/web/20110628035851/http://www.unternehmen-region.de:80/ de/5841.php [Checked on 03/04/20] 
to fulfill the requirement of comfort mentioned in the interview with Thomas above. When we were finished, Stefan asked Michael, Tim, and me,

"Who wants to puke?" Stefan, Tim and I enter the car while Michael goes to the toilet. I expect Stefan to let $\mathrm{MiG}$ replay its mission with a higher speed. Instead he manually drives with squealing wheels across the driving ground (Fieldnote 07/25/12).

I was surprised. I did not expect Stefan to 'blow off steam' after monitoring the car driving in circles for hours. I realized that just because the project aims at turning drivers into passengers it does not mean that members do not enjoy interacting with cars in different ways. The fact that full automation is imagined to be desirable does not mean that members cannot also be attracted by an imaginary of racing. ${ }^{38}$ The project's imaginary, however, is actively resisted in the last two examples. The celebration of driving in a sporty manner contradicts the ideal of comfortable, efficient and safe transport that is central to the project's imaginary.

Members exhibit an ambivalent relationship to automobility. On the one hand they distinguish themselves from working-class masculinity by making their work with MiG seem abstract and distanced, while on the other hand they identify with racing - a traditional masculine activity formed around competition and risk-taking among men (Balkmar and Joelsson 2012, p. 47).

\section{Masculinizing autonomous driving}

In order to understand members' sense of masculinity, I will now consider acts of positioning in relation to robotics, computer science, and autonomous driving. I will also consider the narrative forms in which members tend to articulate their work with respect to the pleasures it affords them.

When describing their motivation for working on the project, most of the projects members I interviewed highlighted the pleasures derived from interacting with technology. For instance, when I asked Thomas what he - as a post-doctoral researcher in computer science-finds interesting about autonomous driving, he began by talking about how autonomous driving differs from his former experiences with robots. Thomas concluded his reply by connecting his interest in robotics to his childhood pleasure of playing with mechanical and electric toys and construction sets.

38 Allusions to driving as racing can be also found in some of the names of the desktop computers in the office that go by sport sports car brands, such as Maserati. 
No, exactly, the whole technical side, the mechanics behind it. That's what I found fascinating - it's all linked to robotics: not just the algorithms, but this embodiment, the physicality. So there is this machine (emphasis). Whether it's a walking robot or a vehicle with wheels and cogs and everything. When I was a kid it was like that, construction kits, something similar to Meccano we had in the GDR (German Democratic Republic), and there were cogs and motors and then you had lamps that lit up-I was always excited about that (Interview Thomas 03/16/15).

Thomas accounts for his interest in autonomous driving by adopting the subject position of a roboticist. He abstracts from the concrete robot-whether it comes with legs or wheels - and from its context of use-whether it is on a soccer field or on the road. The fusion of the physical with the virtual is what fascinates him. As Tine Kleif and Wendy Faulkner have observed, those describing their feelings about working with technology often frame their interaction with it in terms of thrill and excitement (Kleif and Faulkner 2003, p. 301). What is central in such description is the excitement derived from being able to control technical artifacts in a way that they show a desired effect ("Lights light up").

Thomas' story connects early childhood interests and pleasures with his professional work as a roboticist. His biographical narrative thereby highlights continuity. As Mellström argues in his cross-cultural studies of technical specialists in Sweden and Malaysia,

technology has often been an essential part of many men's upbringings as boys and connects closely to definitions of what is masculine and what is not. Crucial for such identification is the early socialization with and the embodiment of different machines and technological knowledge and the pleasures derived from this. Such tinkering pleasures are generally codified as masculine (Mellström 2004, p. 370).

Many team members worked on robots before entering the autonomous car projects, e.g. in RoboCupSoccer teams. These members tend to use comparison with their past experiences to make sense of their current work experiences. The stories I elicited during ethnographic interviews often emphasized the heterogeneous character of work practices in robotics. For example, Michael framed his job experience as a hybrid of writing software and of hands-on tinkering with the car:

But there are nearly always some small things to fiddle with, especially when you're developing something new, and that really is fun. Actually, that would be even more so with the soccer robots, because there you're building a complete robot, but now we cannot (.) we don't want to intervene in the whole car mechanics thing (...). But at any 
rate, that is another aspect why (...) I like working here, that it isn't just (emphasis) about programming but also fiddling around with cars and all the other stuff (Interview Michael 2/22/13).

In answering my question concerning what he enjoys about robotics, Michael stratifies the field of computer science. He also takes up the subject position of a roboticist. According to Michael's cartography, robotics is more than "just [...]ar programming." In this way, he demarcates robotics from other areas of computer science or from many occupations in the IT sector. He highlights the pleasures derived from tinkering with a physical artifact as a means of complementing the manipulation of virtual objects in software development. Robotics is, as it were, the best of both worlds.

Yet for Michael autonomous driving is not ideal robotics. MiG does not allow the same level of intimacy as, for instance, the soccer robots. MiG could not be built from scratch. That would require skills found not among roboticists but among automotive engineers - not to mention the requisite funding and a workshop. For legal reasons, project members also have to refrain from tinkering with the research vehicle (Chapter 2). This invokes a distance between members and MiG.

Stefan makes sense of his commitment to the project by drawing on a different narrative. He identifies more closely with the outcomes of technological projects than with the technological interaction:

GB: And now you're really committed to this, so what motivates you like that? Or what makes it fun?

Stefan: That's very clear, my first motivation was really clear: a moving car. Back then I always thought Knight Rider was cool, so [I was drawn to, GB] robotics and AI and cars. I'm not one of those car-tuners and don't really know that much about cars and so on, but I'm really fascinated by robotics because it's something you can get your hands on. When others say, "so here I've solved an NP complete problem ... optimized something here, found a double approximation" (alters his voice, speaks through his nose in a geeky way) or calculated some theoretical aspect or other, that's, well, I think with a soccer robot, at least you can look at it. You can see that something's going on. A car that drives, that's something real ("etwas Echtes") (Interview Stefan 08/23/13).

Stefan accounts for his interest by fully identifying with autonomous driving while simultaneously distancing himself from car modifiers or car mechanics. Stefan's account documents the pride he takes in being involved in the creation of a publicly visible and tangible artifact. For him, 
autonomous driving is at the intersection of computer science, robotics and automotive engineering. First, Stefan distances himself from car modifiers and car enthusiasts. It is implied that expertise in cars and driving is not a requirement for becoming a project member. Then, he demarcates research in autonomous driving from other areas of computer science. A purely mathematical interest in computer science and a playful interest in soccer robots function as academic others to the AutoNOMOS project. Stefan ridicules computer scientists interested in numerical mathematics and theoretical computer science as stereotypical nerds (see Kendall 2011; Sjögren 2015). He depicts their pursuit as an autistic means-in-itself that pursues purely intra-disciplinary objectives. Stefan belittles RoboCupSoccer as fun to look at with no immediate applicable outcomes and argues that the AutoNOMOS project is more "real" than other domains of computer science. He ascribes reality effects to the project by referring to the successful demonstration of their car. Visible performance is understood as a self-evident marker of meaning and purpose. This makes sense within the "demo culture" (Bean and Rosner 2013) of robotics.

Stefan's account hierarchizes different forms of technical expertise and interest within computer science according to the realness or reality of their outcomes. As opposed to the mechanical skills of a car modifier or the analytical skills of a mathematician, the skills embodied in robotics are universal — and, for this reason, seen as superior. Robotics outdoes computer science; autonomous driving outdoes laboratory robotics. Research in autonomous driving produces "real" artifacts—not something which 'only' exists inside a computer or a laboratory environment. Autonomous driving is positioned at the top of the hierarchy.

Domination is a generative principle of masculinity (Meuser 2010, pp. 123-124). The hierarchization of different areas of computer science is simultaneously a hierarchization of different forms of masculinity in technological worlds. Robotics demands the linking of two forms of technical skills that are symbolically associated with masculinity: the abstract knowledge work of analytical problem-solving, as exemplified by programming and mathematics; and the mechanical skills of problem-solving, such as hands-on tinkering with technical artifacts (see Wajcman 1991, pp. 143-146).

Despite his insistence on the realness of the project's outcomes, Stefan establishes a connection between the 1980s science fiction show Knight Rider (Larson 1982-86), starring David Hasselhoff, and his interest in autonomous driving. For Stefan, Knight Rider depicts a fusion of robotics, artificial intelligence and cars. Knight Rider is a science fiction detective show. Its hero, a former policeman, and his side-kick, a one-of-kind driverless car (KITT), fight evil-usually by assisting women in their struggle with powerful, criminal 
men. It is an iteration of the myth of the lonesome cowboy, who fights for justice with the assistance of his more-than-a-horse partner. ${ }^{39}$

Knight Rider was repeatedly put forward as an existing frame of meaning (Czarniawska 2005, p. 271) by journalists who reported on the project (Kohnen 2009; Oelmaier 5/19/2011; Falkner 2012). Not all team members can relate to that. For some the association between Knight Rider and their research is problematic. For example, Michael and Thomas distance themselves from Knight Rider. Thomas argues that early Terminator movies, for example, serve as a better illustration of how machines sense their environment (Interview Thomas 03/16/15). Michael regards Knight Rider as a curiosity rather than as something with which to identify. Nevertheless, he wonders whether Knight Rider has contributed to making driverless cars conceivable and acceptable ("salonfähig") for broader audiences (Interview Michael 2/22/13).

In the course of this chapter we have learned that project members identify with the subject position of a roboticist. Project members oppose their engagement with cars to the engagement found in car modifiers and car mechanics by signifying their concern for designing the future (see Wajcman 1991, pp. 144-145). This kind of distinction is also at issue when Thomas, in the following interview excerpt, constructs the project's meaning in relation to research in the automotive industry.

[...] they [industrial research, GB] undoubtedly researched their own stuff at some time, but they have to get things that universities have pre-researched ready for the market. Market-maturity ("Marktreife") also means maybe you have to start small, but with things that really function reliably. $100 \%$. Which doesn't mean (emphasis) we don't want that, but we can say we'll build a prototype that can do something (emphasis) really awesome, but is maybe ripe for decision ("spruchreif") in about 10-15 years and not until someone or another makes assumptions on infrastructure, for example. Car2X [...] to put it briefly, I just think that we can look a bit further into the future and aren't interested so much in finished systems [...] where there are quite different specifications concerning safety, with redundancy. We consciously leave some things out; for example, safety concerns: how do we build a middleware-if two laptops fail, a third one takes over?

(GB expresses attentiveness)

39 During the series' intro Knight Rider's protagonists and their motivation are outlined as, "One car, one computer, one man. Knight Rider: One man and his car fight injustice." (German version translated by GB) 
It's also a question of capacity. You have to focus on certain things. Or, now we're looking into using computer vision methods to observe the surroundings even better. Where lots of people_-including the technical inspection agency ("TüV") — say: How is that going to be verified? If it's such a gigantic neural net, then where is the proof that it will always work? So we're not even asking that kind of question, first we just want to see how it can function at all.

(GB expresses attentiveness)

Like I said, our 'raison d'etre' — we look a bit further ahead. And we look for topics that others aren't focusing on yet. To clearly distinguish us from others. (Interview Thomas 03/16/15)

Thomas draws on a linear innovation model in order to position the project as prestigious "basic research" (Calvert 2006). In this model, technology is viewed as an application of science. He characterizes industrial research as constrained by the short-term demand to develop market-mature products. Thomas constructs the project as free not only from time constraints, but also from other constraints, such as those of reliability and safety. In doing so, he constructs the AutoNOMOS project as being able to focus on what matters to it: functionality. By making assumptions about an infrastructure that may or may not be in place, Thomas frees the project from the constraints of designing a prototype that must reliably perform under everyday conditions. Computer scientist call a technology demonstration of the feasibility of an approach a "proof of concept". This is not to confused with a mature product. Proof of concept in this context means that the laboratory conditions are extended to real-world scenarios. Thomas leaves it to the industry to figure out how self-driving cars can be made reliable. If we compare this positioning with Stefan's assessment of a car being "real" in opposition to other forms of computer science research, then we can see how the car's identity is fluid. Depending on the situation, the very same research vehicle can be mobilized as proof of a relevant contribution to tangible real-life consumer products (Stefan's story) or as proof of prestigious basic research that looks "a bit further into the future" (Thomas's story).

Thomas uses branding to defend the project's position in an area dominated by the automotive industry. He distances himself from industrial research by positioning the project vision in the long-term future. The project members look for topics that are not taken seriously by the automotive industry because these topics cannot be turned into a profit fast enough. Thomas locates their project at the frontier - that is, where future is assumed to become present.

Freedom - which is situated at the edge of the 'civilized' world - and the pushing of its limits are central to the frontier imaginary of the project. The 
following brief vignette, which positions the team's research in relation to time and their competitors, documents the use of frontier imagery in order to make sense of their practices.

Talking to a journalist about designing and testing new algorithms for self-driving cars, Michael says, "we do things that maybe nobody has done before". (Fieldnote 03/10/14)

This quote is loosely based on the classic opening lines of Star Trek, ${ }^{40}$ which has a colonial imagination of space travel. Frontier narratives are also pervasive in popular accounts of the internet and hacker culture (Adam 2003). This frame of meaning positions the team as being at the forefront of technological research. They see themselves as pushing the limits of what is possible. This use of the notion "frontier" is grounded in the view of technological research as a form of competition between rival project teams, i.e. of being the first to do something and thus being ahead of those who will follow. The notion of frontier is used as a resource for positioning themselves as "high-tech cowboys" (Both 2015, p. 26) at the cutting edge of robotics and automotive engineering.

Heroic masculinity also manifests itself in framing the work with MiG as a challenge. For example, Michael referred to autonomous driving in urban traffic as "supreme discipline" ("Königsdisziplin") (Fieldnote 01/07/13). In this manner, he imagines their street trials as part of a competition similar to that found in athletics. Rojas talks about autonomous driving in Mexico City as the "ultimate test" (Fieldnote 04/18/13), thereby locating the project at the frontier of autonomous driving. In the following vignette, Stefan tells me about the preparation to qualify for the Grand Challenge 2007 robotics competition funded by DARPA (Defense Advanced Research Projects Agency). In this story, the car is figured as an extension of the heroic and dedicated "we":

And now a little story on the side. We practiced all through the night until $5 \mathrm{am}$. It was the same intersection scenario over and over again, because we only had this one laser scanner in the front,

40 "Space, the final frontier, these are the voyages of the starship Enterprise. [...] to explore strange new worlds, to seek out new life and new civilizations, to boldly go where no man [sic!] has gone before." The analogy of science and the frontier itself is reminiscent of Vannevar Bush's report to the U.S. President_- "Science the Endless Frontier," from 1945 - which called for an expansion of basic research funding by the federal government. (Roddenberry 1966-69). 
(GB expresses attentiveness)

with four beams, they go out at 2.3 degrees, that means they give a really small slice.

GB: Oooh (surprised)

and our intersection was so uneven that if you looked from the north you were looking over other cars, if you looked from the south you were looking into the roads because it was a bit sloped. And that was a huge problem for us (emphasis). And then we were testing all through the night. And after about 25 hours of testing the alternator went up in smoke.

GB: oh no (sympathetic)

So in the morning at 6 and at 8 we had to say, sorry, we can't drive.

(GB expresses empathy)

Yeah, the car has broken down, can we get a second chance? And they said yes, OK, tomorrow morning at 8 .

(GB laughs)

So we had one day to change the alternator and one night for more tests.

(GB expresses attentiveness)

So no sleep again that night and pouring rain at 8 . Our car drives in a circle, everything perfect. Then the people from DARPA come and explain something, and while they're doing that the weather changes, bright sunshine, wet ground. As a human, you couldn't see a thing!

GB: oooh (appreciatively)

Texas rain, Texas sun. That means our car that relied on computer vision, that searched out yellow lines in America, [...] completely messed up, because everything was yellow. The car drove 5 meters, went right and stopped. [...] No way could we drive. So we started, the sun dried up the water, we swept it away. Then we were able to show really well that we could drive in a circle. E-stop and things like that. We thought we were done for anyway, but somehow three weeks later we got news: you made it (Interview Stefan 08/23/13). 
In this "story on the side," Stefan tells me the heroic story of how they managed to make the research vehicle work against all odds and setbacks. The team is figured as underdogs by means of an emphasis on their scarce resources (just one laser scanner) relative to their competitors, who had at their disposal redundant sensors and backup cars. By addressing me as a fellow computer scientist, Stefan invites me to appreciate the challenge of getting the car to work with just one laser scanner. Even though the laser scanner had a very small angle, the team and its car eventually passed the test.

Stefan's storytelling emphasizes the hardships. He presents a story about struggling with a machine, about last-minute improvisations, and about pride. This is the high-tech cowboy way: getting the car to work, not in an elegant or sustainable way, but in an effective way that solves an immediate problem on site and on time. The story documents an ethics of total dedication to the project. Importance is placed on working collectively until an immediate problem has been fixed. This heroic story celebrates effectiveness, stamina, a tolerance for frustration and an ability to deliver on time. Validation comes from being able to pass the test posed by the judges from DARPA. Stefan's story seems to confirm the observation that Cynthia Cockburn makes in her seminal workplace place study: "A good engineer loves a challenge [...] In the excitement of teamwork a mutual admiration arises. One sees oneself reflected in the admired eyes of other men" (Cockburn 1985, p. 172).

Stories about being initiated into a homosocial association provide a sense of what it means to be a man in the context of the project (Mellström 2002, p. 476). In the following interview excerpt, Stefan tells the story of how he joined the project as a Master's student. He had already started his Master's thesis in a different group. During that time, he received a mail that Rojas had sent to all members of the Institute of Computer Science, which invited students to join the project.

I had finished my first chapter and read this mail (...) and I said, so I have to do this, and the next day I went over to the robotics lab in Takustraße and there are Markus, Tim (...) and maybe next door the soccer robots with Ahmed, and they were just sitting there. So I said: "Is this the right place for autonomous driving?"

(GB laughs)

Stefan: And Tim says drily_ our brain—but total genius (Stefan citing Tim) "Do you know what a PID controller is?"

(Stefan citing himself) "no" 
(Stefan citing Tim) "OK, then find out what it is and come back tomorrow!"

(GB laughs)

Stefan: I read up overnight what PID controllers are and then he said (Stefan citing Tim): "OK, you can make the controller for SoB [Spirit of Berlin, the first research vehicle, GB]” (Interview Stefan 08/23/13).

Stefan's story describes how he abandoned his Master's thesis after he had read Rojas' announcement for the autonomous driving project. He self-identifies as one of the "fanboys," a group of dedicated male followers of Rojas that is excited by the prospect of being part of a visionary project. His story documents passion, or even compulsion ("I have to do it"). This compulsion to pursue the topic outweighs any considerations that might follow from a concern for efficiently finishing his ongoing Master's thesis.

Stefan vividly remembers his first encounter with the project members. He describes the basement environment of the robotics lab and his astonishment to see three PhD students sitting around a table. It seems he had expected something fancier ("is this the right place"?). Without any further introduction or getting to know each other, Stefan narrates the occasion as being put to the test immediately. The fact that a call for participation in the project had been made did not necessarily mean that he could join right away. He describes the cool understatement of the PhD student Tim. By labeling Tim "our brain," Stefan depicts him as an exceptionally skilled computer scientist - though one lacking in social sensibility. In Stefan's story, Tim's cognitive capacities make his rudeness permissible.

Stefan tells the story in the compressed form of a challenge. In order to join the project, he must demonstrate that he is willing to understand a new topic on his own, without help or guidance. Once he has passed the trial, he is accepted into the project by having a task assigned to him.

These heroic stories construct the idealized team member as autonomous, self-learning, self-interested and capable of working overnight. It celebrates performance. The story is also about making sacrifices to pursue one's dream. By reproducing traditionally masculine values, this representation iterates the symbolic link between masculinity and technology.

The capacity and willingness to demonstrate one's ability is narrated by Stefan as a necessary condition for joining an elitist group. He remembers joining the group in terms of a test of his will and skill. By subjecting himself to the scrutiny of his abilities by $\mathrm{PhD}$ students and their shared sense of what constitutes a project member, he becomes a project member. Being selected means becoming part of an elite group of young men. 
Autonomy is highly valued by members. In Stefan's story, autonomy is constructed as self-learning. Independence and self-reliance are narrated as features of ideal members. Thomas constructs autonomy as freedom from the external demands:

I think the reason that so many decide to go to university [...] is that we have a huge playing field here.

(GB expresses attentiveness)

Thomas: We have our vehicle here. So first of all we can test out what we want. We're not thinking all the time - and I think that's also really important — now how can we sell that? (Interview Thomas 03/16/15)

In Thomas' narrative MiG symbolizes freedom. He figures university research as a "playing field." This emphasis on playfulness blurs the boundary between work and play. Yet playing here should not be taken to mean that one can simply "goof off" (Kleif and Faulkner 2003, p. 302). Thomas instead highlights the playful and pleasurable characteristics of interacting with machines.

When members talk about the AutoNOMOS project, the gendered composition of the project team is usually not mentioned; it seems to be taken for granted. In an interview with Thomas, I asked about how he joined the project. He shared with me, in retrospect, the impression of the project that he had as an outsider. Most team members during my field work studied at Free University Berlin and joined the project as Master's or PhD students. Thomas joined the project after he completed his $\mathrm{PhD}$ at a different university. His story values performance and collective achievements:

GB: What made you decide to get into this project? How did that happen?

Thomas: So that was when I was at the Winkelmann University in the RoboCup project. And the group around Prof. Rojas was often there [at the RoboCup competitions, GB], too. So I already had an idea at least that the group existed-when I was a student already. And they were very successful, I knew that already, too. Those boys ("Jungs"), they are capable. (...) Because of the RoboCup I got the feeling they were doing really extreme stuff ("die machen ja richtig krasse Sachen”) (Interview Thomas 03/16/15).

Thomas begins his story of joining the group by telling me how he learned about Rojas' project, i.e. through soccer robotics. Computer scientists tend 
to identify with their working group. Robotics is a collective endeavor. Thomas highlights the project's genealogy. The AutoNOMOS project was spearheaded by graduate and $\mathrm{PhD}$ students originally from the RoboCupSoccer team. It is implied that robotics competence is generic - that it is independent of specific tasks and contexts.

By referring to the team as "boys", he mobilizes a gendered and aged membership category to refer to the team. Computer science and gender identity become packaged in this label, i.e. technological competence is simultaneously a performance of professional identity and masculine identity. His statement manifests how the composition of the team, with respect to gender and age, is taken for granted. In this team, the use of a generic 'he,' even when women are part of the group, is widespread. Such use of gendered language renders women invisible, and could even be said to make the "very category of woman engineer a non-sequitur" (Faulkner 2009a, p. 7).

Thomas' assessment highlights the group's capacity to demonstrate "really extreme stuff," i.e. their capacity to make their robot do tasks deemed difficult by the standards of roboticists. By valuing the team's capabilities, he ascribes agency to "the boys" and thereby positions them as the heroes of his story. The robots are the means of simultaneously expressing one's abilities and one's masculinity. It is not the robots who make them heroes. Project members become heroes through mastering their robots.

This chapter has reconstructed the idealized team member as autonomous, self-learning, self-interested and full of stamina. By linking research in autonomous driving with traditionally masculine values, autonomous driving is masculinized. Research in autonomous driving is a "serious game" (Meuser 2007). By joining a project and being able to participate in the serious game, male members can assure themselves that they measure up to what it means to be a man in this field.

In this homosocial group of researchers, many links between masculinity and technology are taken-for-granted. Being associated with an automobile, however, poses a challenge to the roboticists. A car does not sit easily among computer scientists who work on controlling cars through software and sensors. The masculine pleasures of 'joy of driving' and of 'tinkering with cars' are typically underplayed in ethnographic interviews and informal chat. Yet the dissociation from men's love affair with cars is complemented by a celebration of racing both literally and figuratively.

The car as a research platform comes with associations that challenge roboticists, but it also has benefits over humanoid robotics confined to laboratory environments. MiG enables them to explore new terrains and proof their worthiness as roboticists. Research in autonomous driving affords a playing field for trials of masculinity by providing competition with other 
projects over who can first demonstrate certain capabilities, and who can stand his ground in the "real world" of urban traffic (see quote at the beginning of the chapter). The heroism of the field manifests itself in references to frontier imagery and in the popularity of the narrative form of the hero's journey. 


\section{Chapter 5 | Video demonstrations}

Video demonstrations (hereafter: video demos) are ubiquitous in research in AI and robotics. In what follows, I will give attention to some examples of their varying usage and audiences. The Springer Handbook of Robotics addresses expert audiences and is accompanied by a website with video demos for each chapter (Siciliano and Khatib 2016). Video demos are also used in robotics conferences and at public engagement events to communicate completed research. They can serve as a requirement for entering robotics competitions, such as the DARPA Urban Challenge 2007, or as attention-getters on projects' websites $^{41}$ as a means of attracting lay audiences and potential project partners. Video demos are an important resource for network-building as they can continuously attract new allies with little investment (Both 2015).

Video demos constitute a key element of robotics' epistemic culture and serve as a medium for communicating research to both lay and expert audiences (Bischof 2017, pp. 249-265). When video demos are consumed by different audiences, tension can arise between "visually proving research" and "visually communicating research" (Elish 2011, p. 26). Roboticists as audiences can be wary of video demos. Consider the following exchange between Stefan and Benjamin over a popular video demo ${ }^{42}$ from the Google Driverless Car project.

Stefan (annoyed): Google drives allegedly without (emphasis) safety drivers

GB (surprised): what?

Stefan: in their video with the blind guy

Benjamin (sober): OK, that was only a promotional video, but they also must comply to regulatory requirements.

Stefan: Insolence! (“Frechheit!”)

(Interview Benjamin 09/06/13)

41 https://web.archive.org/web/20110719204731/http://autonomos-labs.com/ [Checked on 03/04/20]

42 https://www.youtube.com/watch?v=cdgQpa1pUUE [Checked on 03/04/20] 
Stefan accuses Google of misrepresenting the conditions of street trials. Benjamin dismisses the video demo by treating it as a means of public relation rather than as a serious and accountable work of roboticists. Project members dissect video demos from other projects for clues that indicate whether the video is "fake" or "real" (echt) — does the video document the actual capabilities of a system or does it only provide a series of edited images to sell a project?

This chapter focuses on two video demonstrations which stage MiG through different emplotments: the heroic "Mission Brandenburger Tor: Autonomous Car in Berlin" $" 43$ and the tutorial "Beam me up autonomous car." I complicate the transparency of video demos by uncovering several levels of meaning. My interest in video demos is manifold. I take video demos to be an expression of an imaginary in which fantasies can be lived out. Fantasies take on available narrative forms and draw on existing images and metaphors. The constraints of their work and artifacts can be ignored. For example, editing makes it possible to stage or insinuate actions that cannot be performed without breaking the law or that are too dangerous. I also take video demos to be idealizations that document how members want to be perceived by outsiders and ways of disseminating the imaginary of autonomous driving. Finally, even if video demos can be "fake," they also can have very real consequences for the researchers themselves. I will begin my discussion of the performativity of video demos in this chapter and continue it in the following chapter.

\section{a) The hero's journey}

The video demonstration "Mission Brandenburger Tor: Autonomous Car in Berlin" tells the fantastic story of MiG succeeding in its "mission." ${ }^{\text {45 }}$ The plot of this video demo draws on the archetypical hero's journey. In a hero's journey, the hero goes through the three stages of departure, initiation, and return (Campbell 2004 [1949]). Typically, a human protagonist portrays the hero. If we take this video demo literally, MiG is the hero. Its mission is driving itself through Berlin's city traffic to Brandenburg Gate.

During the stage of departure, the hero-that is, the "autonomous car"-is introduced by being portrayed in its habitat. It is depicted while "training" on the forecourt of former Tempelhof Airport. It is preparing for its journey. The car is portrayed driving on the huge forecourt of former Tempelhof Airport

45 All quotations in this section are taken from captions in the video demo. 
with no visible safety driver. ${ }^{46}$ Heroic agency (Schlechtriemen 2016, p. 28) is formed by the caption, "It needs no driver" (Image 10). MiG is figured as a self-sufficient and bounded technological artifact with a high degree of agency.

The video demo highlights the MiG's IT components, such as "GPS unit, laser scanners, radars, and computers." The sequence on former Tempelhof Airport introduces the hero in terms of its IT components, which enable it "to brave Berlin's streets." It is implied that because of these components the MiG does not require a driver to operate and navigate it.

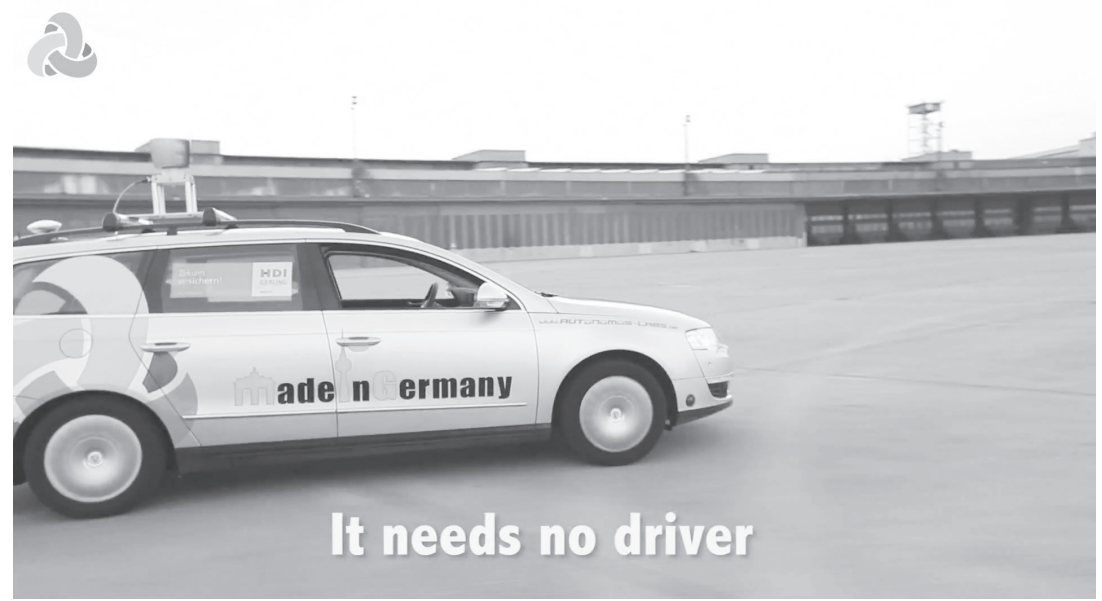

Image 10: MiG on the fenced-off area at former Tempelhof Airport

In its initiation, the autonomous car is staged, during daylight hours, amidst light traffic on the city autobahn and large boulevards in West Berlin. It is not alone any more. Not only is it sharing the road with other vehicles, it also co-exists with human companions. The safety driver is introduced as a passive observer: "a safety driver follows the action." He and the system observer are shown in a high state of concentration and dressed up in white laboratory coats. The physical separation from the car is staged by making it visible - from both the outside and the inside of the car- that the safety driver's hands are off of the steering wheel. The heroic storytelling relies on

46 Thomas tells me how he created the illusion. He hid below the glow department with his finger on an emergency stop button: "I ducked and the car was empty." (Fieldnote $07 / 23 / 15)$ 
concealing the necessary care work of the safety drivers (Chapter 3). Rather than a separation of driver and vehicle, an intimate bond between safety drivers and MiG ensures the safety of street trials.

On the road the hero undergoes a series of trials: traffic lights are to be "recognized"; roundabouts have to be "mastered"; "Berlin's notorious drivers" are to be taken care of; "obstacles" have to be "detected" and lanes tracked; a car is followed. These challenges are narrated as being met by the MiG's IT components.

At the climax, the hero arrives at Brandenburg Gate. This is where MiG and its crew (safety driver, co-pilot, camera men) are united with other human project members. The team is getting ready to pose for a picture, in a manner that soccer teams often do, with MiG visible on the side.

During the stage of return the hero does not return to Tempelhof, as the archetypical hero's journey would suggest. Rather, it is depicted driving through the woods, a place that is neither specified nor visited at any earlier point of the video demo. My reading of this shot is that the car's habitat is no longer the enclosed space of Tempelhof but has become the open road. This shot suggests MiG is released into the wild.

The fantastic storytelling is supported by the heroic soundtrack. It is a heavy metal interpretation of Johann Pachelbel's (1653-1706) Kanon, a victory hymn. The soundtrack is taken from a popular YouTube video ${ }^{47}$ of that time. In this video a male, self-identified "ordinary computer science student" virtuously interprets the Kanon on his electric guitar. The soundtrack combines the traditional (baroque music) with the modern (heavy metal). This move is mirrored by the video demonstration, which combines the traditional (a car) with the modern (a self-driving car).

The heroic plot is also supported by the choice of the setting. The massive terminal building of former Tempelhof Airport is a monument to the madness of national socialist Germany. Its roof was constructed to host 100,000 people watching their heroes during flight shows. The other sites visited by the car during video demo also showcase military heroism. The victory column (Siegessäule) was designed to commemorate the Prussian victory in the Danish-Prussian War. The Brandenburg Gate is a Prussian triumphal arch. ${ }^{48}$ Following West Germany's annexation of East Germany in 1990, the Brandenburg Gate was re-cast as a symbol of what is officially referred to as the reunification of Germany. The heroic emplotment turns the mundane

47 https://youtu.be/TF6cnLnEARo [Checked on 03/04/20]

48 Ironically, it was first used for a triumphal procession by Napoleon and his troops in 1806. 
events of driving on the city autobahn and streets into something exciting: an adventurous quest of an autonomous vehicle.

The video demo combines tech lingo with anthropo-/zoomorphic metaphors in order to reduce the complexity of assembling autonomous driving. In this imagery, each technical component of the assemblage is related to a distinct purpose and compared to an organ. For example, in the following still you can see the combined images from the two cameras that have been installed to detect traffic lights.

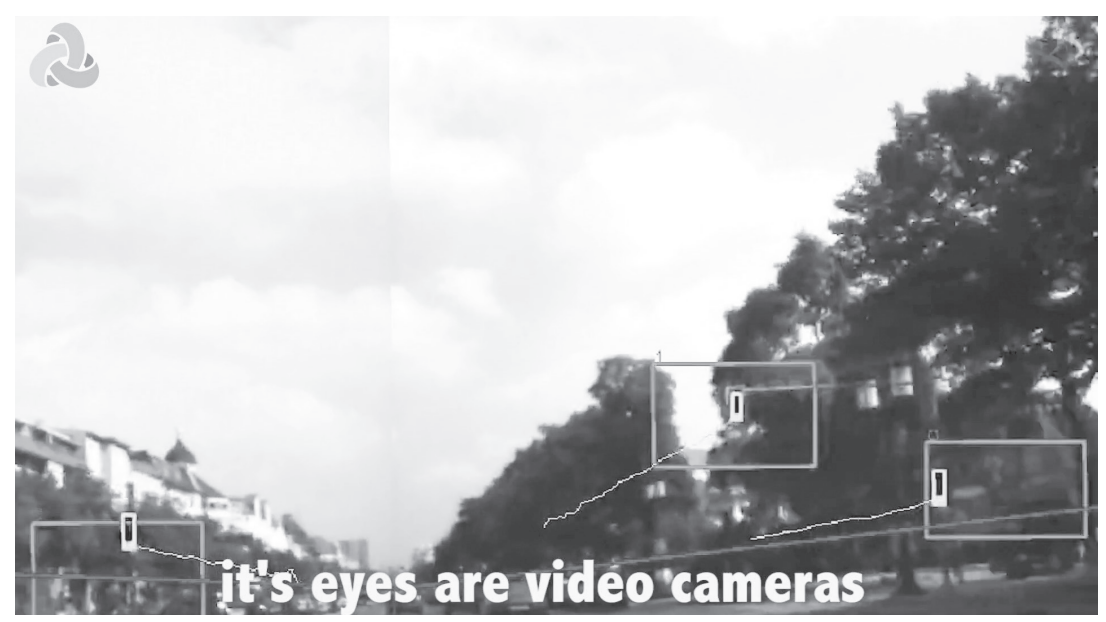

Image 11: MiG's traffic light detection

By figuring the video cameras as the car's eyes (Image 11), it is implied that these technical components are more than sensors. I asked Benjamin how he had implemented MiG's traffic light detection.

Benjamin: you just think that it is easy to detect traffic lights because they are quite bright. But then you realize at some point that camera images do not really reflect what one sees as a human with the eye.

GB: in what way?

Benjamin: Well, I would say that the 'human hardware' is so far better because they afford a better contrast sensitivity than a camera. [...] The biggest problem has always been finding these points. They were not always the brightest. (laughs) [...] What I just want to say is that the problem was not that easy because you just want a high level of reliability. This should work in-let's say — $99 \%$ of cases. [...] to facilitate the problem, 
I used maps on which the positions of the traffic lights had been marked. (Interview Benjamin 09/06/13)

Benjamin struggled with the problem of making MiG detect and classify traffic lights in a reliable way. Just because a camera is capable of capturing video streams in high resolution does not imply that it is similar to the ways that humans see. Benjamin had to find a solution - that is, a way of making a machine work reliably in a road infrastructure built for human road users. It is these actual accomplishments of the project that have become the building blocks of MiG's fantastic adventure.

The video celebrates both MiG and the human project members as heroes. This is articulated through the opening scene of the video demo. The video begins with a shot of the team in front of Brandenburg Gate with the car on the side. Almost all male members are dressed uniformly in the AutoNOMOS t-shirts, while the two female members are dressed in black shirts. The project members smile into the camera and seem proud of their collective accomplishment (Image 12).

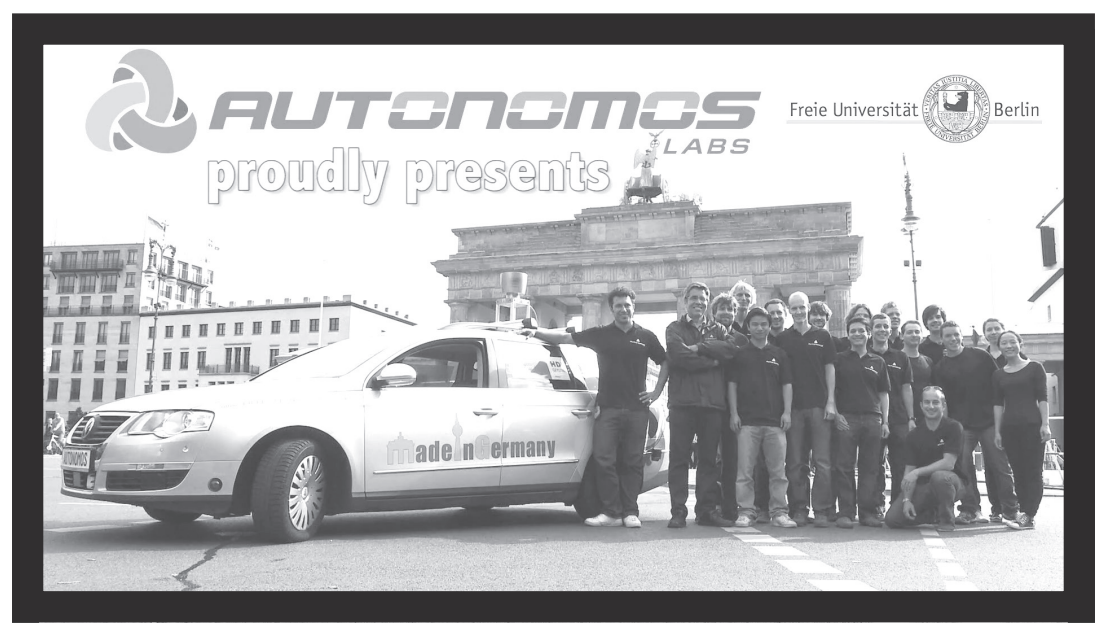

Image 12: The opening scene of the video demo

The plot can be read as an allegory for the AutoNOMOS project as a whole. In this respect, the video demonstration tells a fictionalized story of the project. The viewers of the video demo are invited to identify with the project members and their ways of seeing traffic through ICTs. As an allegory, the trials MiG had to withstand are really the doable problems that the team managed solve with the car's ICTs. ICTs, such as the video cameras, are the tools with which 
the project members work. The anthropo-/zoomorphic metaphors, such as eyes or brain, are also technomorphic metaphors (see chapter 3). The video cameras are not MiG's eyes and the laptop is not MiG's brain; rather, the cameras and the laptop are figuratively the eyes and brains of the practitioners.

\section{b) The fake tutorial}

To demonstrate that an autonomous car could act as a service comparable to today's taxi, the video demonstration "Beam me up autonomous car" ${ }^{49}$ narrates the story of an imagined consumer, portrayed by "Arturo," who was a project member during the time of the video. The title "Beam me up autonomous taxi" associates the video with a well-known quote attributed to the Star Trek (Roddenberry 1966-69) franchise. Yet the actions and events portrayed in the video are narrated in the present.

The video demo opens up with the voice-over "How to call an autonomous taxi in Berlin." This invites for a misreading. The video demo is not a tutorial. Rather, it is a repurposing of the immensely popular tutorial genre on YouTube..$^{50}$ Contrary to ordinary tutorials, the video demo does not explain how viewers could imitate the actions depicted in the video.

Arturo - clad in a white laboratory coat - and his tablet are the protagonists of the story. MiG plays a supporting character, for it is the obedient servant to Arturo and his tablet. The story begins with Arturo leaving a hotel. Arturo calls the autonomous taxi with his tablet. The next shot depicts the car in the company of other cars on a parking ground. We can witness how the car slowly drives out of its parking lot (Image 13). The voice-over says "There is no driver inside".

The car is now represented as an icon on a map on the tablet (image 14). It is implied that the car really drives without supervision. It cannot actually be shown driving without supervision, since this can be done only on enclosed private grounds - not on public roads. Finally, the car is shown arriving at the hotel. Arturo climbs into the backseat and the car drives away.

49 https://www.youtube.com/watch?v=Kyk1VLTSH_U [Checked on 03/27/19]

50 A search query on youtube.com for ,how to“ leads to $270,000,000$ results [Checked on 06/17/17]. 


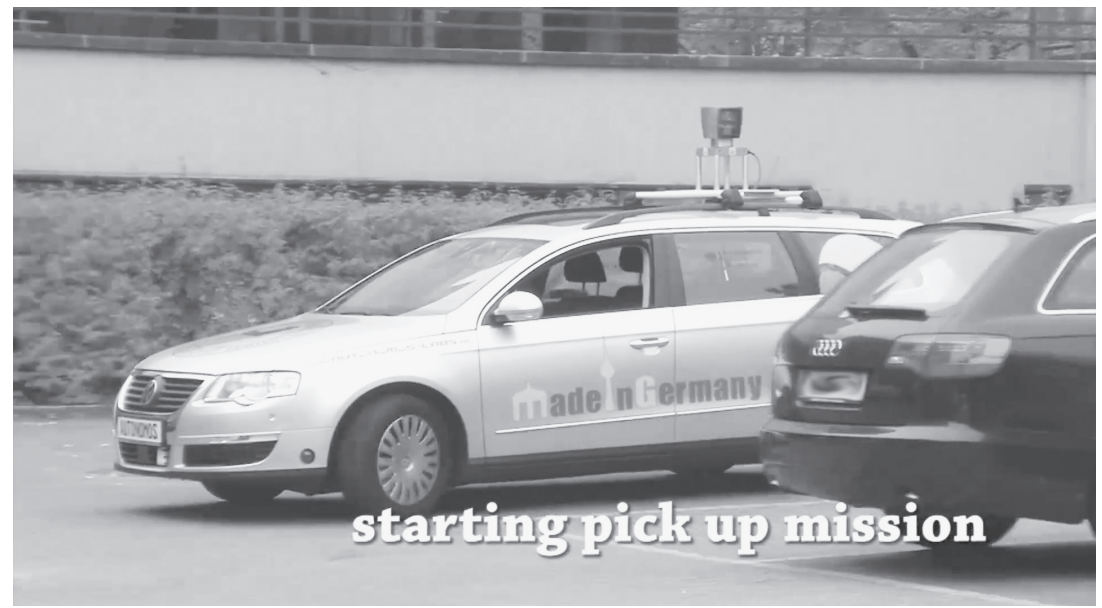

Image 13: MiG leaves its parking lot with no visible safety driver

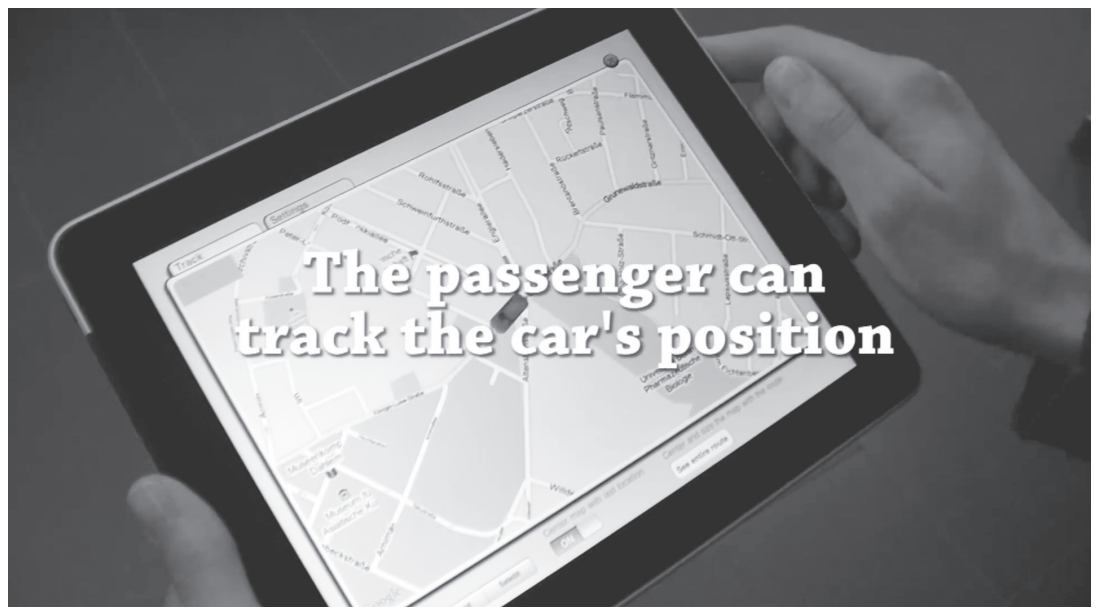

Image 14: The movement of the car is simulated and visualized on the tablet

The video ends with a few stills of the car, highlighting its sensors on the chassis and its electronics in the back, followed by a picture of the project members. The voice-over narrates that "MadeInGermany is a result of the research at the autonomous team at the Free University."

In this video, MiG takes up the role of a supporting character. The video is predominately a demonstration of an app, and the car is figured as an extension of the app. It is a story about exerting power over distance. Hence, 
the vision is translated in an app that can perform one aspect of the vision, i.e. sending the GPS location to a driverless car.

The video reduces uncertainty about driverless cars. It also insinuates actions that are illegal, ${ }^{51}$ since all motorized vehicles require a driver when driving on public roads. Consequently, during street trials MiG is always in the good company of skilled safety drivers and system observers. This video demo is about staging the project's imaginary rather than documenting what it is legally possible. The uncertainty of whether it will be legally acceptable to have a car driving itself unsupervised at some point in the future is avoided is bracketed. The events shown in the video depict not the current state of affairs, but rather what autonomous cars could be used for if unsupervised driving were legal and if autonomous cars were as robust and as autonomous as they seem in this video. The video implies that, with the proper investment, autonomous cars could serve as taxis for customers with mobile devices. By comparing the car with an existing service, the potential capacities of the car are translated into something familiar and intelligible. The car is therefore not figured as something completely new (and potentially scary) but as comparable to a familiar mobility service.

The video demo is not a heroic story about the MiG's agency. Quite the contrary! This story tells about how docile the car could potentially be. It is about Arturo-with-the-tablet's agency. The story is told from the perspective of an individualized user, i.e. Arturo-with-his-tablet. The systemic level of the narrative and the promise of more "environmentally sustainable" (Chapter 2) transport are called into question. There is no indication that the car could be shared nor that it could be connected to existing modes of transport. Ironically, the narrative is transformed in a way that subverts the vision of autonomous taxis. The vision of autonomous taxis promised no more parked cars, yet this video demo shows how the car is parked in a parking lot among other cars. It also leads to an empty car driving through the city and thus contributing to even more traffic.

The video seeks to convince its audience that it is feasible to remotely control a driverless car with a tablet and that there is a demand for autonomous taxi services. Hence, this particular video demo settles two uncertainties at once. By showing a supposedly empty driverless car, it provides proof for the feasibility of autonomous driving. One could argue that the label "autonomous taxi" already performs the rhetorical work of sustaining the vision. The label indexes something that does not exist outside of controlled environments. Yet it insinuates the possibility of becoming realized someday. By telling the story

51 In Chapter $2 \mathrm{I}$ describe why MiG cannot be operated driverless on public roads. 
of an imagined customer, the video demo tries to settle the controversy over whether autonomous driving could be acceptable (see chapter 6).

\title{
Fragile demonstrator
}

Video demos produce repeatable accounts of technology, giving rise to the impression that those capacities for action displayed in video demos have ongoing existence (Suchman 2011b). Video demos stabilize the project by staging MiG's capacities as enduring. Video demos erase all traces of the human labor that goes into producing the account. However, the ongoing existence of the demonstrated capabilities has to be sustained. Consider the following vignette, where Stefan and Michael debate whether it is still possible to demonstrate the capabilities portrayed in a video.

\begin{abstract}
Stefan and Michael talk about an upcoming technology demonstration for a team from German public television. The TV producers requested filming how the car is remote controlled through the tablet. The software has not been used for a long time and the operating system on the tablet has been updated since. Even with the old operating system the software was already "buggy." For example, the transmission of the video stream from cameras only worked once on the smart phone and never on tablet. Michael and Stefan agree to contact the software developer, a former project member, for "old time's sake" and ask him whether he could assist them with the software (Fieldnote 02/13/13).
\end{abstract}

The demonstrator in this vignette is performed as fragile ("buggy") and in need of competent technological care. The decision to reach out to the old software developer highlights how humans and nonhumans are interdependent elements of the assemblage of an autonomous vehicle and a mobile device. Components are entangled with former or present project members. With people moving on to jobs outside the project, the assemblage is threatened by dissociation.

The TV producers have most likely watched the video demo. The video demo succeeded in interesting the media, but it also created accountability. The members are expected to be able to re-enact it. The members fall victim to their own ways of promoting their research. The video demo has performative effects for the members themselves. 


\section{Chapter 6 | Defending autonomous driving}

Automation discourses promise to relieve humans of dangerous or unwanted labor (Downey 1998). For advocates of present-day automobility (Urry 2004; Böhm et al. 2006), driving is not unanimously considered to be unwanted labor, though. For proponents of autonomous driving, its core vision-the driverless car-is self-evident. Human drivers make automobility inefficient, dangerous, and a waste of time. The solution seems simple; all the functions of human drivers should be delegated to machines. Not everyone shares the project members' enthusiasm about the prospect of autonomous driving. For example, unavoidable IT security risks of driverless cars and potential job losses for professional drivers are expected as potential downsides of autonomous driving. The self-evidence of the vision can become problematic when faced with hegemonic definitions of what automobility is about.

This chapter analyzes three different strategies of innovation communication (Plesner and Horst 2013, p. 1118; Horst et al. 2017, pp. 892-893) in dealing with the acceptability of autonomous driving. This chapter begins with a description of actors speaking in defense of contemporary German regime of automobility and its economy which is said to depend of its competitive automotive industry. I then describe how project members deploy different tactics and strategies to promote their research area: a) being chauffeured over driving; b) appeasing the audience; c) celebrating control and technical mastery. These tactics and strategies take the form of visionary stories which are told about autonomous driving to different audiences. Taken together, these strategies produce different versions of the project, its purposes, and its visions. These tactics and strategies are supposed to stabilize and maintain the project. However, not all stories told about the project are equally beneficial. I analyze how one particular strategy produces overflow so that the roboticists become victims of their efforts to sell the project. The chapter concludes with a description of how project members try to minimize the damage of the overflow.

\section{Rejection}

Autonomous driving is contested. According to a recent survey, two thirds of all German drivers oppose to the idea of handing over full control to a driverless car (Kropp and Renn 2018, p. 7). In this section, I focus on the issue of human control over cars and the manner in which it is linked to the acceptability of autonomous driving. I start my argument by introducing two 
dissenters ${ }^{52}$ to autonomous driving and bringing their accounts into conversation with cultural and social studies of automobility.

Winfried Hermann (The Green Party) is the minister for transportation of the federal German state of Baden-Würtemberg. Baden-Würtemberg is one Germany's centers for the automotive industry. During a podium discussion with representatives of the automotive industry in 2015, he criticized autonomous driving for leading to "the emasculation of the German driver." During a subsequent radio debate on autonomous driving (Eva-Maria Götz, Michael Roehl 5/27/2015) he elaborated his proposition. Hermann situates his claim regarding the emasculation of the German driver by distancing himself from those who are excited by the prospect of autonomous driving:

And there I made the point that the philosophy of the automotive industry has really been for 100 years, you are your own master ("Herr"), your own helmsman ("Steuermann"), your own pilot and now this is so-to-say going to be turned upside down. If one thinks about the testosterone-driven automobile drivers ("Autofahrer"), the race-car drivers ("Rennfahrer") on the Autobahn, who enjoy stepping on the accelerator, taking risks, they will be emasculated by such a system. I said this with a wink (Eva-Maria Götz, Michael Roehl 5/27/2015).

As the minister of transport of Baden-Württemberg, Hermann is concerned about the future of the German automotive industry:

Because everyone knows Germany is an automotive center, and particularly Baden-Württemberg. And we are doing everything possible to maintain this standard and make cars fit for the future. So we must not miss any new technological developments (Eva-Maria Götz, Michael Roehl 5/27/2015).

Hermann imagines autonomous driving by comparing it to the affects and desires afforded by today's cars. He envisions driverless cars as a technological assemblage that abolishes manual driving. Hermann reminds the automotive industry how it branded the automobile by associating it with freedom and autonomy ${ }^{53}$ and he goes on to argue that the selling points of cars are powerful emotions and masculine desires rather than their capacity to transport.

52 I have selected these specific dissenters because they both prompted Rojas to respond in a defense of autonomous driving.

53 For a history how freedom and autonomy were associated with cars and driving as an ideological strategy in the conflict between the U.S. and the Soviet Union, see Seiler (2007). 
He illustrates his point by referring to men ${ }^{54}$ who enjoy risk-taking on the Autobahn, i.e. the German limited access highways that are renowned for having no speed limit on many segments. He puts his claim into perspective by saying it was also meant to be a humorous statement. Hermann does not clarify whether the humor is owing to his statement's reliance on exaggeration and simplification. It might also be that he is distancing himself from the normalization of risk-taking on the Autobahn as an acceptable driving practice.

Wolfgang Sachs' psychoanalytic and cultural historical analysis of automobility (Sachs 1992) maintains that the car incomparably makes available to private citizens a means of amplifying their power. In his view, cars can function as prosthetic devices for those seeking enjoyment through power and independence. According to Sachs, the motor drives the automobile-self, creating an ideal human-machine symbiosis. This is why the car materializes emotions of omnipotence. As Sachs also reminds us, omnipotence can easily lead to emasculation. The figure of the race-car driver imagines traffic as a form of competition. When drivers are stuck in traffic congestion or are overtaken by other drivers, feelings of omnipotence can easily be substituted by feelings of emasculation.

Leaning on Horst (2008), I view acceptability as a pattern of positive associations with the vision. Challenging the acceptability of the driverless vision, then, means associating it with an element deemed negative: emasculation. ${ }^{55}$ By contrasting autonomous driving with today's driving practices and their affective economy, Hermann associates autonomous cars with a negative element. By drawing on the interpretative frame of automation as emasculating, and by qualifying his imagined driver as German and localizing him on the Autobahn, Hermann contextualizes his claim. The Autobahn provides the stage for the performance of a specific configuration of nation, masculinity, and technology. The freedom to risk one's life and the lives of others by speeding is lawfully supported by the German state and serves as a showroom for German automobile brands. It is known that severe-and thus fatal - traffic accidents could be reduced by introducing and enforcing a speed limit, but there is no indication of any German policy change in the near

54 All of his analogies are expressed in the male gender.

55 The trope of emasculation is mobilized in other countries, too. As Jutta Weber and I have shown with the example of a 2012 Superbowl ad, the US American sports car brand Dodge relies on the trope of emasculation to sell their cars as vehicles of freedom and autonomy (Both and Weber 2014). Self-driving cars are framed as a stepping stone to humanity's enslavement through robots. Speeding in a sports car is represented as a heroic act of resistance. 
future. ${ }^{56}$ Hermann presents himself as a spokesperson for the German driver who does not want to give up the thrill of speed on the Autobahn and who values driving over being driven. Hermann uses masculinity as an organizing principle to demarcate manual driving from autonomous driving.

Herman speaks out against the enthusiasm for autonomous driving that may be found among leaders of the automotive industry. Yet not everyone in the automotive industry is excited about autonomous driving. When asked by a German automotive journalist about his position on autonomous driving, then-CEO of Porsche Matthias Müller, replied

that his customer base enjoys accelerating, steering, braking, and switching gears. He does not see the point in self-driving cars because you can already take a cab or a train (Alex and Katemann 2013).

Müller does not associate the driverless car vision with emasculation; he disqualifies it by claiming that his customers would not recognize it as a car. Autonomous vehicles are not cars! Driving, he observes, involves mastering the machine and enjoying its powerful force. Müller furthermore denies that autonomous driving is an innovation, since cabs and trains can already transport passengers.

Hermann and Müller speak on the behalf of an imagined driver. They both reject the driverless car vision by questioning the acceptability of the envisioned technology. The driverless car vision is about reconfiguring identities - those of the driver, the car, and their relations.

Automobility has successfully conquered most parts of the world because of its capacity to transcend national boundaries. Nevertheless, it continues to be shaped by national histories and driving cultures (Edensor 2004). The German state was built around cars (Sachs 1992). Sachs argues that the success of cars in Germany is not because of some inherent nature that would make them superior to other available modes of transportation. In fact, cars tended to be fiercely rejected and viewed as a meaningless hobby for adventurous elites. According to Sachs, cars came to dominate Germany because of a political will to craft a competitive automotive industry for both civilian and military

56 In January 2019, Germany's federal minister of transport and infrastructure, Andreas Scheuer, has rejected the suggestions of the government committee "Nationale Plattform Zukunft der Mobilität" (national platform future of mobility) to raise taxes on diesel and to introduce a speed limit on the Autobahn as "against all common sense" ("gegen jeden Menschenverstand") (N.N. 2019). This is an example of the nihilation strategy (Berger and Luckmann 1991 [1966], pp. 132-133). 
purposes.$^{57}$ Building a national network of Autobahns, car manufacturers, carfriendly regulations, and car-friendly cities contributed to the stabilization of the private automobile as the dominant mode of transport.

Emergent technologies tend to be conceived within two familiar registers: a rhetoric of hope and a rhetoric of fear. Anna-Lena Berscheid's (Berscheid 2014) discourse analysis of the reporting done by leading German newspapers and technology-focused media on autonomous driving found that self-driving cars are envisioned by drawing on two different but symmetric plots: utopian stories of salvation, which claim that driverless cars will save us or make a better world; and dystopian stories of threat, which claim that the technologies we create will take away joy in driving by eliminating control and autonomy.

We have now heard what dissenters have to say about autonomous driving: it is not a car, it is not an innovation, and - on top of that - it should be expected to emasculate its driver. Project members tend to refer to acceptability as one of autonomous driving's challenges. In the following interview transcript, Thomas reflects on the communication of autonomous driving to various publics, as well as on how he believes it is necessary for the project to become meaningful to others. He argues that innovation communication can be the solution.

[...] it is in our interest to raise awareness about the topic because our technology can only be deployed, if, for example, proper legal conditions are established, [...] 2006 through 2007 nobody had heard of it [autonomous driving, GB]. There was rather disapproval. If you talked to somebody, then "For what? What's the point?"

GB (puzzled): What do mean by 'for what'?

Thomas: When we said, we are developing an autonomous vehicle, people said, "For what purpose?" They looked at us, "What's the point?" (Interview Thomas 03/16/15)

Thomas makes the argument that innovation communication can be instrumental in influencing regulators to change the law in favor of the technology being advanced. In doing so, he takes up the subject position of an innovator who cares for the fate of their collective creation. He hints at the current traffic code in Germany (or anywhere else) that requires a driver to be present and conscious at the steering wheel at all times. Thomas ties the effectiveness

57 Volkswagen, which is still partly state-owned, can serve as the prime example. The town of Wolfsburg was practically built from the ground up to supply Volkswagen with the necessary infrastructure (including workforce). Volkswagen did not deliver any civilian cars until its relaunch after World War II. 
of their research to the manner in which driving is legally regulated. He maintains that the technology can only become meaningful if regulators allow autonomous driving. You have to sell the innovation in order to be allowed to make it. If regulations are not changed to accommodate fully autonomous driving, then the innovation journey will hit a dead end.

Thomas ties acceptability to the presence or absence of a sense of usefulness. In Thomas' account, laypersons tended to question autonomous driving research because they could not see how it could be useful. The public understanding of technological research that he attributes to laypersons is one in which such research is obliged to provide answers to societal problems. According to Thomas, laypersons do not appreciate autonomous driving research because it is unclear what kind of problem it seeks to solve.

I have chosen this interview excerpt because it shows how researchers like Thomas struggle to make their research meaningful, or translatable in a coherent manner, to lay audiences. The car needs to be embedded in a plausible and positive narrative. This is what characterizes the project. The meaning and purpose of autonomous driving is neither fixed nor self-evident. The project must find an answer to the question of meaning (Sinnfrage). Innovation communication is not only about allocating resources from elsewhere but also about developing and disseminating meanings for the project.

\section{Accommodating rejection}

This section analyzes the different tactics and strategies for communicating autonomous driving as useful, acceptable, and desirable. I will demonstrate that different frames and stories emerge in relation to other frames and stories. The visionary stories are born out of conflict. They respond to challenges or they anticipate challenges. Finally, I will analyze the consequences of these versions with respect to the interactions between the stories.

How does the project accommodate resistance to the driverless vision? By producing positive stories. First, I will scrutinize two tactics for accommodating the resistance: valuing being chauffeured over driving; and appeasing the audience. Afterwards I will take a closer look at video demos and show how some follow the strategy of celebrating control and technical mastery. My focus is on the different frames and stories they produce and the implicated forms of masculinity. 


\section{a) Valuing being chauffeured over driving}

As the driverless vision is contested, project members find themselves in situations where they are expected to defend their project and/or to generate support for it. For example, during the already quoted radio debate on autonomous driving with Hermann, Rojas is asked for a rebuttal. He remarks:

I do not think that freedom means controlling the accelerator or brakes. Ask the three million drivers in Mexico City on the road everyday if they enjoy driving. They will all say I'd rather sit in a taxi than suffer from this traffic situation (Eva-Maria Götz, Michael Roehl 5/27/2015).58

Rojas represents himself as a spokesperson on behalf of those who do not experience driving as 'freedom of the road' or speeding on the Autobahn. He challenges the configuration of freedom with the operation of a machine by drawing on the experiences of drivers locked in traffic congestion in a global megacity. Rojas problematizes driving by associating driving with an element that is deemed negative: congestion. To make his local network stronger and its vision more persuasive, he mobilizes as support three million drivers stuck in traffic. By associating driving with the mundane experience of immobility, driving is positioned as annoying rather than desirable. Rojas draws on a classic frame of automation: relieving humans of undesirable work.

Low acceptance of autonomous driving is considered to be an issue among project members, who therefore engage in what could be called 'lay acceptance research.' For example, in the following vignette, Rojas elaborates on his strategy in selling their research:

I am sitting with roughly 20 men and 2 women in a historic seminar room at an institute of the Max Planck Society. During his presentation Rojas talks about his experiences in selling the vision of autonomous taxis to the automotive industry and journalists. After mentioning the skepticism among car manufacturers towards self-driving cars, Rojas refers to Porsche CEO Müller, who publicly spoke out against autonomous driving in an interview. Rojas says that usually he would reply 'What do the rich people do? First they hire a cook and then a chauffeur so that they can do other things during the drive.' And Rojas adds, the CEO of Porsche must surely have a chauffeur at his service (Fieldnote 04/18/13).

58 "Ich denke nicht, dass Freiheit darin besteht, dass ich Gaspedal oder Bremse betätige. [...] Fragen Sie mal die 3 Millionen Autofahrer die in Mexiko-City jeden Tag unterwegs sind, ob sie Freude am Fahren haben. Die werden alle sagen, ich sitze lieber in einem Taxi, als diese Verkehrssituation zu erleiden." 
Rojas discredits the CEO of Porsche as a hypocrite. By imagining a dialogue between himself and Müller, Rojas illustrates how he would argue for the benefits of being chauffeured over driving. He uses comparison to support his value judgment and draws on relations of power and privilege in a classed society to sell the vision. Autonomous driving is embedded in a narrative of emancipation of the masses.

Valuing being chauffeured over driving is a nihilation strategy (Berger and Luckmann 1991 [1966], pp. 132-133) that aims to make the driverless car vision resilient against claims of non-acceptance. By speaking on behalf of frustrated drivers locked in traffic and by associating being driven with class privilege, Rojas imagines drivers as rational individuals who maximize individual comfort. In this imagination, drivers prefer the comfort of being chauffeured over driving. Private car ownership and driver autonomy is positioned as the result of individual, rational decision-making. Consequently, automobility in its current form could lose its hegemony and attractiveness through the introduction of autonomous driving. It should be noted that this story figures driving and car ownership in terms of an instrumental relationship that could easily be replaced by future modes of transportation. It reduces manual driving and car ownership to transportation.

\section{b) Appeasing the audience}

The following vignette is based on my fieldnotes from a final presentation and demonstration of a large public-private research project in the area of autonomous driving. At the two-day event I joined Michael in order to browse through the different subprojects and chat with their representatives. In the following vignette, Michael and a corporate automotive engineer reflect on their professional practice in communicating autonomous driving to lay audiences.

Michael and an engineer from a major German car manufacturer talk about the acceptability of autonomous driving. They agree that it is necessary to familiarize laypersons with automation in a step-by-step manner. Michael adds that they usually point out to laypersons that autonomous driving will be an optional feature and not obligatory. There are people who are afraid of being patronized and of losing the joy of driving. (09-19-13 Tech Demo KOFAS: 27)

Michael and the automotive engineer share a common imaginary. As experts and proponents of autonomous driving, they view automation as desirable and beneficial. However, they are also aware that not everybody shares their enthusiasm. Their hero-to-be can also be viewed by others as a villain-to-be. Michael tells the engineer about how he positions their project by anticipating 
objections. This is a therapeutic strategy (Berger and Luckmann 1991 [1966], pp. 130-131). Michael argues that laypersons need time to adapt to autonomous driving, which is presented as a certainty. Laypersons will eventually come to understand that they really do not want to drive manually. To avoid associating autonomous driving with emasculation, Michael presents a different vision of self-driving cars: advanced driving assistance systems (ADAS). This defensive tactic is to appease dissenters by affirming human control. Rather than rejecting objections altogether, fears are acknowledged and anticipated by adjusting expectations accordingly. As a result, prospective accounts of autonomous driving can be designed for specific recipients.

Rather than making autonomous driving a technical default, Michael envisions automatic functions as an optional feature of future cars. Comparable to present ADAS, such as adaptive cruise control, the driver will choose whether $\mathrm{s} /$ he engages in autonomous driving. As a result, autonomous driving is imagined as an improved version of today's cars, leaving manual driving with its externalities unquestioned. Instead of reconfiguring automobility through the bold vision of autonomous taxi, a modest version of ADAS is put forward.

\section{c) Celebrating control and technical mastery}

The third strategy celebrates human control and technical mastery rather than full automation or assistance. It tries to associate autonomous driving with more positive elements - such as playfulness, iPhone hype, mind control, and eye control - to communicate the project and to attract potential supporters. While the other strategy relies on imagination and projection to make the project and the research area meaningful, this strategy relies on demonstration to inspire imagination. The project produced a series of video demonstrations in which the research vehicle is controlled through extraordinary human-car interfaces.

The first interface they tried out was the iPhone ${ }^{59}$. The release of the iPhone had created a huge media hype at that time. This particular video demo shows how project members remotely control the car through an iPhone interface (brakes, steering, acceleration). At the climax of the video, a project member rides on top of the vehicle while controlling it with his iPhone (Image 15). 


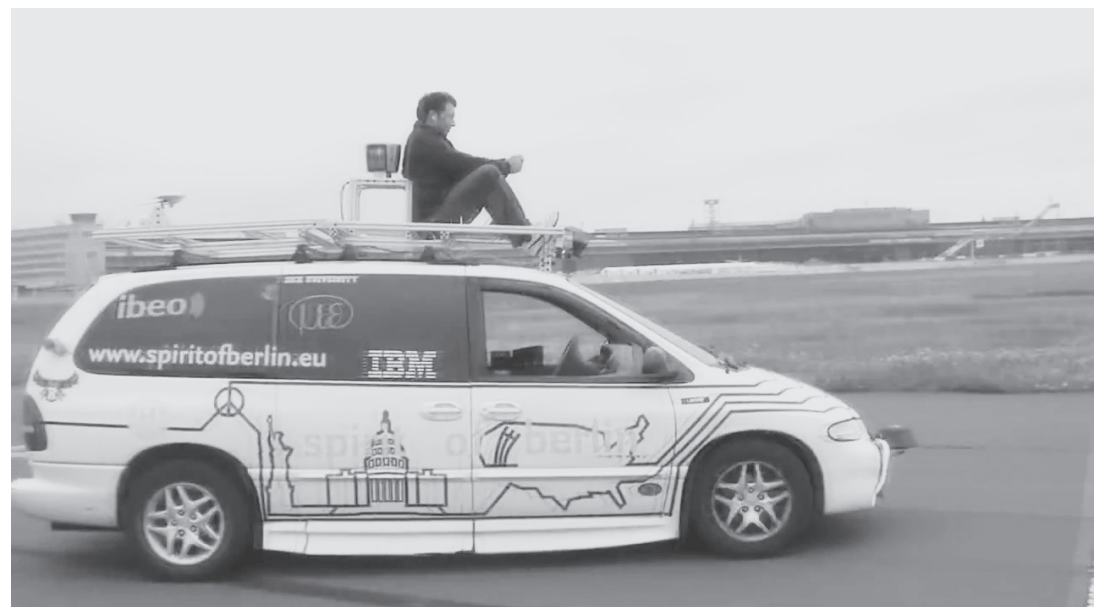

Image 15: Still from the video demo "iDriver - iPhone remote controlled car"

The idea was inspired by the James Bond movie Tomorrow never dies (Spottiswoode 1997). In this movie the hero controls his car remotely via an early smartphone.

Trying to ride the wave, the project continued along these lines using eye-tracker ${ }^{60}$ and a brain-computer interface ${ }^{61}$ (an EEG-headset). These video demos connect the car to off-the-shelf interfaces which have been developed elsewhere and which are meant to be used for gaming or for disabled people. In particular, the brain-interface seems to attract journalists. Although very unpractical (only one out 20 members was able navigate the car in a reliably way), it seems to inspire imaginations of the future. A regular car, like the Dodge Caravan in the video, hardly symbolizes 'the future.' But mind controlling a car has 'the future' written all over it. Rather than making the driver expendable, these demonstrations are about reconfiguring the human-car interface by enrolling sophisticated human-computer interfaces. I argue that these videos, and particularly the one involving the iDriver, can be understood as compensating for the lack of human control in the driverless car vision.

This chapter has described the contestation of autonomous driving with respect to the issues of control and 'joy of driving'. The chapter has uncovered the latent meaning that defending the status quo of automobility is 
simultaneously a defense of certain links between masculinity, driving, and cars. The iDriver and similar demos celebrate human control albeit through uncommon means. These demos link masculinity and technological skillswith a slight but crucial difference. The power of ICTs is celebrated and thus computer scientists are the heroes.

\section{"Is your project a real project?"}

Playful and entertaining demonstrations that celebrate technological mastery proved to be a successful strategy for creating awareness about the project. It succeeded in attracting journalists and potential project partners, and it significantly boosted the project's search rank. However, as Michael comments in the following interview excerpt, there is no connection between the video demo and the state of research (at that time) in autonomous driving.

So it was just the video that provoked most of the attention, it was really simply driving a car with an iPhone. Because at that time the iPhone was relatively new, and so it was when there was this iPhone hype, then all of a sudden it's like "OK, they programmed an iPhone control," and everyone who more or less has a clue about it knows: OK, so if I practically have the option to control the car by computer, then to control it with an iPhone or access the steering, accelerator, brakes, just like that, [...] but from the scientific perspective it was practically a joke. (Interview Michael 2/22/13)

Michael explains the success of the video by relating it to the hype of particular smartphones rather than to autonomous driving. Yet he is wary of misinterpretations. By watching the video, experts could construe an undesirable image of the project. Michael does not see much scientific value in the demonstration because it does not contribute to their core competencies in the field of robotics. This is not artificial intelligence, this is plain engineering. A prerequisite for autonomous vehicles is that you can control the car with a computer. Once you have a computer controlling the car you can use any kind of human-computer interface to control the car.

In this final section I will describe how the heroic and playful video demos of controlling the car through different interfaces have produced overflow. Some members respond by mobilizing basic research as 'new' frame in communicating their project.

Celebrating human control and technical mastery in video demonstrations was beneficial for the project in terms of awareness but, as Michael already hinted, it also has its downside. In the following vignette of a Monday morning 
team meeting, the project's website ${ }^{62}$ is problematized and a call for action is issued. The project has become a victim of its own ways of communicating and selling robotics.

The Monday morning meeting begins with Martin's presentation of his ongoing $\mathrm{PhD}$ thesis, which evolves into a lively discussion of different suggestions and the potentiality of different approaches with several project members. After the discussion, Thomas - who to my surprise did not engage in the previous discussion - goes to the front, followed by Tim. Thomas introduces Tim by referring to Tim's past involvement in updating the project's website. Thomas says, this is about "representing the project in an adequate way." He adds that new people have joined and that you cannot find them on the website. I think to myself, he does not mention the fact that half of the members listed on the website have already left, including one of the few female members. Thomas mentions that two years ago Stefan received an email from an international peer asking "is your project a real project?" This is because there are no publications on the website and the website has not been updated for four years. Tim puts emphasis on the fact that they are also really doing research here. Thomas and Tim ask all project members to send them short abstracts and a bibliography of their publications. Tim stresses the importance of everybody pulling together in the same direction. I am amazed by Tim's choice of words. It sounds as if he anticipates resistance or inertia. Rojas joins in and demands that the videos of their trip to and through Mexico be made available. Michael interjects that first somebody has to edit the 100 hours of video footage. Rojas complains about the music. Michael says that he really liked the music and that Rojas had asked for it. Everybody breaks out in laughter and the meeting is adjourned. (Fieldnote 08/04/14)

The project is caught between audiences with conflicting expectations. Using heroic and playful video demos to excite lay audiences has, in the past, undermined their credibility as academic roboticists. The videos and their website have led peer researchers to doubt the seriousness of their project. Their innovation communication created expectations that came back to haunt them. Thomas and Tim argue for highlighting scientific achievements that would account for the professional skepticism among roboticists towards its demo culture (Chapter 4). Thomas and Tim want to take up a frame of basic research by presenting academic publications and ongoing work, such as current $\mathrm{PhD}$ projects on the project's website.

62 This is how the website looked like before the meeting: https://web.archive.org/ web/20140529004631/http://autonomos-labs.com:80/ [Checked on 03/04/20] 
Rojas pushes for making their street trial in Mexico visible as a story on the website. The group was invited to present their car at several institutions in Mexico, including universities. This created opportunities to observe MiG's performance under Mexican conditions - both in rural and in urban environments. Rojas' suggestion narrates a heroic and bold version of the project. It positions the project as capable of constructing technology that can withstand "real world" trials. It emphasizes MiG's capacity to drive autonomously rather than the project's academic achievements.

After the update of the website, ${ }^{63}$ the video demonstrations were moved to "past projects." ${ }^{64}$ The website's menu was also re-designed. A new menu item, "Research," features ongoing work, open theses, and publications.

\section{Complimentary visions}

Autonomous driving is controversial: Will legislators and potential consumers accept it? What is the use of it? The members try to settle the controversy by visionary storytelling. Rather than promoting a single interpretation, the project embraces the multiplicity of autonomous driving both as a field of research in robotics \& AI and as an emerging technology. In this chapter, we have heard the four stories and frames through which members make sense of autonomous driving: driverless car vision, ADAS, controlling cars through different means, and basic research. The driverless car vision is an element of the grander autonomous taxi vision which has been thoroughly analyzed in Chapter 2 .

In the second version, the project is portrayed as contributing to ADAS rather than to unsupervised autonomous driving. ADAS is not a substitution for drivers, rather it is aimed at making manual driving safer and-in the case of congestion, for example - it is promised to be more comfortable. The desire for and the appeal of human control is recognized, even if only as a means for making autonomous driving less threatening and more acceptable.

The third strategy, i.e. celebrating human control through different means, neither promises assistance nor emphasizes the promised benefits of autonomous driving. This version, as I have demonstrated, draws on masculine images as a means of making the project seem exciting. The fourth versionbasic research-is a fallback strategy. It figures the project as contributing to the advancement of robotics and AI as a field of technoscientific research.

63 https://web.archive.org/web/20141209011607/http://autonomos-labs.com:80/ [Checked on $03 / 04 / 20]$

64 https://web.archive.org/web/20150207105404/http://autonomos-labs.com/projects/ past-projects/ [Checked on 03/04/20] 
If you put these different versions side-by-side, as I have in my report, it becomes clear that autonomous driving is framed and narrated as more than one thing. Its purposes and its figuration of cars and drivers/passengers are manifold. These different versions are not simply variations that relate to one another. They are complimentary, but also inconsistent, particularly in relation to the question of human control. We might take as an example the relation between the driverless car vision and the ADAS vision: if human control is seen as an obstacle for more efficient use of resources and safety, then the prospect of 'optional' autonomy undermines all these promises.

Inconsistencies between visions can be attributed to the relentless search for meaning and purpose. In this chapter, I have presented four versions, but this is not an exhaustive list. In an effort to attract funding and potential partners, the project created additional frames of autonomous driving by imagining how a driverless car could be useful for potential collaborators - for example, driverless sidewalk sweeping for Berlin's city cleaning service and a driverless surveillance vehicle to guard former Tempelhof airport (Interview Stefan 08/23/13). Multiple visions like these are not unusual, nor are they inherently malevolent. Ambivalence, as Singleton and Michael (1993) have argued, can contribute to the stabilization of networks. Brunsson (2006, xi) claims with regard to formal organizations that inconsistencies are unavoidable and they often do not pose a problem but the solution.

In the promotional materials of the project, such as the FAQ, you can find both versions - the bold vision and the modest vision - side-by-side. In this example, we can see how these two strategies and their respected visions complement each other: a bold vision of the future to inspire a technophile audience and a modest vision to appease a skeptical audience of automobilists. They can be seen as answering to contradictory demands. The bold version answers to the need for radical change in urban transport and sustainable automobility. Those who are favorable towards automatizing driving can be excited about the imagined potentials of driverless cars. The more modest version of ADAS answers to a different demand - maintaining the status quo of automobility by promising to increase safety and comfort. The playful video demonstrations seem to respond to a demand for awe-inspiring technology. The different versions allow for different resources to be allocated. $\mathrm{PhD}$ projects are funded by the automotive industry and its suppliers for ADAS, peer researchers can take the project seriously as an endeavor in basic research while journalists and laypersons can be interested by the bold vision of autonomous taxis and entertaining demonstrations of technological mastery. Depending on their audience, project members may switch colors to promote their project.

The classic promise of automatization is the liberation of humans from undesirable or dangerous work (Downey 1998). As we have seen in this 
chapter, in the case of autonomous driving this promise is rejected by some audiences. A dystopian story has emerged which associates autonomous driving with emasculation. This story links acceptability of autonomous driving with human control over cars. Manual driving of cars is highly valued by those defending the hegemonic configuration of Germany, masculinity, and technology. Only a car that can afford masculine desires is an acceptable car. The project members, with their commitment to autonomous driving, find themselves on contested ground for automatization.

This chapter has demonstrated that the project's visionary stories and video demonstrations are not isolated but rather produced in relation to other stories and expectations. Visionary stories and video demonstrations are analyzed as an effect of different tactics and strategies of innovation communication. This is why there are multiple stories and demos of the project. The different versions are not free-floating. They have different degrees of substance as they depend on what project members can make the car do or what members can imply by hiding certain aspects. ${ }^{65}$

In defense of their project and research area, hopeful narratives are crafted. People living in cities are promised emancipation from the regime of automobility: Everybody will become privileged! Or, the dystopian narrative of emasculation is called into question by positioning autonomous driving as an optional feature. In addition, the group produces alternative configurations of drivers, cars and ICTs in the shape of heroic video demonstrations. These can be read as a form of compensation for the lack of human control in the driverless car vision. In these video demos, the figure of the driver is reinstated-not in its original form, with him/her on the steering wheel, but mediated through information technology. These video demos celebrate human control through unusual interfaces, although not without side-effects. Prioritizing excitement and visual effect over academic performance can have negative repercussions for the project's scientific credibility among peer researchers. In order to counter these challenges a narrative of basic research is also mobilized.

65 See Chapter 5 for a discussion of how the safety driver hides in the car or how a visualization of a drive, rather than of the driving car, is depicted. 



\section{Conclusion}

\section{Care}

This study engages with the phenomenon of autonomous driving. It seeks to contribute to the recent interest in applying care as an analytical lens to the social studies of technology (Both and Cohn 2017; Cohn 2013; Denis and Pontille 2015; Mol et al. 2010; Singleton 2010). It takes the vulnerability and fragility of the visions and demonstrators as a point of departure. The study describes and analyzes the various ways of sustaining autonomous driving symbolically and materially within a university research project. It demonstrates that by maintaining the project - a sociotechnical assemblage of roboticists, visionary stories, and technological artifacts - its members perform specific connections between technology and masculinity.

The study has investigated autonomous driving by engaging in ethnographic fieldwork among the research project AutoNOMOS at the Institute of Computer Science at FU Berlin between June 2012 and November 2015. The window study (Czarniawska 1997, p. 65) scrutinizes autonomous driving by following a robotics project, which started in 2006. Market-oriented funding by Germany's Federal Ministry of Education and Research allowed the AutoNOMOS project to advance from 'driving around in circles' on enclosed training grounds to street trials in Berlin's city traffic. The time window was opened by the ethnographer after the funding from the ministry had ceased. In this time period, the practitioners struggled to sustain symbolically and materially the demonstrator $\mathrm{MiG}$, which serves not only as the project's research instrument, but also its vision of driverless cars, which is embedded in its vision of autonomous driving. The demonstrators need maintenance, but the human members have needs, too. Grant applications had been turned down. With few funded positions left, many members abandoned the project to take up lucrative jobs in the industry. At the same time the project seemed active and thriving from the outside. The project had more interview and technology demonstrations requests from journalists then the members could fulfill. Public interest in autonomous driving really took off during that time. This created a paradoxical situation: While the project was struggling to continue, it seemed active and thriving from the outside.

Members of the AutoNOMOS project have subscribed themselves to tackling a complex and "new challenge" (chapter 2). To automate driving in the "real world"- as roboticists say-is different from doing robotics within enclosed and highly controllable environments. Nevertheless, the projects' 
approach relies on the "basic robotic paradigm" (Wang 2012, p. 21) which presumes that a robot can model its environment based on sensor data. The bold promises of AI and robotics claim that all human capabilities may be substituted by ICTs. Yet, MiG's sensors do not 'sense' in human-like ways. Cameras do not 'see' in a human-like fashion. All these common anthropomorphic metaphors misconstrue the actual capacities of sensors. Rather, the sensors and cameras are the 'eyes' and 'ears' of the computer scientists, who strive to make the most of MiG's actual capacities. The resources researchers have at their disposal are quite limited; for example, laser scanners can only determine the relative position of objects in the vicinity of the vehicle and at a certain point in time. The limited affordances of the ICTs influence the ways in which members approach driving in traffic. Their approach places trust on the belief that driving can be formalized and compartmentalized into distinct scenarios and rules. The imaginary realized in the configuration of MiG is mechanistic. It seeks to control urban traffic by rendering it meaningful as a collection of isolated, rule-abiding, moving "obstacles" (Chapter 3) localized on a map of the road infrastructure.

During street trials, uncertainty and ambiguity is produced by traffic, weather conditions, and unreliable technical components. The safety drivers perform a specific type of care. They take care of an assemblage, which is individualized into an agent. In diagnosis, project members try to construct a coherent narrative that explains MiG's behavior. MiG becomes a characterwith a masculine pronoun "he".

For the Safety drivers, who operate and monitor MiG carefully, control is always precarious. The demonstrator's capacities to master autonomous driving can be exceeded within "interesting situations" (chapter 3). Safety drivers skillfully remedy MiG's deficiencies and irregularities. Safety driver interventions are not only a normal part of street trials, but they are really the 'tip of the iceberg'. The stressful part of being a safety driver is revealed in their stories; safety drivers continuously anticipate potential traffic situations that could evolve into an accident. They perform the invisible but necessary work of temporarily stabilizing the assemblage in an environment, which they cannot control. Care is necessary in order to make MiG's imaginary of control work.

Street trials are sustained through the safety driver's care of and intimacy with the research vehicle. Safety drivers are enmeshed with the assemblage in an affective bond. They are responsive by exercising perspective-taking. Safety drivers must reconcile the tensions between MiG's idiosyncratic way of 'understanding' and responding to the ever-evolving surrounding traffic. Developing a 'feel' for MiG's behavior patterns is calming for safety drivers, but it may also lead to carelessness. Safety drivers say that they ought to 
maintain a certain level of alertness and suspicion in order to stay responsive. To be able to care they must control themselves. This tension is complicated by the conditions of street trials. In street trials, safety drivers have no control over how other traffic participants will react to MiG's behavior. MiG may also respond to literally anything and anyone in its sensor range in an idiosyncratic way. In order to care for $\mathrm{MiG}$ and anyone in its environment, safety driver may always resume manual control of the research vehicle. This creates an irreconcilable tension that safety drivers have to live with. If they care too much, MiG cannot control itself and they cannot evaluate and improve its performance. If safety drivers care too little, they might lose control of the assemblage. Control and care are linked in street trials.

It might be tempting to conclude that the roboticists' ideal of autonomy is not realized in street trials. Roboticist Wang acknowledges that autonomous vehicles are not autonomous because they rely on "external inputs" (2012, p. 18). Yet, this line of argument would presume that autonomy can be a discreet property of system (Bradshaw et al. 2013, pp. 2-8). No being-human or otherwise - is simply autonomous. Autonomous agency is not contained in individuals or machines (Suchman 2007, p. 213). Rather, MiG exhibits agency not despite its lack of autonomy but because it is supported by a network of humans and nonhumans.

I find it generative to ask whether this is actually driving and not something else. Computational enhanced automobiles certainly appear to drive within traffic, but their movements are "merely agented-responsive to conditions to satisfy goals" (Brown and Laurier 2017, p. 422). Being transported by MiG feels less like riding in a car and more like riding a tram with invisible tracks. There are elements of driving, such as embodied communication between road users, that escape the androcentric imaginary realized in the configuration of MiG. Driving in traffic is an ongoing sociomaterial accomplishment; for example, road users coordinate each other's actions reciprocally (Juhlin 2010, p. 53-54). Responsible human drivers are "responsive to a background knowledge of what maneuvers are thoughtless, polite, safe in traffic" (Brown and Laurier 2017, p. 422). Coordination is a local, situated activity (Juhlin 2010, p. 53-54). This is in opposition to how the assemblage performs 'driving' and how traffic registers from its 'point of view'. For example, MiG's maps prescribe a stable backdrop for its behavior when encountering other road users. MiG's access to the contingencies of unfolding traffic situations is limited.

Critical computer scientist Agre (1997, pp. 27-48) argues that AI concepts and tools are figurative rather than descriptive. Early AI scientist McDermott (1976) argues in a similar vein that robotics and AI suffer from the malpractice of "wishful mnemonics". For example, to attribute 'understanding' to a piece of software tells more about the aspiration of its programmer than the actual 
capabilities of the program. This view suggests that autonomous driving is a metaphor, and specifically one, which serves to conceal that ICTs do not fully substitute for drivers.

\section{Masculinity}

Feminist scholars have criticized classic studies of actor networks for their lack of attention to gender and for celebrating heroic innovators (Star 1991; Haraway 1997; Wajcman 2004; Clarke 2005). Other feminist researchers promote ANT as a useful tool to avoid the reification of gender (Omrod 1995; Lagesen 2012). ANT suggests to follow the actors and describe how they assemble their networks. But what if the actors we follow claim that their network is gender neutral (see Paulitz et al. 2016)? During my fieldwork gender relations were hardly a topic of conversation. The core team was all men, but its lack of diversity was never problematized in my presence. This posed a methodological challenge: How can I describe relations of gender and technology without forcing my own categories upon the research material? My strategy was to closely examine acts of positioning in project member's self-narratives and their efforts to defend autonomous driving against automobilists.

The project's vision of autonomous taxis calls for an abandonment of what many drivers in Germany hold dear: Owning your car and driving it yourself. This creates a controversy where the potential acceptance of autonomous driving is at stake. Driverless cars appear to automobilists as completely senseless at best and as a dystopian, emasculating nightmare at worst. Project members respond to these challenges by e.g. drawing on class distinction rather than masculinity. Being chauffeured is associated with freedom and privilege, whereas manual driving is figured as a nerve-wrecking waste of time.

In assembling gender, the computationally enhanced car plays an ambivalent role. By bonding with a computationally enhanced automobile, project members articulate the world from the position of a driver. Being associated with an automobile creates tensions and uncertainties for the roboticists. Cars and their meanings are an ambivalent cultural resource for project members. $\mathrm{MiG}$ is unlike the humanoid robots they used to work with. Due to regulations and safety requirements, the computationally enhanced automobile cannot afford the same level of intimacy. To stabilize their identities as roboticists, project members tend to distance themselves from car modifiers, and car mechanics. By rejecting these available subject positions, project members separate themselves from the profane. As visionaries (Law 1994, pp. 79-80), roboticists aim for the ultimate goal - making drivers expendable by mastering driving through ICTs. 
By analyzing the talk-in-interaction during my fieldwork, I found that the symbolic link between masculinity and technological competence is iterated not despite but through denying expertise over cars. The subject position of the roboticist is constructed as a master of robots in general - not automobiles. The roboticist allows for a dismissal of the assumed masculine working-class affinity to cars as his/her interest in cars is mainly that $\mathrm{s} /$ he can control it through software.

The subject position of the roboticist is often emplotted in a heroic narrative. Performing in-what roboticists call-the "real world" is what counts and serves as a means of distinction from other computer scientists. The "real" serves as a code for masculinity in the project. Frontier narratives turn the mundane practice of street trials into a heroic proving ground, which is described as the "supreme discipline" (Chapter 4) of autonomous driving. Projects compete over who can first demonstrate certain capabilities and functionalities that have been deemed relevant for the realization of autonomous driving. To make a computational enhanced automobile withstand trials outside the lab or computer simulations is to prove oneself in the male-centered community. According to members' own codes of masculinity, research vehicles are not only demonstrators by which approaches from AI and robotics are tested, evaluated, and improved; in this homosocial association of male computer scientists, the research vehicle is also an instrument to test and measure masculinity. Research in autonomous driving creates a "playing field" (Chapter 4) in which conjunction and distinction among men is accomplished. Women are almost entirely physically absent; femininity as such is symbolically absent.

\section{Narrative}

Safety driver's practices and narratives of care co-exist with practices of visionary communication and narratives of mastery. Care is always relational, but so are narratives, stories, promises, and visions. They are the product of a relationship between roboticists and their audiences. Roboticists are spokespersons of yet-unrealized artifacts and systems (see Woolgar 1985, p. 566). Roboticists depend on storytelling to make their envisioned creations useful, meaningful, acceptable, desirable, and potentially feasible. Emerging technologies are characterized by a discrepancy between technology demonstrations, e.g. "proof of concept" or a physical demonstrator, and the envisioned working systems, such as a driverless car or a public transportation system of autonomous taxis. This gap is typically filled with promises and speculation (Stilgoe 2018, p. 33). 
Video demos are a medium in which visions can be narrated as if they were already realized. In these video demos, the enchantment of autonomous driving is achieved through "cutting the network" (Suchman 2007, p. 283). Video demos stage research vehicles as autonomous by masking the networks of humans and nonhumans of which they are necessarily a part. Video demos are performative, for "the videos create a record that can be reliably repeated and reviewed in what becomes a form of eternal ethnographic present" (Suchman 2008, p. 148). These videos imply that what might have only worked once will work anytime, anywhere, and without the implicated networks of human and nonhuman actants. Video demos play a significant role in sustaining the promises of AI and robotics (Suchman 2011). These videos seem to provide visual proof of the ongoing existence of autonomous robots and of the feasibility of the imagined futures.

Visionary storytelling is not performed in a vacuum. In their quest for autonomous driving, members rely on available standardized technical components and established approaches to robotics, but they also recycle and reconfigure available plots and frames of meaning which are reconfigured in relation to specific audiences and in relation to competing frames and plots. Members tell complimentary visionary stories in order to immunize the promises against dissenters and to excite audiences about these visions. For example, members can appease automobilists by narrating autonomous driving as an incremental improvement of today's automobility. Rather than taking the driver out of the control loop of the automobile, members promise that it will be up to the driver to decide whether the car is driven manually or autonomously.

The roboticists in my study are skilled and versatile story-tellers. Project members have adjusted to the demand for expectation making and visionary storytelling. They might disagree over how the project should present itself (Chapter 6); to "play the drums" (Interview Rojas 07/13/15), however, is viewed as an undisputed necessity. The project relies on third-party funding to continue. Project members place hope on innovation communication to increase their chances for further funding and to influence regulators in favor of autonomous driving. The production of narratives is a crucial element of technological research practices. Innovation communication is not what comes 'after' technological research but is rather integral to the very processes of innovation (Horst et al. 2017, pp. 892-893).

There are ongoing conversations, within the humanities and social sciences, about material relations and material agency (Barad 2007; Ernst et al. 2017; Palm et al. 2018). These conversations are often labeled as New Materialism. It might be surprising that this study, which is based on fieldwork among men, cars, and computers, argues for the centrality of promises and storytelling in 
autonomous driving. The fact that this study draws on more 'traditional' conversations, such as actor-network-theory (Mol 2010; Law 2009) and narrative analysis (Czarniawska 1997, 2004, 2008, 2014), should not be understood as a dismissal of New Materialism. In fact, the study shares with New Materialism an emphasis on and advocacy of posthumanist approaches. Nevertheless, I argue that nonhuman agency is not always the missing ingredient in the stories we tell about our objects of study. In some cases, one's research topic may not be illuminated by putting emphasis on material agency. In regimes of research and innovation 'the technical' is centered, "whereas 'the social' is separated out and relegated to the margins." (Suchman 2007, pp. 269-270) To accomplish adequacy (Strübing et al. 2018, p. 86) with regard to autonomous driving, it is vital to strategically decenter nonhuman agency. To do otherwise risks reproducing uncritically the dominant rhetoric of autonomous driving. 



\section{References}

Adam, Alison (2003): Hacking into Hacking: Gender and the Hacker Phenomenon. In ACM SIGCAS Computers and Society 33 (4), p. 3. DOI: 10.1145/968358.968360.

Agre, Philip (1997): Computation and Human Experience. Cambridge: Cambridge University Press (Learning in Doing).

Akrich, Madeleine (1992): The De-Scription of Technical Objects. In Wiebe E. Bijker, John Law (Eds.): Shaping Technology, Building Society: Studies in sociotechnical Change. Cambridge, MA: MIT Press (Inside Technology).

Alex, Ralph; Katemann, Jens (2013): Elfer allein reicht Porsche nicht: PorscheChef Matthias Müller im Interview. In auto motor und sport (8). Available online at http://www.auto-motor-und-sport.de/news/porsche-chef-matthias-mueller-im-interview-elfer-allein-reicht-porsche-nicht-6871945.html, checked on $02 / 10 / 2020$.

Balkmar, Dag (2012): On Men and Cars: An Ethnographic Study of Gendered, Risky and Dangerous Relations. Linköping: Linköpings universitet, Institutionen för Tema (Linköping Studies in Arts and Science, 558). Available online at http://www.diva-portal.org/smash/get/diva2:552946/ FULLTEXT01.pdf, checked on 02/10/2020.

Balkmar, Dag; Joelsson, Tanja (2012): Feeling the Speed: The Social and Emotional Investments in Dangerous Road Practices. In Maria Jansdotter Samuelsson, Clary Krekula, Magnus Åberg (Eds.): Gender and Change: Power, Politics and Everyday Practices. Karlstad: Karlstad University Press, pp. 37-52.

Balkmar, Dag; Mellström, Ulf (2018): Masculinity and Autonomous Vehicles: A Degendered or Resegregated Future System of Automobility? In Transfers 8 (1), pp. 44-63. DOI: 10.3167/TRANS.2018.080105.

Barad, Karen (2007): Meeting the Universe Halfway: Quantum Physics and the Entanglement of Matter and Meaning. Durham: Duke Univ. Press.

Bean, Jonathan; Rosner, Daniela (2013): Demo or Die? The Role of Video Demonstrations in the Public Domain. In interactions 20 (5), pp. 80-81. DOI: $10.1145 / 2500502$.

Berg, Anne-Jorunn; Lie, Merete (1995): Feminism and Constructivism: Do Artifacts Have Gender? In Science, Technology, \& Human Values 20 (3), pp. 332-351. DOI: 10.1177/016224399502000304.

Berger, Peter L.; Luckmann, Thomas (1991 [1966]): The Social Construction of Reality: A Treatise in the Sociology of Knowledge. London: Penguin.

Berscheid, Anna-Lena (2014): Autonome Fahrzeuge und hegemoniale Männlichkeit in der Automobilkultur. In Femina Politica 23 (2), pp. 22-34. 
Best, Amy L. (2006): Fast Cars, Cool Rides: The Accelerating World of Youth and their Cars. New York: New York University Press.

Bijker, Wiebe E.; Law, John (1992): General Introduction. In Wiebe E. Bijker, John Law (Eds.): Shaping Technology, Building Society: Studies in Sociotechnical Change. Cambridge, MA: MIT Press (Inside Technology).

Bischof, Andreas (2017): Soziale Maschinen bauen: Epistemische Praktiken der Sozialrobotik. Bielefeld: Transcipt Verlag (Science Studies).

Bissell, David; Birtchnell, Thomas; Elliott, Anthony; Hsu, Eric L. (2018): Autonomous Automobilities: The Social Impacts of Driverless Vehicles. In Current Sociology 3 (11), pp. 1-19. DOI: 10.1177/0011392118816743.

Bochmann, Annett; Negnal, Dörte; Scheffer, Thomas (2019): Politische Ethnographie: Beitrag zur Ad-Hoc-Gruppe "Politische Ethnographie". In Nicole Burzan (Ed.): Komplexe Dynamiken globaler und lokaler Entwicklungen: Verhandlungen des 39. Kongresses der Deutschen Gesellschaft für Soziologie in Göttingen 2018. 39 volumes, pp. 1-4. Available online at http://publikationen.soziologie.de/index.php/kongressband_2018/article/ view/986/1232, checked on 01/24/2020.

Böhm, Steffen; Jones, Campbell; Land, Chris; Paterson, Mat (2006): Introduction. Impossibilities of Automobility. In The Sociological Review 54 (s1), pp. 3-16. DOI: 10.1111/j.1467-954X.2006.00634.x.

Borup, Mads; Brown, Nik; Konrad, Kornelia; van Lente, Harro (2006): The Sociology of Expectations in Science and Technology. In Technology Analysis \& Strategic Management 18 (3-4), pp. 285-298.

Both, Göde (2015): Youtubization of Research: Enacting the High Tech Cowboy through Video Demonstrations. In Sarah R. Davies, Maja Horst: Studying Science Communication: A panel of the EASST2014 Conference (September 17-19 ${ }^{\text {th }}, 2014$, Torun, Poland). Edited by Erik Stengler. Bristol: Science Communication Unit, University of the West of England, pp. 24-27. Available online at https://uwe-repository.worktribe.com/OutputFile/828482, checked on 01/24/2020.

Both, Göde (2017): Accomplishing Autonomous Driving: An Unfinished Description. In Julie Mewes, Estrid Sørensen (Eds.): Ethnographies of Objects in Science and Technology Studies: Bochum, pp. 29-35. DOI: 10.13154/eoo.1.2017.29-35.

Both, Göde; Cohn, Marisa Leavitt (2017): Maintaining Technological Worlds: Care and its Ambivalences. In EASST Review 36 (1), pp. 54-58. Available online at: https://easst.net/article/maintaining-technological-worlds-careand-its-ambivalences/, checked on 01/24/2020.

Both, Göde; Weber, Jutta (2014): Hands-free driving? Automatisiertes Fahren und Mensch-Maschine Interaktion. In Eric Hilgendorf (Ed.): Robotik im Kontext von Recht und Moral. Baden-Baden: Nomos, pp. 171-188. 
Boytchev, Hristio (2014): Informatiker Raúl Rojas im Porträt. Eine kommunistische Utopie des Stadtverkehrs. In Der Tagesspiegel, 11/12/2014. Available online at: https://www.tagesspiegel.de/wissen/informatiker-ral-rojas-importraet-eine-kommunistische-utopie-des-stadtverkehrs/10965596-all. html, checked on 2/12/2020.

Bradshaw, J. M.; Hoffman, R. R.; Johnson, M.; Woods, D. D. (2013): The Seven Deadly Myths of "Autonomous Systems". In IEEE Intell. Syst. 28 (3), pp. 2-9. DOI: 10.1109/MIS.2013.70.

Braun-Thürmann, Holger (2002): Künstliche Interaktion: Wie Technik zur Teilnehmerin sozialer Wirklichkeit wird. Wiesbaden: Westdeutscher Verlag.

Bray, Francesca (2007): Gender and Technology. In Annu. Rev. Anthropol. 36 (1), pp. 37-53. DOI: 10.1146/annurev.anthro.36.081406.094328.

Breidenstein, Georg; Hirschauer, Stefan; Kalthoff, Herbert; Nieswand, Boris (2013): Ethnografie: Die Praxis der Feldforschung. Konstanz, München: UVK (UTB: Sozialwissenschaften, Kulturwissenschaften, 3979).

Broggi, Alberto; Zelinsky, Alexander; Özgüner, Ümit; Laugier, Christian (2016): Intelligent Vehicles. In Bruno Siciliano, Oussama Khatib (Eds.): Springer Handbook of Robotics. $2^{\text {nd }}$ edition. Berlin, Heidelberg: Springer, pp. 1627-1655.

Brown, Barry; Laurier, Eric (2017): The Trouble with Autopilots: Assisted and Autonomous Driving on the Social Road. In Gloria Mark, Susan Fussell, Cliff Lampe, m.c schraefel, Juan Pablo Hourcade, Caroline Appert, Daniel Wigdor (Eds.): CHI'17. Proceedings of the 2017 ACM SIGCHI Conference on Human Factors in Computing Systems, May 6-11, 2017, Denver, CO, USA. the 2017 CHI Conference. Denver, Colorado, USA, 6/5/2017-11/5/2017. Association for Computing Machinery; CHI 2017; Annual CHI Conference on Human Factors in Computing Systems. New York, NY: ACM, pp. 416-429.

Brunsson, Nils (2006): The Organization of Hypocrisy: Talk, Decisions and Actions in Organizations. $2^{\text {nd }}$ edition. Copenhagen: Business School Press. Bundesministerium für Bildung und Forschung (8/15/2012): Mobil bleiben im Alter. 100/2012. Berlin, Hannoversche Straße 28-30, 10115 Berlin. Available online at https://www.unternehmen-region.de/_media/PM BMBF_Sommerreise_AutoNOMOS.pdf, checked on 11/14/2018.

Büscher, Monika; Coulton, Paul; Efstratiou, Christos; Gellersen, Hans; Hemment, Drew (2012): Connected, Computed, Collective: Smart Mobilities. In Margaret Grieco, John Urry (Eds.): Mobilities: New Perspectives on Transport and Society. Farnham, England, Burlington, VT: Ashgate.

Callon, Michel (1986): Some Elements of a Sociology of Translation: Domestication of the Scallops and the Fishermen of St Brieuc Bay. In John Law 
(Ed.): Power, Action and Belief: A New Sociology of Knowledge? London: Rouledge, pp. 196-223.

Callon, Michel; Lascoumes, Pierre; Barthe, Yannick (2009): Acting in an Uncertain World: An Essay on Technical Democracy. Cambridge Mass.: MIT Press (Inside Technology).

Callon, Michel; Law, John (1997): After the Individual in Society: Lessons on Collectivity from Science, Technology and Society. In Canadian Journal of Sociology / Cahiers canadiens de sociologie 22 (2), pp. 165-182. DOI: $10.2307 / 3341747$.

Calvert, Jane (2006): What's Special about Basic Research? In Science, Technology \& Human Values 31 (2), pp. 199-220. DOI: 10.1177/0162243905283642. Clarke, Adele E. (2005): Situational Analysis: Grounded Theory after the Postmodern Turn. Thousand Oaks: SAGE Publications.

Campbell, Joseph (2004 [1949]): The Hero with a Thousand Faces. Commemorative Edition. Princeton, Oxford: Princeton University Press.

Carlson, W. Bernard (1992): Artifacts and Frames of Meaning. Thomas A. Edison, His Managers, and the Cultural Construction of Motion Pictures. In Wiebe E. Bijker, John Law (Eds.): Shaping Technology, Building Society: Studies in Sociotechnical change. Cambridge, MA: MIT Press (Inside Technology), pp. 175-198.

Cockburn, Cynthia (1985): Machinery of dominance: Women, men and technical know-how. London: Pluto Press.

Cockburn, Cynthia; Ormrod, Susan (1993): Gender and Technology in the Making. London: SAGE.

Cohn, Marisa Leavitt (2013): Lifetimes and Legacies: Temporalities of Sociotechnical Change in a Long-Lived System. Ph.D. Dissertation. University of California, Irvine. Available online at: https://search.proquest.com/ docview/1469746267, checked 2/12/2020.

Collins, H. M. (1995): Science Studies and Machine Intelligence. In Sheila Jasanoff, Gerald E. Markle, James C. Peterson, Trevor J. Pinch (Eds.): Handbook of Science and Technology Studies. $2^{\text {nd }}$ edition. Thousand Oaks: SAGE, pp. 286-301.

Collins, Harry (1990): Artificial Experts: Social Knowledge and Intelligent Machines. Cambridge: MIT Press (Inside Technology).

Czarniawska, Barbara (1997): Narrating the Organization: Dramas of Institutional Identity. Chicago: Univ. of Chicago Press (New Practices of Inquiry).

Czarniawska, Barbara (2004): Narratives in Social Science Research. London: SAGE Publications (Introducing Qualitative Methods Series).

Czarniawska, Barbara (2005): Karl Weick: Concepts, Style and Reflection. In The Sociological Review 53 (s1), pp. 267-278. DOI: 10.1111/j.1467-954X.2005.00554.x. 
Czarniawska, Barbara (2008): A Theory of Organizing. Cheltenham: Elgar.

Czarniawska, Barbara (2014): Social Science Research: From Field to Desk. Los Angeles: SAGE.

Czerwionka, Paul; Wang, Miao; Wiesel, Fabian (2011): Optimized Route Network Graph as Map Reference for Autonomous Cars Operating on German Autobahn. In IEEE (Ed.): The $5^{\text {th }}$ International Conference on Automation, Robotics and Applications. ICARA 2011. Wellington, New Zealand, December 6-8, 2011, pp. 78-83.

Dant, Tim (2004): The Driver-Car. In Theory, Culture \& Society 21 (4-5), pp. 61-79.

Davies, Brownyn; Harré, Rom (1990): Positioning: The Discursive Production of Selves. In Journal for the Theory of Social Behaviour 20 (1), pp. 43-63. DOI: 10.1111/j.1468-5914.1990.tb00174.x.

Davies, Sarah R.; Horst, Maja (2016): Science Communication: Culture, Identity and Citizenship. London: Palgrave Macmillan UK.

Degele, Nina (2002): Einführung in die Techniksoziologie. München: Fink (UTB für Wissenschaft Soziologie, 2288).

Dellwing, Michael; Prus, Robert (2012): Einführung in die interaktionistische Ethnografie: Soziologie im Außendienst. Wiesbaden: Springer VS.

Denis, Jérôme; Pontille, David (2015): Material Ordering and the Care of Things. In Science, Technology, \& Human Values 40 (3), pp. 338-367. DOI: $10.1177 / 0162243914553129$.

Deuten, J. Jasper; Rip, Arie (2000): Narrative Infrastructure in Product Creation Processes. In Organization 7 (1), pp. 69-93.

Downey, Gary Lee (1998): The Machine in Me: An Anthropologist Sits among Computer Engineers. New York, London: Routledge.

Edensor, Tim (2004): Automobility and National Identity: Representation, Geography and Driving Practice. In Theory, Culture \& Society 21 (4-5), pp. 101-120. DOI: 10.1177/0263276404046063.

Edwards, Paul N. (1996): The Closed World: Computers and the Politics of Discourse in Cold War America. Cambridge: MIT Press (Inside Technology). Elish, Madeleine Claire (2011): Responsible Storytelling: Communicating Research in Video Demos. In ACM (Ed.): Proceedings. 5 $^{\text {th }}$ International Conference on Tangible, Embedded, and Embodied Interaction. Funchal, Portugal, January 22-26, 2011, pp. 25-28. DOI: 10.1145/1935701.1935707.

Emerson, Robert M.; Fretz, Rachel I.; Shaw, Linda L. (2011): Writing Ethnographic Fieldnotes, Second Edition. $2^{\text {nd }}$ revised edition. Chicago: University of Chicago Press.

Ernst, Waltraud; Bath, Corinna; Vehviläinen, Marja (2017): Political Objects: Prescriptions, Injustices and Promises of Material Agents. Guest editorial. In International Journal of Gender, Science and Technology 9 (2), 
pp. 76-79. Available online at http://genderandset.open.ac.uk/index.php/ genderandset/article/download/546/854, checked on 3/22/2019.

Götz, Eva-Maria; Roehl, Michael (2015): Die Autobahn wird zur Teststrecke für selbststeuernde Fahrzeuge (Länderzeit). Deutschlandfunk, 5/27/2015. Falkner, Markus (2012): FU testet fahrerloses Auto im Berliner Straßenverkehr.

In Berliner Morgenpost, 8/15/2012. Available online at https://www.morgenpost.de/web-wissen/article108641589, checked 2/12/2020.

Faulkner, Wendy (2001): The Technology Question in Feminism: A View from

Feminist Technology Studies. In Women's Studies International Forum 24 (1), pp. 79-95.

Faulkner, Wendy (2009a): Doing Gender in Engineering Workplace Cultures:

I. Observations from the Field. In Engineering Studies 1 (1), pp. 3-18. DOI: 10.1080/19378620902721322.

Faulkner, Wendy (2009b): Doing Gender in Engineering Workplace Cultures: II. Gender In/Authenticity and the In/Visibility Paradox. In Engineering Studies 1 (3), pp. 169-189. DOI: 10.1080/19378620903225059.

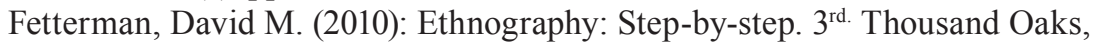
New Delhi, London: SAGE Publications.

Forsythe, Diana E. (2001): Studying Those Who Study Us: An Anthropologist in the World of Artificial Intelligence. Stanford: Stanford University Press. Fraedrich, Eva; Lenz, Barbara (2016): Societal and Individual Acceptance of Autonomous Driving. In Markus Maurer, J. Christian Gerdes, Barbara Lenz, Hermann Winner (Eds.): Autonomous Driving: Technical, Legal and Social Aspects. Berlin, Heidelberg: Springer Open, pp. 621-640.

Freie Universität Berlin (9/13/2011): Freie Universität Berlin präsentiert autonomes Auto im Berliner Stadtverkehr: Einladung zur Pressekonferenz am 16. September und zur Erprobungsfahrt am 17. September. Berlin. Carsten Wette, Pressestelle der Freien Universität Berlin. Available online at https://idw-online.de/en/news440476, checked on 11/14/2018.

Fujimura, Joan H. (1987): Constructing 'Do-able' Problems in Cancer Research: Articulating Alignment. In Social Studies of Science 17 (2), pp. 257-293.

Gad, Christopher; Bruun Jensen, Casper (2010): On the Consequences of PostANT. In Science, Technology, \& Human Values 35 (1), pp. 55-80. DOI: 10.1177/0162243908329567.

Gasser, Tom M.; Arzt, Clemens; Ayoubi, Mihiar; Bartels, Arne; Bürkle, Lutz; Eier, Jana et al. (2012): Rechtsfolgen zunehmender Fahrzeugautomatisierung. Gemeinsamer Schlussbericht der Projektgruppe. Edited by Bundesanstalt für Straßenwesen. Bergisch Gladbach (Berichte der Bundesanstalt für Strassenwesen. F, Fahrzeugtechnik, F 83). Available online at http:// bast.opus.hbz-nrw.de/volltexte/2012/587/pdf/F83.pdf, checked on 1/28/2020. 
Gay y Blasco, Paloma; Wardle, Huon (2007): How to Read Ethnography. London: Routledge.

Gobo, Giampietro (2008): Doing Ethnography. London: SAGE.

Göhring, Daniel; Wang, Miao; Schnurmacher, Michael; Ganjineh, Tinosch (2011): Radar/Lidar Sensor Fusion for Car-Following on Highways. In IEEE (Ed.): The $5^{\text {th }}$ International Conference on Automation, Robotics and Applications. ICARA 2011. Wellington, New Zealand, December 6-8, 2011, pp. 407-412.

Götsch, Monika (2014): Bilder von Informatik und Geschlecht. In Anja Zeising, Claude Draude, Heidi Schelhowe, Susanne Maaß (Eds.): Vielfalt der Informatik: Ein Beitrag zu Selbstverständnis und Außenwirkung. Bremen: Staats- und Universitätsbibliothek Bremen, pp. 79-92. Available online at http://nbn-resolving.de/urn:nbn:de:gbv:46-00104194-14, checked on $3 / 21 / 2019$.

Hammersley, Martyn; Atkinson, Paul (2007): Ethnography: Principles in Practice. $3^{\text {rd }}$ ed. London: Routledge.

Haraway, Donna Jeanne (1988): Situated Knowledges: The Science Question in Feminism and the Privilege of Partial Perspective. In Feminist Studies 14 (3), pp. 575-599.

Haraway, Donna Jeanne (1997): Modest_Witness@Second_Millennium. FemaleMan_Meets_OncoMouse ${ }^{\mathrm{TM}}$ : Feminism and Technoscience. New York, NY: Routledge.

Häußling, Roger (2014): Techniksoziologie. $1^{\text {st }}$ Edition. Baden-Baden, Stuttgart: Nomos; UTB (4184).

Helfferich, Cornelia (2011): Die Qualität qualitativer Daten: Manual für die Durchführung qualitativer Interviews. 4. Auflage. Wiesbaden: VS Verlag für Sozialwissenschaften/ Springer Fachmedien Wiesbaden GmbH Wiesbaden. DOI: 10.1007/978-3-531-92076-4.

Helmreich, Stefan (1998): Silicon Second Nature. Culturing Artificial Life in a Digital World. Berkeley: University of California Press.

Hersch, Rush (1997): FAQs about FAQs. Edited by FAQS.ORG. Available online at http://www.faqs.org/faqs/faqs/about-faqs/, checked on 11/13/2018.

Hiepe, Hans-Peter (2007): Bekanntmachung. Edited by Federal Ministry for Education and Research. Berlin. Available online at https://www.bmbf.de/ foerderungen/bekanntmachung-268.html, checked on 1/10/2019.

Holth, Line (2014): Passionate Men and Rational Women: Gender Contradictions in Engineering. In NORMA: Nordic Journal for Masculinity Studies 9 (2), pp. 97-110. DOI: 10.1080/18902138.2014.908629.

Horst, Maja (2008): The Laboratory of Public Debate: Understanding the Acceptability of Stem Cell Research. In Science and Public Policy 35 (3), pp. 197-205. 
Horst, Maja (2013): A Field of Expertise, the Organization, or Science Itself? Scientists' Perception of Representing Research in Public Communication. In Science Communication 35 (6), pp. 758-779. DOI: 10.1177/1075547013487513.

Horst, Maja; Davies, Sarah R.; Irwin, Alan (2017): Reframing Science Communication. In Ulrike Felt, Rayvon Fouché, Clark A. Miller, Laurel Smith-Doerr (Eds.): The Handbook of Science and Technology Studies. $4^{\text {th }}$ edition. Cambridge: MIT Press, pp. 881-907.

Hyysalo, Sampsa (2010): Health Technology Development and Use: From Practice-Bound Imagination to Evolving Impacts. New York, London: Routledge.

Inland Transport Committee (1968): Convention on Road Traffic. Done at Vienna on 8 November 1968. Edited by Economic Commission for Europe. United Nations. Vienna. Available online at https://www.unece.org/filead$\mathrm{min} / \mathrm{DAM} /$ trans/conventn/crt1968e.pdf, checked on 11/20/2018.

Inland Transport Committee (2014): Report of the Sixty-Eighth Session of the Working Party on Road Traffic Safety. Edited by Economic Commission for Europe. United Nations - Economic and Social Council. Geneva. Available online at https://www.unece.org/fileadmin/DAM/trans/doc/2014/wp1/ ECE-TRANS-WP1-145e.pdf, checked on 11/20/2018.

Innovationslabor AutoNOMOS (10/13/10): MadeInGermany: Autonomes Fahrzeug aus Berlin. Freie Universität Berlin zeigt am 13. Oktober die Zukunft der Mobilität. Berlin. Available online at https://www.fu-berlin.de/ presse/informationen/fup/2010/media/Infotext_MadeInGermany_131010. pdf, checked on 12/20/2019.

Jackson, Steven H. (2014): Rethinking Repair. In Tarleton Gillespie, Pablo J. Boczkowski, Kirsten A. Foot (Eds.): Media technologies: Essays on communication, materiality, and society. Cambridge, Mass.: MIT Press (Inside Technology), 221-239.

Jarzabkowski, Paula; Pinch, Trevor (2013): Sociomateriality is 'the New Black': Accomplishing Repurposing, Reinscripting and Repairing in Context.InM@n@gement 16 (5),pp.579-592. DOI: 10.3917/mana.165.0579.

Jasanoff, Sheila (2015): Future Imperfect: Science, Technology, and the Imaginations of Modernity. In Sheila Jasanoff, Sang-Hyun Kim (Eds.): Dreamscapes of Modernity: Sociotechnical Imaginaries and the Fabrication of Power. Chicago: University of Chicago Press, pp. 1-33.

Jorgensen, Danny L. (1989): Participant Observation: A Methodology for Human Studies. Newbury Park: SAGE Publications (Applied Social Research Methods Series, 15).

Juhlin, Oskar (2010): Social Media on the Road: The Future of Car Based Computing. London: Springer (Computer Supported Cooperative Work, 50). 
Kendall, Lori (2011): "White and Nerdy": Computers, Race, and the Nerd Stereotype. In The Journal of Popular Culture 44 (3), pp. 505-524. DOI: 10.1111/j.1540-5931.2011.00846.x.

Kleif, Tine; Faulkner, Wendy (2003): "I'm No Athlete [but] I Can Make This Thing Dance!': Men's Pleasures in Technology. In Science, Technology, \& Human Values 28 (2), pp. 296-325.

Kneer, Georg; Schroer, Markus; Schüttpelz, Erhard (Eds.) (2008): Bruno Latours Kollektive: Kontroversen zur Entgrenzung des Sozialen. Frankfurt am Main: Suhrkamp (Suhrkamp-Taschenbuch Wissenschaft, 1862).

Knorr-Cetina, Karin (2002): Wissenskulturen: Ein Vergleich naturwissenschaftlicher Wissensformen. Frankfurt am Main: Suhrkamp (Suhrkamp-Taschenbuch Wissenschaft, 1594).

Kohnen, Alexander (2009): So lässt sich ein Auto mit dem iPhone lenken. In DIE WELT, 10/29/2009. Available online at http://www.welt.de/5004021, checked on $03 / 27 / 19$.

Kröger, Fabian (2016): Automated Driving in Its Social, Historical and Cultural Contexts. In Markus Maurer, J. Christian Gerdes, Barbara Lenz, Hermann Winner (Eds.): Autonomous Driving. Berlin, Heidelberg: Springer Berlin Heidelberg, pp. 41-68.

Kröger, Michael (2012): Der Mensch denkt, das Auto lenkt. In SPIEGEL ONLINE. Hamburg. Available online at http://www.spiegel.de/auto/aktuell/ fu-berlin-stellt-selbstfahrendes-elektroauto-vor-a-855918.html, checked on $1 / 10 / 2019$.

Kropp, Cordula; Renn, Ortwin (2018): TechnikRadar 2018: Was die Deutschen über Technik denken. Edited by acatech, Körber-Stiftung. München, Hamburg. Available online at https://www.acatech.de/wp-content/ uploads/2018/05/Booklet-Technikradar-Einzelseiten-final-1.pdf, checked on $2 / 25 / 2019$.

Lagesen, Vivian Anette (2012): Reassembling Gender: Actor-Network Theory (ANT) and the Making of the Technology in Gender. In Soc Stud Sci 42 (3), pp. 442-448. DOI: 10.1177/0306312712437078.

Landström, Catharina (2006): A Gendered Economy of Pleasure: Representations of Cars and Humans in Motoring Magazines. In Science Studies (2), pp. 26-48.

Larson, Glen A. (1982-86): Knight Rider. NBC, 1982-86.

Latour, Bruno (1987): Science in Action: How to Follow Scientists and Engineers through Society. Cambridge: Harvard University Press.

Latour, Bruno (1993): We have never been modern. Cambridge: Harvard University Press.

Latour, Bruno (1996): Aramis or the Love of Technology. Cambridge: Harvard University Press. 
Latour, Bruno (1999): On Recalling Ant. In John Law, John Hassard (Eds.): Actor Network Theory and After, vol. 47. Oxford: Blackwell (Sociological Review Monographs), pp. 15-25.

Latour, Bruno (2005): Reassembling the Social: An Introduction to Actor-Network-Theory. Oxford, New York: Oxford University Press.

Laurier, Eric; Dant, Tim (2012): What We Do Whilst Driving: Towards the Driverless Car. In Margaret Grieco, John Urry (Eds.): Mobilities: New Perspectives on Transport and Society. Farnham, England, Burlington, VT: Ashgate, pp. 223-244.

Law, J.; Afdal, G.; Asdal, K.; Lin, W.-y.; Moser, I.; Singleton, V. (2014): Modes of Syncretism: Notes on Noncoherence. In Common Knowledge 20 (1), pp. 172-192. DOI: 10.1215/0961754X-2374817.

Law, John (1987): Technology and Heterogeneous Engineering: The Case of Portuguese Expansion. In Wiebe E. Bijker, Thomas P. Hughes, Trevor J. Pinch (Eds.): The Social Construction of Technological Systems: New Directions in the Sociology and History of Technology. Cambridge: MIT Press, pp. 111-134.

Law, John (1994): Organizing modernity. Oxford: Blackwell.

Law, John (2004): After Method: Mess in Social Science Research. London: Routledge (International Library of Sociology).

Law, John (2009): Actor Network Theory and Material Semiotics. In Bryan S. Turner (Ed.): The New Blackwell Companion to Social Theory. Chichester United Kingdom, Malden USA: Wiley-Blackwell (Blackwell Companions to Sociology), pp. 141-156.

Law, John; Bijker, Wiebe E. (1992): Postscript: Technology, Stability and Social Theory. In Wiebe E. Bijker, John Law (Eds.): Shaping Technology, Building Society: Studies in Sociotechnical change. Cambridge, MA: MIT Press (Inside Technology), pp. 290-308.

Law, John; Callon, Michel (1992): The Life and Death of an Aircraft. a Network Analysis of Technical Change. In Wiebe E. Bijker, John Law (Eds.): Shaping Technology, Building Society: Studies in Sociotechnical change. Cambridge, MA: MIT Press (Inside Technology), pp. 21-52.

Lengersdorf, Diana (2011): Arbeitsalltag ordnen: Soziale Praktiken in einer Internetagentur. Wiesbaden: VS Verlag.

Lengersdorf, Diana (2015): Ethnographische Erkenntnisstrategien zur Erforschung sozialer Praktiken. In Franka Schäfer, Anna Daniel, Frank Hillebrand (Eds.): Methoden einer Soziologie der Praxis. Bielefeld: transcript (Sozialtheorie), pp. 177-196.

Lohan, Maria; Faulkner, Wendy (2004): Masculinities and Technologies: Some Introductory Remarks. In Men and Masculinities 6 (4), pp. 319-329. DOI: $10.1177 / 1097184 X 03260956$. 
MacKenzie, Donald A.; Wajcman, Judy (1999): Introductory Essay: The Social Shaping of Technology. In Donald A. MacKenzie, Judy Wajcman (Eds.): The Social Shaping of Technology. $2^{\text {nd }}$ edition. Buckingham, Philadelphia: Open University Press, pp. 3-27.

Maibaum, Arne (2018): Innovating while Inventing. In Jannis Hergesell, Arne Maibaum, Clelia Minnetian, Ariane Sept (Eds.): Innovationsphänomene. Wiesbaden: Springer Fachmedien Wiesbaden, pp. 209-224.

Manderscheid, Katharina (2018): From the Auto-Mobile to the Driven Subject? Discursive Assertions of Mobility Futures. In Transfers 8 (1). DOI: 10.3167/TRANS.2018.080104.

Marres, Noortje (2016): What if Nothing Happens? On Street Trials as Experiments in Interpretation. publicETHOS \#11 lecture. IT University Copenhagen, 10/21/2016.

McDermott, Drew (1976): Artificial Intelligence Meets Natural Stupidity. In SIGART Bulletin (57), pp. 4-9. DOI: 10.1145/1045339.1045340.

McNeil, Maureen; Arribas-Ayllon, Michael; Haran, Joan; Mackenzie, Adrian; Tutton, Richard (2017): Conceptualizing Imaginaries of Science, Technology, and Society. In Ulrike Felt, Rayvon Fouché, Clark A. Miller, Laurel Smith-Doerr (Eds.): The Handbook of Science and Technology Studies. $4^{\text {th }}$ edition. Cambridge, Massachusetts: MIT Press, pp. 435-463.

Mellström, Ulf (1995): Engineering Lives: Technology, Time and Space in a Male-Centred World. Linköping: Linköping University (Linköping Studies in Arts and Science, 128).

Mellström, Ulf (2002): Patriarchal Machines and Masculine Embodiment. In Science, Technology, \& Human Values 27 (4), pp. 460-478. DOI: $10.1177 / 016224302236177$.

Mellström, Ulf (2003): Masculinity, Power and Technology: A Malaysian Ethnography. Hampshire, Burlington: Ashgate.

Mellström, Ulf (2004): Machines and Masculine Subjectivity: Technology as an Integral Part of Men's Life Experiences. In Men and Masculinities 6 (4), pp. 368-382.

Meuser, Michael (2007): Serious Games: Competition and the Homosocial Construction of Masculinity. In NORMA: Nordic Journal for Masculinity Studies 2 (1), pp. 38-51.

Meuser, Michael (2010): Geschlecht und Männlichkeit. Soziologische Theorie und kulturelle Deutungsmuster. $3^{\text {rd }}$ edition. Wiesbaden: VS Verlag für Sozialwissenschaften/ Springer Fachmedien.

Miller, Daniel (Ed.) (2001): Car cultures. Oxford: Berg (Materializing Culture). Mol, Annemarie (2010): Actor-Network Theory: Sensitive Terms and Enduring Tensions. In Kölner Zeitschrift für Soziologie und Sozialpsychologie. Sonderheft 50, pp. 253-269. 
Mol, Annemarie; Moser, Ingunn; Pols, Jeannette (Eds.) (2010): Care in Practice: On Tinkering in Clinics, Homes and Farms. Bielefeld: transcript (VerKörperungen / MatteRealities - Perspektiven empirischer Wissenschaftsforschung, 8).

Murphy, Robin R.: Introduction to AI Robotics. Cambridge, London: Bradford Book/MIT Press.

N.N. (2015): Hybrid - die neue Porsche-Strategie? Porsche-Chef Müller im Interview. In auto motor und sport, 9/14/2015. Available online at https:// www.auto-motor-und-sport.de/news/porsche-chef-mueller-interview-hybrid-strategie/, checked on 2/11/2020.

N.N. (2019): Für Verkehrsminister Scheuer sind Tempolimits „gegen jeden Menschenverstand“. Tempolimit und Dieselsteuer? Verkehrsminister Andreas Scheuer hat zu den Überlegungen einer Regierungskommission eine klare Meinung. In Handelsblatt, 1/19/2019. Available online at https://www.handelsblatt.com/politik/deutschland/umweltdebattefuer-verkehrsminister-scheuer-sind-tempolimits-gegen-jeden-menschenverstand/23886030.html, checked on 3/21/2019.

Norton, Peter D. (2011): A Historical Perspective on the Future of the Car. William J. Mitchell, Christopher E. Borroni-Bird, and Lawrence D. Burns: Reinventing the Automobile: Personal Urban Mobility for the $21^{\text {st }}$ Century. Cambridge: MIT Press, 2010, 240 pp, \$21.95 HB. In Metascience 20 (3), pp. 593-595. DOI: 10.1007/s11016-010-9479-z.

Oelmaier, Tobias (2011): Fahrerlose Autos unterwegs in Berlin. Eine Live-Reportage und ein Gespräch mit Raúl Rojas, Professor für künstliche Intelligenz (Mobilität). DRadio Wissen, 5/19/2011.

Oldenziel, Ruth (1999): Making Technology Masculine: Men, Women and Modern Machines in America, 1870-1945. Amsterdam: Amsterdam University Press.

Omrod, Susan (1995): Feminist Sociology and Methodology: Leaky Black Boxes in Gender/Technology Relations. In Keith Grint, Rosalind Gill (Eds.): The Gender-Technology Relation. Contemporary Theory and Research. London: Taylor \& Francis, pp. 31-47.

Orr, Julian Edgerton (1996): Talking about Machines: An Ethnography of a Modern Job. Ithaca: Cornell University Press (Collection on Technology and Work).

Palm, Kerstin; Jähnert, Gabriele; Völker, Susanne; Grenz, Sabine (Eds.) (2018): Materialität/en und Geschlecht: Beiträge zur 6. Jahrestagung der Fachgesellschaft Geschlechterstudien e.V. 12./13. Februar 2016. With assistance of Humboldt-Universität zu Berlin, Kerstin Palm, Gabriele Jähnert, Susanne Völker, Sabine Grenz. Berlin. DOI: 10.25595/461. 
Paulitz, Tanja (2012): Mann und Maschine: Eine genealogische Wissenssoziologie des Ingenieurs und der modernen Technikwissenschaften, 1850-1930. Bielefeld: transcript Verlag (Science Studies).

Paulitz, Tanja; Kink, Susanne; Prietl, Bianca (2016): Analytical Strategy for Dealing with Neutrality Claims and Implicit Masculinity Constructions: Methodological Challenges for Gender Studies in Science and Technology. In Forum Qualitative Sozialforschung / Forum: Qualitative Social Research 17 (3). Available online at http://dx.doi.org/10.17169/fqs-17.3.2469. Plesner, Ursula; Horst, Maja (2012): Selling the Selling Point: How Innovation Communication Creates Users of Virtual Worlds Architecture. In Convergence: The International Journal of Research into New Media Technologies 18 (1), pp. 49-70. DOI: 10.1177/1354856511419915.

Plesner, Ursula; Horst, Maja (2013): Before Stabilization: Communication and Non-Standardization of 3D Digital Models in the Building Industry. In Information, Communication \& Society 16 (7), pp. 1115-1138. DOI: 10.1080/1369118X.2012.695387.

Raasch, Josefine; Sørensen, Estrid (2014): Helen Verran: Pionierin der Postkolonialen Science \& Technology Studies. In Diana Lengersdorf, Matthias Wieser (Eds.): Schlüsselwerke der Science \& Technology Studies. Wiesbaden: Springer VS.

Redshaw, Sarah (2018): Combustion, Hydraulic, and Other Forms of Masculinity: An Essay Exploring Dominant Values and Representations of the Driver in Driverless Technology. In Transfers 8 (1), pp. 86-103. DOI: 10.3167/TRANS.2018.080107.

Reichertz, Jo (2013): Gemeinsam interpretieren: Die Gruppeninterpretation als kommunikativer Prozess. Wiesbaden: Springer Fachmedien Wiesbaden.

Reichertz, Jo; Englert, Carina Jasmin (2011): Einführung in die qualitative Videoanalyse: Eine hermeneutisch-wissenssoziologische Fallanalyse. Wiesbaden: VS Verlag für Sozialwissenschaften/ Springer Fachmedien Wiesbaden GmbH Wiesbaden (Qualitative Sozialforschung).

Reuschenbach, Arturo; Wang, Miao; Ganjineh, Tinosch; Gohring, Daniel (2011): iDriver: Human Machine Interface for Autonomous Cars. In IEEE (Ed.): Eighth International Conference on Information Technology: New Generations. ITNG. Las Vegas, NV, USA, April 11-13, 2011, pp. 435-440. Richardson, Kathleen (2015): An Anthropology of Robots and AI: Annihilation Anxiety and Machines. New York: Routledge, Taylor \& Francis Group (Routledge Studies in Anthropology, 20).

Roddenberry, Gene (1966-69): Star Trek. NBC, 1966-69.

Rojas, Raúl (1989): Das unvollendete Projekt: Zur Entstehungsgeschichte von Marx“ „Kapital“. Berlin: Argument-Verlag (Edition Philosophie und Sozialwissenschaften, 14). 
Rojas, Raúl (2012): Autopie: Autonome Fahrzeuge für Car-Sharing. In Telepolis, 5/13/2012. Available online at https://www.heise.de/tp/features/ Autopie-Autonome-Fahrzeuge-fuer-Car-Sharing-3394013.html, checked on $2 / 11 / 2020$.

Rojas, Raúl (2013): Das wahre Auto-Mobil. In Spektrum der Wissenschaft (12), pp. 88-93.

Rojas, Raúl (2014): Auto: Der Kampf ums Cockpit. In Telepolis, 11/24/2014. Available online at https://www.heise.de/tp/features/Auto-Der-Kampfums-Cockpit-3368478.html, checked on 2/11/2020.

Rojas, Raúl; Ulbrich, Fritz (2013): Voraussetzungen für dynamische Fahrplanung: Telematik für autonome Fahrzeuge. In Jürgen Sieck (Ed.): Wireless Communication and Information: Ubiquitous Communication. Glückstadt: Hülsbusch (Multimedia), pp. 11-18.

Rosental, Claude (2013): Toward a Sociology of Public Demonstrations. In Sociological Theory 31 (4), pp. 343-365. DOI: 10.1177/0735275113513454.

Rotolo, Daniele; Hicks, Diana; Martin, Ben R. (2015): What is an emerging technology? In Research Policy 44 (10), pp. 1827-1843. DOI: 10.1016/j. respol.2015.06.006.

Sachs, Wolfgang (1992): For Love of the Automobile: Looking Back into the History of our Desires. Berkeley: University of California Press.

Schlechtriemen, Tobias (2016): The Hero and a Thousand Actors. On the Constitution of Heroic Agency. In helden. heroes. héros 4 (1), pp. 17-32. Available online at https://freidok.uni-freiburg.de/data/11511, checked on $1 / 5 / 2019$.

Schönball, Ralf (2009): FU-Forscher steuern Auto mit iPhone. In Der Tagesspiegel, 11/3/2009. Available online at https://www.tagesspiegel.de/berlin/ technik-fu-forscher-steuern-auto-mit-iphone/1626044.html, checked on 2/11/2020.

Sharkey, Noel; Suchman, Lucy (2013): Wishful Mnemonics and Autonomous Killing Machines. In AISB Quarterly (136), pp. 14-22. Available online at https://eprints.lancs.ac.uk/id/eprint/65657/1/Sharkey_Suchman_AISBQ_136.pdf, checked on 1/23/2020.

Sheller, Mimi (2004): Automotive Emotions: Feeling the Car. In Theory, Culture \& Society 21 (4-5), pp. 221-242.

Siciliano, Bruno; Khatib, Oussama (Eds.) (2016): Springer Handbook of Robotics. $2^{\text {nd }}$ edition. Berlin, Heidelberg: Springer.

Singleton, Vicky (2010): Good Farming: Control or Care? In Annemarie Mol, Ingunn Moser, Jeannette Pols (Eds.): Care in Practice. On Tinkering in Clinics, Homes and Farms. Bielefeld: transcript (VerKörperungen/ MatteRealities - Perspektiven empirischer Wissenschaftsforschung, 8), pp. 235-256. 
Singleton, Vicky; Michael, Mike (1993): Actor-Networks and Ambivalence: General Practitioners in the UK Cervical Screening Programme. In Social Studies of Science 23 (2), pp. 227-264. DOI: 10.1177/030631293023002001. Sismondo, Sergio (2004): An Introduction to Science and Technology Studies. 1st ed. Malden: Blackwell Publishing.

Simakova, Elena (2010): RFID 'Theatre of the proof': Product Launch and Technology Demonstration as Corporate Practices. In Soc Stud Sci 40 (4), pp. 549-576. DOI: 10.1177/0306312710365587.

Sjögren, Fredrik (2015): Technoscience, Gender and Value: A Study of the Doing of Gender and Technoscience in Four Swedish ICT-Research Organizations. Doctoral Thesis. Luleå tekniska universitet, Luleå. Department of Business Administration, Technology and Social Sciences. Division of Human Work Science. Available online at http://tu.diva-portal.org/smash/ get/diva2:991786/FULLTEXT01.pdf, checked on 01/23/2020.

Smith, Wally (2009): Theatre of Use: A Frame Analysis of Information Technology Demonstrations. In Soc Stud Sci 39 (3), pp. 449-480. DOI: 10.1177/0306312708101978.

Solga, Heike; Pfahl, Lisa (2009): Doing Gender im technisch-naturwissenschaftlichen Bereich. In Joachim Milberg (Ed.): Förderung des Nachwuchses in Technik und Naturwissenschaft. Berlin, Heidelberg: Springer Berlin Heidelberg, pp. 155-218.

Sørensen, Estrid (2009): The Materiality of Learning: Technology and Knowledge in Educational Practice. Cambridge: Cambridge University Press.

Sørensen, Knut H.; Faulkner, Wendy; Rommes, Els (2011): Technologies of Inclusion: Gender in the Information Society. Trondheim: Tapir Acad. Press (Science and technology studies).

Spottiswoode, Roger (1997): James Bond 007: Tomorrow Never Dies. Starring Pierce Brosnan. Michael G. Wilson, Barbara Broccoli.

Star, Susan Leigh (1991): Power, Technology and the Phenomenology of Conventions: On Being Allergic to Onions. In John Law (Ed.): A Sociology of Monsters: Essays on Power, Technology, and Domination. London, New York: Routledge (Sociological Review Monograph, 38), pp. 26-56.

Stilgoe, Jack (2018): Machine Learning, Social Learning and the Governance of Self-Driving Cars. In Social Studies of Science 48 (1), pp. 25-56.

Stilgoe, Jack (2020): Who's Driving Innovation? New Technologies and the Collaborative State. Cham, Switzerland: Palgrave Macmillan.

Strübing, Jörg; Hirschauer, Stefan; Ayaß, Ruth; Krähnke, Uwe; Scheffer, Thomas (2018): Gütekriterien qualitativer Sozialforschung: Ein Diskussionsanstoß. [Criteria for Qualitative Research. A Stimulus for Discussion]. In Zeitschrift für Soziologie 47 (2), pp. 83-100. DOI: 10.1515/ zfsoz-2018-1006. 
Suchman, Lucy (2007): Human-Machine Reconfigurations. Plans and Situated Actions. $2^{\text {nd }}$ Edition. Cambridge, New York, Melbourne, Madrid, Cape Town, Singapore, São Paulo, Delhi, Daubei, Tokyo, Mexico City: Cambridge University Press.

Suchman, Lucy (2008): Feminist STS and the Sciences of the Artificial. In Edward J. Hackett, Olga Amsterdamska, Micheal Lynch, Judy Wajcman (Eds.): The Handbook of Science and Technology Studies. $3^{\text {rd }}$ edition. Cambridge: MIT Press, pp. 139-163.

Suchman, Lucy (2011a): Practice and its Overflows: Reflections on Order and Mess. In TECNOSCIENZA: Italian Journal of Science \& Technology Studies 2 (1), pp. 21-30. Available online at http://www.tecnoscienza.net/ index.php/tsj/article/download/63/44, checked 2/12/2020.

Suchman, Lucy (2011b): Subject objects. In Feminist Theory 12 (2), pp. 119-145. DOI: $10.1177 / 1464700111404205$.

Tesla (2019): Autopilot. Available online at https://web.archive.org/ web/20191211152110/, https://www.tesla.com/autopilot, checked on $12 / 12 / 2019$.

The Federal Government (2015): Strategy for Automated and Connected Driving: Remain a lead provider, become a lead market, introduce regular operations. Edited by Federal Ministry of Transport and Digital Infrastructure. Berlin. Available online at https://www.bmvi.de/SharedDocs/EN/ publications/strategy-for-automated-and-connected-driving.pdf, checked on $1 / 28 / 2020$.

The Federal Government (2017): Report on the Implementation of the Automated and Connected Driving Strategy. Edited by Federal Ministry of Transport and Digital Infrastructure. Berlin. Available online at https:// www.bmvi.de/SharedDocs/EN/Documents/DG/report-implementation-of-acd-strategy.pdf, checked on 2/25/2019.

Thio, Laurence (2012): Ich habe nicht einmal ein Handy. [I do not even have a cell phone]. In Die Tageszeitung, 9/9/2012. Available online at https://taz. de/Montagsinterview/!5084447/, checked on 2/11/2020.

Tonso, Karen L. (2007): On the Outskirts of Engineering: Learning Identity, Gender, and Power via Engineering Practice. Rotterdam: Sense (New Directions in Mathematics and Science Education, 6).

Trischler, Helmuth (2007): 'Made in Germany': Die Bundesrepublik als Wissensgesellschaft und Innovationssystem. In Thomas Hertfelder, Andreas Rödder (Eds.): Modell Deutschland: Erfolgsgeschichte oder Illusion? Göttingen: Vandenhoeck \& Ruprecht, pp. 44-60.

TU Braunschweig (10/7/2010): Forschungsfahrzeug „Leonie“ fährt automatisch auf dem Braunschweiger Stadtring: Weltweit erstes automatisches Fahren im realen Stadtverkehr. Braunschweig. Dr. Elisabeth Hoffmann. 
Available online at https://magazin.tu-braunschweig.de/pi-post/forschungsfahrzeug-leonie-fahrt-automatisch-auf-dem-braunschweiger-stadtring/, checked on 3/13/2019.

Tuma, René; Schnettler, Bernt; Knoblauch, Hubert (2013): Videographie. Wiesbaden: Springer Fachmedien Wiesbaden.

Tychsen, Janine (2014): Wir wollen alle Menschen reich machen! Hermann von Helmholtz-Gemeinschaft Deutscher Forschungszentren e.V. Bonn. Available online at http://www.helmholtz.de/artikel/wir-wollen-allemenschen-reich-machen-2893/\#, checked on 2/11/2020.

Urry, John (2004): The ‘System’ of Automobility. In Theory, Culture \& Society $21(4-5)$, pp. 25-39.

van Maanen, John (2011): Tales of the Field: On Writing Ethnography. $2^{\text {nd }}$ ed. Chicago: University of Chicago Press (Chicago Guides to Writing, Editing, and Publishing).

van Woensel, Lieve; Archer, Geoff; Panades-Estruch, Laura; Vrscaj, Darja (2015): Ten Technologies which Could Change Our Lives: Potential Impacts and Policy Implications. European Parlament. Scientific Foresight Unit. Brussels (PE 527.417). Available online at https://doi.org/10.2861/610145, checked on 3/29/2019.

Verran, Helen (1998): Re-Imagining Land Ownership in Australia. In Postcolonial Studies 1 (2), pp. 237-254.

Vertesi, Janet (2012): Seeing like a Rover: Visualization, Embodiment, and Interaction on the Mars Exploration Rover Mission. In Soc Stud Sci 42 (3), pp. 393-414. DOI: 10.1177/0306312712444645.

Vobker, Marc (2016): Automobil und Geschlecht: Explorative Analysen jenseits stereotyper Zuschreibungen. Wiesbaden: Springer VS.

Wajcman, Judy (1991): Feminism Confronts Technology. Cambridge: Polity.

Wajcman, Judy (2000): Reflections on Gender and Technology Studies: In what State Is the Art? In Social Studies of Science 30 (3), pp. 447-464.

Wajcman, Judy (2004): TechnoFeminism. Cambridge: Polity.

Wajcman, Judy (2017): Automation: Is It Really Different this Time? In The British Journal of Sociology 68 (1), pp. 119-127. DOI: 10.1111/1468-4446.12239.

Wang, Miao (2012): A Cognitive Navigation Approach for Autonomous Vehicles. Berlin: mbv Mensch-und-Buch-Verlag.

Wetmore, Jameson (2003): Driving the Dream: The History and Motivations Behind 60 Years of Automated Highway Systems in America. In Automotive History Review 40 (Summer), pp. 4-19.

Whatmore, Sarah (2003): Generating Materials. In Michael Pryke, Gillian Rose, Sarah Whatmore (Eds.): Using Social Theory: Thinking through 
research. London, Thousand Oaks, New Delhi: SAGE in association with the Open University.

Woolgar, Steve (1985): Why not a Sociology of Machines? The Case of Sociology and Artificial Intelligence. In Sociology 19 (4), pp. 557-572. DOI: 10.1177/0038038585019004005.

Wynne, Brian (1988): Unruly Technology. Practical Rules: Impractical Discourses and Public Understanding. In Social Studies of Science 18 (1), pp. 147-167. DOI: 10.1177/030631288018001006. 


\title{
Index
}

\author{
A \\ D \\ acceptability 103-110, 117 \\ ADAS (advanced driving assistance \\ systems) 9, 11, 52-54, 73, 111, \\ 115-116 \\ adequacy 30,125 \\ AHS (automated highway systems) \\ 9-11 \\ AI (artificial intelligence) 11-12, 22, \\ $30,33,40,45,52,63,70,82-83$, \\ 93, 120-124 \\ Ambivalence 116 \\ ANT (actor-network-theory) 15, \\ 22-26, 28-29, 122, 125 \\ anthropomorphism $30,58,70$ \\ anthropo-/zoomorphic metaphor 97, \\ 99, 120 \\ automobilists 116, 122, 124 \\ automobility 9-11, 19, 51, 75-78, 80, \\ 103-112, 116-117, 124 \\ autonomous driving 9-17, 28-34, \\ 39-42, 47-48, 50-57, 62-63, \\ 71-74, 78-92, 101-113, 115-117, \\ 119-120, 122-125 \\ C \\ carelessness 120 \\ code for masculinity 123 \\ configuration $12,16,56,58,105$, \\ $109,117,120-121$ \\ controversy $24,46,102,115,122$ \\ cultural resource 27,122 \\ Czarniawska, Barbara 26-27, 29, 31, \\ 36-37, 50, 84, 119, 125 \\ DARPA (Defense Advanced \\ Research Projects Agency) 11, \\ 32, 48, 86-88, 93 \\ definition of reality 20 \\ demonstrator $17,39,42,45-46,102$, \\ 119-123 \\ diagnosis $60,68,120$ \\ distinction $68,71,76,84,122-123$ \\ driverless car 9, 17, 45-49, 53, 83, \\ 101, 103, 106-110, 115-117, 123 \\ $\mathbf{E}$ \\ emancipation 110,117 \\ emasculation 104-106, 111, 117 \\ enactment 13, 23, 26 \\ estrangement 31 \\ ethnography $15,17,29-30,34-37$ \\ expectation 9-10, 12-13, 19-21, \\ 26-28, 48, 75-78, 111, 114, 117 \\ F \\ feasibility $10,12,53,56,85,101$, \\ 124 \\ Feminist STS 25 \\ fragility 102,119 \\ frame of meaning 84,86 \\ frontier imaginary 85
}




\section{G}

gender-blindness 14

gender neutral 77,122

gender studies 7, 14, 19, 36

gender-technology relation 13, 25

Germany 9, 14-17, 32, 34, 39, 43,

$46,54,60,75,96,103-107,117$,

119,122

Google Driverless Car 93

GPS (Global Positioning System)

$21,31,50,59,61-63,95,101$

\section{H}

Hermann, Winfried 104-106, 109 heroic masculinity 86 heroism 92, 96 homosocial association 35, 88, 123 Horst, Maya 7, 13, 26-28, 103, 105, 124 hype $12,20,41,111,113$

\section{I}

ICT (Information and communication technology) 21 , $23,31,34,43,48,51,53,60,62$, $76,98,113,117,120,122$

identity $27-28,33,70,76,85,91$ imaginary of autonomous driving

$29,42,94$

imaginary of control $16,58,62,120$ imaginary of racing 80 inevitability 12,52

innovation communication 13,16 , $103,107-108,114,117,124$ intimacy $15,74,82,120,122$
James Bond 112

K

Knight Rider 82-84

$\mathbf{L}$

Lagesen, Vivian 23, 25, 75, 122 laser scanner (LIDAR) 21, 44, 63, 95, 120

Latour, Bruno 22-25, 29, 51, 56

Law, John 7, 13, 22-24, 26, 28, 35, $54,74,122,125$

\section{M}

masculinity as an organizing principle 106

Mellström, Ulf 7, 14-15, 81, 88

metaphor 41, 46, 122

middle-class masculinity 76

military ground vehicle 11

Müller, Matthias 8, 20, 106, 109-110

\section{$\mathbf{N}$}

narrative $9,13,16,23,26-27,37,49$, $53,86,117,122-124$ narrative analysis 36,125

New Materialism 124-125 nihilation 20, 106, 110 nonhuman agency 125 


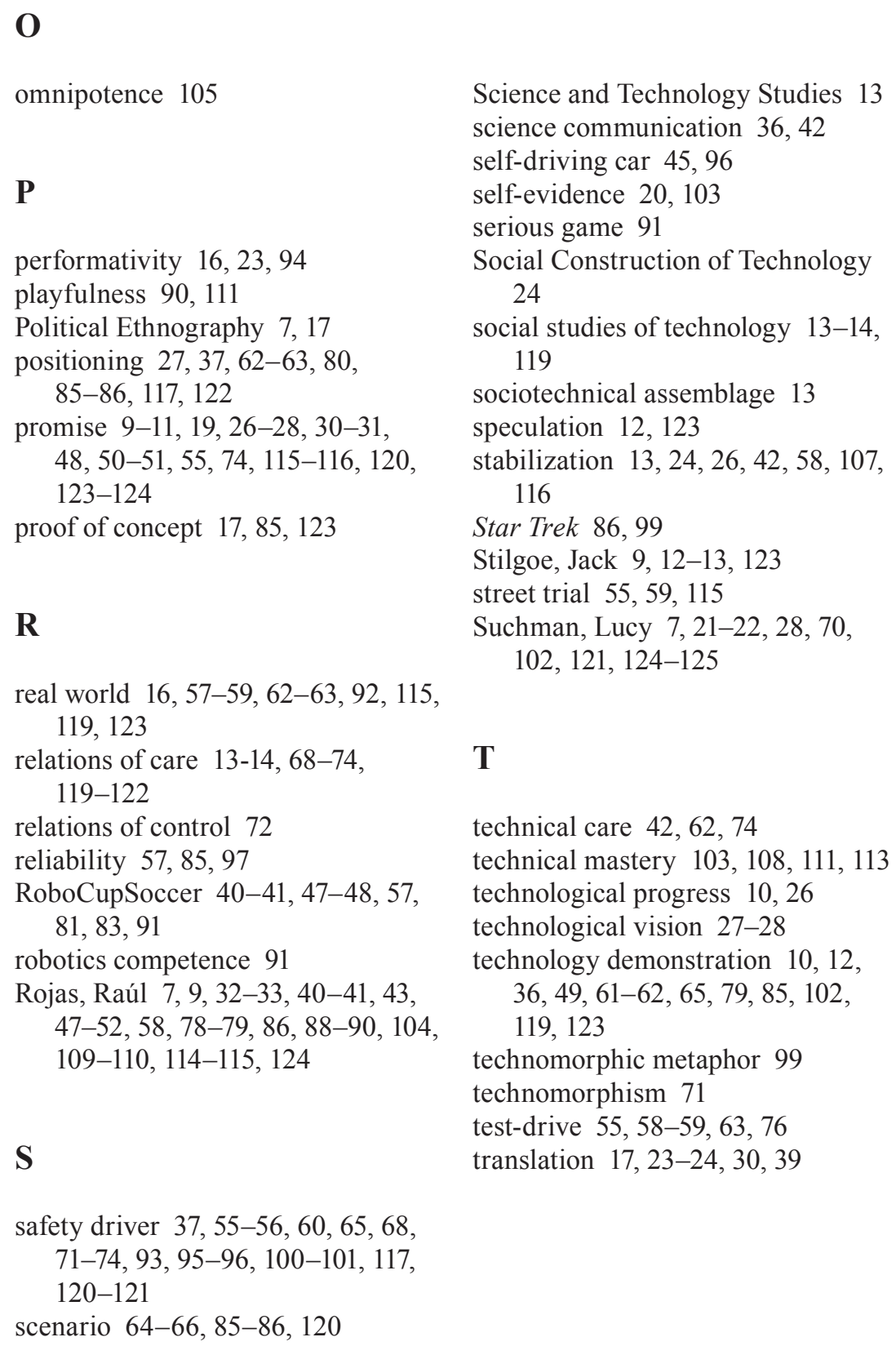

omnipotence 105

$\mathbf{P}$

performativity $16,23,94$

playfulness 90,111

Political Ethnography 7, 17

positioning $27,37,62-63,80$,

$85-86,117,122$

promise $9-11,19,26-28,30-31$,

$48,50-51,55,74,115-116,120$,

$123-124$

proof of concept $17,85,123$

$\mathbf{R}$

real world $16,57-59,62-63,92,115$, 119,123

relations of care $13-14,68-74$,

119-122

relations of control 72

reliability $57,85,97$

RoboCupSoccer 40-41, 47-48, 57,

$81,83,91$

robotics competence 91

Rojas, Raúl 7, 9, 32-33, 40-41, 43, 47-52, 58, 78-79, 86, 88-90, 104, 109-110, 114-115, 124

$\mathbf{S}$

safety driver $37,55-56,60,65,68$,

71-74, 93, 95-96, 100-101, 117, 120-121

scenario $64-66,85-86,120$

Science and Technology Studies 13

science communication 36,42

self-driving car 45, 96

self-evidence 20,103

serious game 91

Social Construction of Technology

24

social studies of technology 13-14, 119

sociotechnical assemblage 13

speculation 12,123

stabilization $13,24,26,42,58,107$, 116

Star Trek 86, 99

Stilgoe, Jack 9, 12-13, 123

street trial 55, 59, 115

Suchman, Lucy 7, 21-22, 28, 70, $102,121,124-125$

\section{T}

technical care $42,62,74$ technical mastery $103,108,111,113$ technological progress 10,26 technological vision $27-28$ technology demonstration 10,12 , $36,49,61-62,65,79,85,102$, 119,123

technomorphic metaphor 99 technomorphism 71 test-drive $55,58-59,63,76$ translation 17, 23-24, 30, 39 


\section{$\mathbf{U}$}

uncertainty $26,30,52-53,57,68$,

$71-72,101,120$

\section{V}

video demo $16,32,93-102,108$, 111-114, 117, 124

visionary communication 26,123

visionary storytelling $13,47,49$,

115,124

vision of autonomous taxi 49-52, 101, 109-110, 116, 122

vision of self-driving cars 45-53,

109-111

W

Wajcman, Judy 7, 14-15, 25, 30, 53, $76,83-84,122$

wishful mnemonics 121

working-class masculinity 76,80 


\section{Göde Both Keeping Autonomous Driving Alive}

An Ethnography of Visions, Masculinity and Fragility

In Keeping Autonomous Driving Alive, Göde Both studies the relationships between researchers and artefacts held together by contested visions. Drawing on ethnographic fieldwork in a pioneering research project in Germany, he argues we can make sense of technological visions only if we simultaneously grasp the role of care, gender, and narrative in sustaining technological research.

The author: Göde Both, computer scientist (university diploma), researcher, Centre for transdisciplinary Gender Studies, Humboldt-University Berlin

Visit https://goede-both.info/ for more information 